Daniel da Costa UchôA

\title{
Proposta de middleware para multidifusão em redes sobrepostas
}

São Paulo 
Daniel da Costa UchôA

\section{Proposta de middleware para multidifusão em redes sobrepostas}

Dissertação apresentada à Escola Politécnica da Universidade de São Paulo para obtenção do título de Mestre em Engenharia

São Paulo

2009 
Daniel da Costa UchôA

\title{
Proposta de middleware para multidifusão em redes sobrepostas
}

\author{
Dissertação apresentada à Escola Politécnica \\ da Universidade de São Paulo para obtenção \\ do título de Mestre em Engenharia
}

Área de concentração: Sistemas Digitais

Orientador: Profa. Dra. Regina M. Silveira

São Paulo

2009 


\section{FICHA CATALOGRÁFICA}

Uchôa, Daniel da Costa

Proposta de middleware para multidifusão em redes sobrepostas / D. C. Uchôa. - São Paulo, 2009.

$158 \mathrm{p}$.

Dissertação (Mestrado) - Escola Politécnica da Universidade de São Paulo. Departamento de Engenharia de Computação e Sistemas Digitais.

1. Middleware (Arquitetura) 2. Redes multimídia (Projeto) 3. Redes de computadores I. Universidade de São Paulo. Escola Politécnica. Departamento de Engenharia de Computação e Sistemas Digitais. II. t. 
Dedico esta dissertação à todos os anjos da minha vida, que infalivelmente me acompanham em cada jornada, me guiando e abrindo caminhos. 


\section{Agradecimentos}

A todos os colegas do LARC, e em especial, ao Luiz Gustavo, Reinaldo, Samuel, Hélcio, Sérgio, Júnior e Fernando Almeida. À Professora Graça Bressan, que me convidou para a USP em 2005, para participação no projeto SBTVD, e que vem me acompanhando e apoiando desde então. Ao Professor Wilson Ruggiero, pela sua admirada sabedoria transmitida em suas aulas e/ou reuniões de projeto, e agora por seus valiosos comentários como membro de minha banca.

À Professora Regina Silveira, pela grande confiança depositada nas minhas idéias, e pela abertura e convivência nestes mais de três anos acumulados entre os projetos GTGV e GTOverlay. E claro, também pela grande orientação nesta dissertação.

Ao Professor Guido Lemos e toda sua equipe do Lavid/UFPB pela excelente parceria nos GTs da RNP, o que resultou em uma importante contribuição na implementação do sistema de middleware aqui proposto. Especialmente, gostaria de agradecer ao Hacks, Bidu, Lincoln e Anselmo.

À Rede Nacional de Ensino e Pesquisa (RNP), pelo financiamento nos três anos de GT, pelo excelente apoio logístico, essencial para a concretização desta pesquisa, e pela grande valorização dos resultados obtidos, custeando inscrições e passagens para importantes eventos da área, nacionais e internacionais. Em especial, gostaria de agradecer ao Michael, lara, Ana, Túlio e Felipe.

Aos Professores Francisco Marcos e Francisco Tejo da UFCG pela grande orientação no projeto PIBIC, o começo de tudo. Ao pessoal do GEPOTI e do Embedded, em especial ao Professor Angelo Perkusich pela orientação do TCC e estágio, e pela coordenação no projeto da Nokia. Ao pessoal do IECOM, especialmente ao Professor Marcelo Sampaio, o qual propiciou minha primeira participação no projeto SBTVD.

A meu melhor amigo Júlio César, meu irmão e "eterno" companheiro da juventude, que marcou para sempre minha vida com sua alegria e bondade, e cuja fraternidade e companheirismo ensinam o verdadeiro sentido da amizade. "Cometa Jubiraca", sei que onde estiveres, estás curtindo à Bessa, oh grande catedrático da Liga da Justiça! Nossos momentos estarão sempre vivos, eternizados, pois ainda estamos todos jun- 
tos, reunidos n'algum lugar do tempo, seja na casa do Bessa, no Água Marinha, ou na casa de Erické. Também agradeço à sua família, que em muitos momentos se confundiu com a minha (Tia Deda, Seu Jesus, Lula, Renata, Rebeca, e todos).

À minha segunda família, meus amigos de sempre, na alegria e na tristeza. "Alegria é agora, agora e amanhã!". E foram muitas! Festas, churrascos, shows, vaquejadas, São João, Micarandes, carnavais, praias, etc. Muitas tristezas também, mas continuamos firmes e fortes! Vocês sempre foram e sempre serão muito importantes para mim. Agradeço bastante a existência desses "elementos": Pierrot, Lapa, Bisteca, Erické, Erickson, e Negão. Apesar de que, como diz nosso grande Cravo, "amizade tá uma m. hein!".

A meu grande amigo Raoni, que parece ter a missão de me abrir as portas, como que um anjo protetor. Agradeço pelos grandes momentos compartilhados, seja em Campa ou Sampa, e pelas várias histórias hilárias que passamos juntos. Agradeço também ao Nandinho pela recepção e convivência em Sampa, e à Maité, por colocar estes dois na linha!

Ao amigo Ulisses, grande companheiro das cervejadas e "amendoimzadas" no "mosqueiro" da Feira de Jaguaribe, vizinho ao CEFET-PB. Também aos Professores Alfredo e Aléssio, daquela instituição.

Aos amigos e companheiros de república Juba e Sandro, e aos vizinhos Rei e Alessi, além do Russo, para completar "A Diretoria" das festas do maior São João do mundo. Também aos outros companheiros de república, como o Hélder, Lula, Fábio e Moacir. Ainda ao Sr. Lucena, locador do apartamento, e as "vizinhas", claro! As de cima e as de baixo.

Aos amigos Georgina, Isabela e Alec, companheiros de tardes (ou madrugadas) filosóficas regadas a doces e cafés (ou "cervas" geladas) na La Suissa (ou em qualquer boteco copo sujo). Também agradeço aos outros amigos e colegas da UFCG.

A todos os colegas, amigos, e Professores do colégio Marista Pio X de João Pessoa.

Um agradecimento mais especial ainda para: meus irmãos Leo, Rafael e Flavinha, e minha esposa Gisela. Também à minha filhota Gabi, grande fonte de renovação, diversão e alegria, para quem ultimamente não tenho conseguido dedicar muito tempo, mas que com certeza será agora recompensada com muitas brincadeiras e fins de semana em parques e zoológicos. Também à toda família Uchôa e Gondim da Costa. Vocês são a base de tudo. 
E finalmente, à minha mãe Alice, pela doação da vida, e ao meu pai Flávio, pela preparação à ela, e por todo amor, carinho e atenção que sempre me iluminaram. 


\section{Resumo}

Redes sobrepostas são consideradas uma forma fácil e eficaz de implantar serviços de Internet de valor agregado através da extensão do serviço de entrega de melhor esforço oferecido pela camada de rede IP. No entanto, para aproveitar-se de seus benefícios, um projeto cuidadoso torna-se necessário. Como ainda não existem padrões para redes sobrepostas, com frequência estas são projetadas de forma independente, o que significa que cada uma aplica sua própria descoberta de topologia e toma suas próprias decisões de roteamento. Como resultado, elas podem afetar negativamente umas às outras, através da geração de uma sobrecarga de informações de controle ou através da criação de gargalos na rede física. Portanto, para evitar tais situações, este trabalho propõe uma arquitetura e organização de middleware para serviços em redes sobrepostas. Dentre os possíveis serviços, um esquema de multidifusão sobreposta foi projetado e implantado, no qual um protocolo de middleware baseado em padrões internacionais implementa tanto um cenário intradomínio quanto interdomínio. Validamos o sistema proposto através de dois tipos de análise: uma análise de desempenho e uma análise funcional. A primeira análise mostra que o desempenho do protocolo aqui proposto pode ser comparado ao desempenho dos protocolos tradicionais de multidifusão IP, a menos de uma métrica: a latência. Entretanto, o modelo analítico desenvolvido mostra a possibilidade de se traçar heurísticas para um projeto de serviço sobreposto com latência controlada. Além disso, a análise funcional utiliza-se de medidas experimentais no sistema real para confirmar a funcionalidade de multidifusão interdomínio, facilidade antes inviável em ambientes de rede pública utilizando-se as técnicas tradicionais.

Palavras-chave: Projeto e arquitetura de middleware; serviços de rede sobreposta; protocolo para multidifusão sobreposta, provisionamento dos nós de serviço. 


\section{Abstract}

Overlay networks are considered an easy and effective way to deploy value-added Internet services by extending the best-effort delivery service supported by IP layer. However, a careful design is needed in order to take advantage of these benefits. Since there are no standards for overlay networks yet, they are often independently designed, which means that each one applies its own topology discovery and takes its own routing decisions. As a result, they may negatively affect each other by generating control overhead and by creating bottlenecks in the physical network. In order to avoid such a situation, this work proposes an overlay network organization and architecture for overlay network services. Among possible services, an overlay multicast scheme was projected and deployed, on which a middleware protocol based on international standards implements both intradomain and interdomain scenarios. We validate the proposed system by two kind of analysis: performance analysis and functional analysis. The first one shows the performance of the proposed protocol can be compared to the performance of traditional IP multicast protocols, except for one metric: latency. Nevertheless, the developed analytical modeling shows the possibility to outline heuristics for a controlled-latency overlay service project. Moreover, functional analysis uses experimental measurements on real system to confirm interdomain multicast functionality, facility before unfeasible in public network environments when using traditional techniques.

Keywords: Middleware architecture and design; service overlay networks; overlay multicast protocol; service node provisioning. 


\title{
Lista de Abreviações e Siglas
}

\author{
ALM Application-Level Multicast \\ ALMI Application Level Multicast Infrastructure \\ BOS Basic Overlay Services \\ BTP Banana Tree Protocol \\ CAN Content-Addressable Networks \\ CDN Content Delivery Network \\ DHT Distributed Hash Table \\ DT Delaunay Triangulations
}

GMA Gateway Multicast Agent

GPS Global Position System

HTTP Hypertext Transfer Protocol

IGMP Internet Group Management Protocol

IPC Inter-Process Communication

ISMA Internet Streaming Media Alliance

ISP Internet Service Provider

MA Multicast Agent

MBGP Multiprotocol Border Gateway Protocol

MDS Multimedia Distribution Service

MSON Multicast Service Overlay Network

MST Minimum Spanning Tree

OAS Overlay Autonomous System

OIL Outgoing Interface List

OSPF Open Shortest Path First 
OVERSEA Scalable and Effective Architecture for OVERlay Networks

P2P Peer-to-peer

PIM-DM Protocol Independent Multicast - Dense Mode

PIM-SM Protocol Independent Multicast - Sparse Mode

PTT Packet Transmission Time

RDP Relative Delay Penalty

RMA Relay Multicast Agent

RMI Java Remote Method Invocation

RPF Reverse Path Forwarding

RPT Reverse Path Tree

RTP Real-time Transport Protocol

RTT Round-Trip-Time

SA Source Agent

SDP Session Description Protocol

SIP Session Initiation Protocol

SLP Service Location Protocol

SMA Source Multicast Agent

SMCP Simple Multicast Control Protocol

SNMP Simple Network Management Protocol

SON Service Overlay Network

SPT Shortest Path Tree

TCP Transmission Control Protocol

TFP Time to First Packet

UA User Agent

UDP User Datagram Protocol

UMA User Multicast Agent

URI Uniform Resource Identifier

WAN Wide Area Network 


\section{Lista de Figuras}

2.1 Estratégias para multidifusão: (a) multidifusão nativa em rede; (b) multidifusão sobreposta direta; (c) multidifusão sobreposta mediada (figura adaptada de (LAO et al., 2005)). . . . . . . . . . . . . p. 29

2.2 Transmissão de fluxo contínuo para quatro receptores utilizando o mecanismo de entrega por multidifusão (figura redesenhada de (LEE, 2005)). . . . . . . . . . . . . . . . . . p. 30

2.3 Redirecionamento pelo caminho reverso (adaptado de (EDWARDS et al., 2002)).

2.4 Exemplo de uma árvore de caminho mais curto - SPT (adaptado de (EDWARDS et al., 2002)). . . . . . . . . . . . . . . . p.34

2.5 Exemplo de construção da estrutura virtual de entrega por multidifusão sobre a rede implícita. . . . . . . . . . . . . . . . . . . . . p. 35

2.6 Roteando uma mensagem a partir do nó 65A1FC com chave D46A1C (adaptado de (ROWSTRON; DRUSCHEL, 2001)). Os pontos representam nós ativos em um espaço de nomes circular de 128 bits.

3.1 Modelo de referência adaptado para um middleware de comunicação em redes sobrepostas.

3.2 Rede sobreposta para extensão do serviço de melhor esforço para um serviço de rede avançada. . . . . . . . . . . . . . p.60

3.3 Rede de serviços sobrepostos para aplicações multimídia. . . . . . . p.61

3.4 Proposta de arquitetura para redes sobrepostas. . . . . . . . . . . . p. 64

3.5 Exemplo de implementação de serviços sobrepostos pelo sistema de

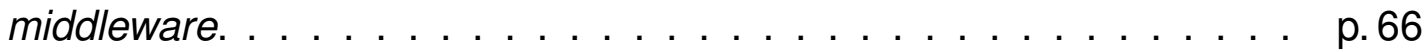

4.1 Exemplo de árvore de escoamento construída pelo Session Manager para multidifusão dos dados de aplicação. . . . . . . . . . . . . p. 85

4.2 Modelo de interação entre as entidades SMCP. . . . . . . . . . . . p. p. 86

4.3 Um aglomerado de UAs em torno de um mesmo representante para uma mesma sessão. . . . . . . . . . . . . . . . . . . . p. 87

4.4 Exemplo de evento de inicialização do MA. . . . . . . . . . . p.96

4.5 Sequência de troca de mensagens SMCP na inicialização de um com-

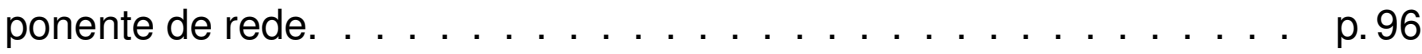

4.6 Participação em sessão ativa por um novo cliente. . . . . . . . . . . p.97

4.7 Entrada de novos participantes na sessão. . . . . . . . . . . . p. 100 
4.8 Sequência de troca de mensagens SMCP para participação em sessão de um novo cliente: interação UA/Publishing Manager e UA/Session Manager.

4.9 Sequência de troca de mensagens SMCP para participação em sessão de um novo cliente: interação UA/MAs e MAs/Session Manager. . . . p. p.101

4.10 MAs mantém status das sessões de multidifusão das quais participam e enviam curtos informes de status periodicamente.

4.11 Mensagem SMCP REGISTER periodicamente enviada por todos os MAs ao Session Manager. . . . . . . . . . . . . . . . . . . . . . p. 102

4.12 Quando houver interesse, o Session Manager solicita um relatório de monitoração detalhado a um dado MA, o qual precisa responder com todas as informações solicitadas. . . . . . . . . . . . . . . . . p. 103

4.13 Troca de mensagens envolvidas quando da solicitação de relatório de monitoração enviada pelo Session Manager a um dado MA, e sua respectiva resposta.

4.14 Cenário de multidifusão interdomínio através de três sistemas autônomos sobrepostos: OAS X, OAS Y, e OAS Z.

4.15 Troca de mensagens fora do escopo SMCP, mensagens SMCP intradomínio para estabelecimento de parte do canal de dados, e atuação dos GMAs para se alcançar o Session Manager do OAS Y. . . .

4.16 Continuação da troca de mensagens SMCP da Figura 4.15. O fluxo de dados é roteado para o OAS Y, através do qual é possível alcançarse a máquina do Cliente A no OAS Z . . . . . . . . . . . . . . p. 107

4.17 Session Manager do OAS X percebe que este cliente pertence à sua rede, e aciona um UMA representante, o qual solicita aos outros MAs participação no fluxo de subida, fechando o caminho de redirecionamento da fonte primária até o representante do cliente, interconectando os três OASs. . . . . . . . . . . . . . . . . . . . p. p.108

5.1 Topologia física considerada como sistema para a análise de desempenho das técnicas de distribuição de fluxos multimídia. . . . . . . . p. p.111

5.2 Topologia física considerada apresentando o custo como peso dos enlaces. . . . . . . . . . . . . . . . . . . . . p. 115

5.3 Stress nos enlaces utilizando um entrega de dados por unidifusão. . . p. 124

5.4 Stress nos enlaces utilizando um entrega de dados por multidifusão nativa em rede. . . . . . . . . . . . . . . . . . . . . . p. 124

5.5 Stress nos enlaces utilizando um entrega de dados por multidifusão sobreposta. . . . . . . . . . . . . . . . . . p.125

5.6 Topologia física detalhada configurada em laboratório didático para realização de medições experimentais. . . . . . . . . . . . p. p. 126

5.7 Árvore de escoamento sobreposta construída pelo SMCP. . . . . . . p. 128 
5.8 Árvore de escoamento evidenciando os enlaces sobrepostos como uma composição de um ou mais enlaces físicos. . . . . . . . . . . . . p. 129

5.9 Modelagem do TFP para o caso da entrega de dados por unidifusão. p. 132

5.10 Análise dos pacotes enviados e recebidos pelo máquina cliente $\mathrm{J}$, na estratégia de multidifusão sobreposta, através do software Wireshark. p.139

5.11 Cenário de validação da funcionalidade de multidifusão interdomínio. p. 146 


\section{Lista de Tabelas}

2.1 Resumo da classificação das propostas de multidifusão sobreposta. . p.57

5.1 A Tabela reúne valores de stress com o custo de cada enlace do sistema, tanto para a unidifusão (subíndice $u$ ) quanto para a multidifusão sobreposta (subíndice $o$ ), e por fim apresenta o resultado do cálculo da utilização de recursos. Observe que a soma dos custos representa a utilização de recursos da multidifusão nativa em rede, já que todos os seus enlaces apresentam um valor de stress igual a 1. . . . . . . . p. 127

5.2 Custo de todos os enlaces sobrepostos da Figura 5.8. . . . . . . . . . p. 129

5.3 Caminhos de redirecionamento da fonte para cada receptor de mídia, e o valor da respectiva RDP. . . . . . . . . . . . . . . . . . . . . . . p. 130

5.4 Amostras do TFP, em segundos, medidos experimentalmente nos nós de interesse para o caso da multidifusão sobreposta. . . . . . . . . . . . p. 140

5.5 Amostras do TFP, em segundos, medidos experimentalmente nos nós de interesse para o caso da multidifusão nativa. . . . . . . . . . . . . p.140

5.6 Amostras do $\operatorname{ptt}\left(d_{7}, \eta_{5}\right)$, onde $d_{7}$ representa o receptor $L$ e $\eta_{5}$ o roteador 5 , em segundos, medidos experimentalmente.

5.7 Amostras do tempo de atendimento ao nó $L$ quando o nó $F$ já participa da sessão, medido em segundos. . . . . . . . . . . . . . . . . . . p. 141

5.8 Provisionamento da rede sobreposta. . . . . . . . . . . . . . . . p. 146

5.9 Resultados experimentais coletados a partir de uma transmissão por multidifusão sobreposta interdomínio de fluxos de vídeo ao vivo. . . . . p. 146 


\section{Sumário}

$\begin{array}{lll}1 \text { Introdução } & \text { p. } 20\end{array}$

1.1 Escopo . . . . . . . . . . . . . . . . . . p. 23

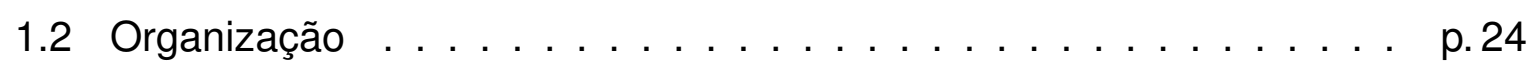

2 Um Novo Paradigma: A Multidifusão Sobreposta $\quad$ p. 25

2.1 Evolução das Arquiteturas para Multidifusão . . . . . . . . . . . . . p. 25

2.2 Taxonomia da Multidifusão na Internet . . . . . . . . . . . . . . p. 28

2.3 Multidifusão Nativa em Rede . . . . . . . . . . . . . . . . . . . . . . p. 29

2.3.1 Redirecionamento pelo Caminho Reverso (RPF) . . . . . . . . p. 31

2.3.2 Árvore de Caminho mais Curto (SPT) . . . . . . . . . . . p. 32

2.4 Multidifusão Sobreposta . . . . . . . . . . . . . . . . . . . p.33

2.4.1 Arquitetura de Distribuição $\ldots \ldots \ldots \ldots \ldots$

2.4 .2 Topologia Sobreposta . . . . . . . . . . . . . . . . . . p. 38

2.4.3 Modelo de Serviço de Comunicação em Grupo . . . . . . . . . p. 43

2.5 Trabalhos Correlatos . . . . . . . . . . . . . . . . p. 45

3 Proposta de Middleware para Redes Sobrepostas p. 58

3.1 Middleware para Comunicação em Rede . . . . . . . . . . . p.58

3.2 Modelo de Rede Sobreposta . . . . . . . . . . . . . . . . . p.59

3.2.1 Vantagens e Desvantagens . . . . . . . . . . . . p. p. 61

3.3 Arquitetura para Redes Sobrepostas . . . . . . . . . . . . . . p. 62

3.3.1 OVERSEA: Uma Arquitetura Escalável e Eficaz para Redes Sobrepostas . . . . . . . . . . . . . p. 63

3.3.2 Cenário de Utilização da Arquitetura OVERSEA . . . . . . . p. 65

3.4 Camada de Middleware . . . . . . . . . . . . . . p. 66

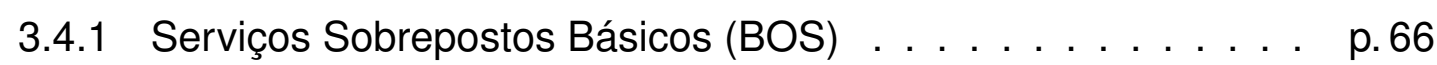

3.4.2 Rede Sobreposta de Serviços (SON) . . . . . . . . . . . p. 69

3.5 Implantação do Sistema de Middleware . . . . . . . . . . . p.73 
4 Protocolo de Middleware para Controle da Multidifusão Sobreposta

4.1 Visão Geral . . . . . . . . . . . . . . . . . . . . . . . . . . . . . . p.74

4.1 .1 Escopo . . . . . . . . . . . . . . . . . . p.75

4.1 .2 Funcionalidades . . . . . . . . . . . . . . p. 75

4.1 .3 Descrição . . . . . . . . . . . . . . . . . . . p. 77

4.2 Definições e Entidades . . . . . . . . . . . . . . . . p. 78

4.2.1 Definições . . . . . . . . . . . . . . . . . . p.78

4.2 .2 Entidades . . . . . . . . . . . . . . . . p. 82

4.2.3 Modelo de Interação . . . . . . . . . . . . . . . . . . . . p. 84

4.3 Estrutura das Mensagens . . . . . . . . . . . . . . . . . . p. 87

4.3.1 Solicitações . . . . . . . . . . . . . . . . . . . p.91

4.3 .2 Respostas . . . . . . . . . . . . . . p. . . . . . . . .

4.4 Cenários de Operação . . . . . . . . . . . . . . . . . . . . . . . . . p.94

4.4.1 Inicialização da Rede Sobreposta . . . . . . . . . . . . . . p.94

4.4.2 Participação de um Novo Cliente . . . . . . . . . . . . . . . p.96

4.4.3 Monitoração da Topologia de Controle . . . . . . . . . . . . . . p. 101

4.4.4 Monitoração da Topologia de Dados . . . . . . . . . . . . . . p. 103

4.4 .5 Multidifusão Interdomínio . . . . . . . . . . . . . . . . p. 104

5 Validação da Proposta $\quad$ p. 110

5.1 Análise de Desempenho . . . . . . . . . . . . . . . . . . p. 110

5.1 .1 Objetivos e Definição do Cenário . . . . . . . . . . . . . . . p. 110

5.1 .2 Métricas . . . . . . . . . . . . . . . . . . . . p. 112

5.1 .3 Listagem dos Parâmetros . . . . . . . . . . . . . . . . . . . p. 114

5.1.4 Técnica de Avalilação e Carga de Trabalho . . . . . . . . . . . p.117

5.1 .5 Projeto do Experimento . . . . . . . . . . . . . . . p. 118

5.1 .6 Análise e Interpretação dos Dados . . . . . . . . . . . . . . . . p. 122

5.1 .7 Conclusões da Análise . . . . . . . . . . . . . . . . . . p. 142

5.2 Análise Funcional . . . . . . . . . . . . . . . . . . . p. 145

5.2.1 Resultados Experimentais . . . . . . . . . . . . . . . . p. 146

5.2 .2 Discussão . . . . . . . . . . . . . . . . . . . . . p. 147

6 Conclusões e Trabalhos Futuros $\quad$ p. 148 
6.1 Contribuições . . . . . . . . . . . . . . . . . . . . . . . . p. 148

6.2 Trabalhos Futuros . . . . . . . . . . . . . . . . p. 150

6.3 Considerações Finais $\ldots \ldots \ldots \ldots$. . . . . . . . . . . . . . . . .

$\begin{array}{ll}\text { Referências Bibliográficas } & \text { p. } 153\end{array}$ 


\section{Introdução}

O serviço de multidifusão ${ }^{1}$ é caracterizado por sua capacidade de enviar informação para diversos destinos simultaneamente, porém de forma seletiva. Este é um esquema de transmissão eficiente para suportar comunicação de grupo em redes. Ao contrário da técnica de unidifusão tradicional, a qual configura conexões ponto-a-ponto entre transmissor e receptor, a multidifusão envia informação simultânea para um grupo através do uso de conexões multi-ponto. Desde que a mensagem é entregue apenas uma vez para cada enlace, e cópias do pacote são criadas na rede apenas quando o caminho para os destinos se divide, tal estratégia utiliza os recursos empregados de uma forma mais inteligente, aliviando o tráfego na rede e a utilização no transmissor.

Uma quantidade significativa de esforço tem sido dedicada a incorporar funcionalidades de multidifusão no atual modelo de serviço de entrega da Internet. Apesar de méritos incontestáveis, a multidifusão IP está longe de ser amplamente adotada como um serviço aberto na Internet, devido a várias razões técnicas e mercadológicas (DIOT et al., ; ALMEROTH, 2000). Na multidifusão IP tradicional, roteadores precisam manter estado de roteamento completo para cada grupo de multidifusão. Este modelo apresenta uma baixa escalabilidade relacionada ao número de grupos ativos concorrentemente. Além de violar os argumentos fim-a-fim (SALTZER et al., 1984), isso introduz altas complexidades e limitações dentro da camada IP. O gerenciamento de endereços pode ser citado como um outro problema. A multidifusão IP requer que cada grupo obtenha dinamicamente um endereço único global. Isto é difícil de se garantir de forma escalável, distribuída, e consistente. No entanto, consideramos o roteamento interdomínio como a questão mais crucial. A falta de um protocolo de roteamento interdomínio escalável, divergências na política de roteamento entre domínios administrativos dos sistemas autônomos, e a ausência de um modelo de cobrança bem definido, impedem sua adoção na prática (LAO et al., 2005; LEE, 2005).

\footnotetext{
${ }^{1}$ Alguns autores preferem chamar de difusão seletiva, já que a difusão caracteriza-se pelo envio de dados do transmissor para todos os receptores da rede, e a palavra multidifusão daria uma idéia de ainda ampliar esta entrega, o que não é o caso.
} 
Embora existam esforços para se contornar os problemas tradicionais relacionados com a mutidifusão IP (HOLBROOK; CHERITON, 1999; STOICA et al., 2000), questões relacionadas à manutenção de estado e à requisitos de características de mais alto nível ainda precisam ser solucionadas (UCHôA et al., 2009). Apesar de vários avanços, a implantação da multidifusão IP nativa encontra diversas dificuldades. Já há algum tempo, a multidifusão IP nativa vem se restringindo apenas à pequenas "ilhas" de utilização. Neste caso, torna-se necessária a configuração estática de tunelamento IP para conectar as zonas disjuntas da rede.

Atualmente, até mesmo o mais forte argumento em favor da inclusão de funcionalidades de multidifusão dentro da camada de rede está caindo por terra. A estratégia de multidifusão IP tradicional defende o custo de uma maior complexidade por um melhor desempenho obtido pelo fato da multidifusão ser aplicada na camada de rede IP (SALTZER et al., 1984). Entretanto, estudos recentes de análise de desempenho mostram que este é um argumento discutível (LAO et al., 2005; FAHMY; KWON, 2007).

Visando então resolver os problemas de implantação da multidifusão nativa, um nova abordagem foi proposta: a multidifusão sobreposta² (CHU et al., 2000; CHAWATHE, 2003; BANERJEE et al., 2006; LAO et al., 2007; UCHôA et al., 2007; UCHôA; SILVEIRA, 2007; UCHôA et al., 2008, 2009). Redes sobrepostas são obtidas através da superposição de uma infraestrutura de entrega construída em nível de aplicação sobre o substrato de roteamento da rede IP (neste caso, a rede implícita). Seguindo esta idéia, a técnica de multidifusão sobreposta insere características de multidifusão na infraestrutura sobreposta completamente em nível de aplicação, enquanto que, em nível de rede, a transmissão dos dados de fato usa o modelo de serviço de unidifusão tradicional da rede IP. Os sistemas finais envolvidos na multidifusão sobreposta tratam exclusivamente do gerenciamento do grupo, do roteamento, e da construção da árvore de entrega, sem qualquer suporte de roteadores para estes propósitos.

As principais vantagens oferecidas pelas redes sobrepostas ${ }^{3}$ são: flexibilidade, adaptatividade, e facilidade de implantação. A multidifusão sobreposta pode superar todos os problemas da multidifusão nativa discutidos anteriormente, até mesmo aqueles relacionados com a multidifusão interdomínio (UCHôA et al., 2009; LAO et al., 2007). Entretanto, existe um custo associado, e um projeto cuidadoso torna-se necessário para obter benefícios com essas vantagens. Comumente, redes sobrepostas transportam um tráfego crescente em largura de banda, devido a sua grande utilização no

\footnotetext{
${ }^{2}$ Adotamos o termo multidifusão sobreposta como tradução ao termo original overlay multicast.

${ }^{3} \mathrm{O}$ termo redes sobrepostas é aqui utilizado como tradução ao termo original overlay networks.
} 
transporte de dados de aplicações multimídia. Além disso, a eficiência dessa abordagem está intimamente relacionada ao conhecimento da topologia da rede implícita.

A falta de padrões para redes sobrepostas faz com que estas redes sejam projetadas de forma completamente independente, o que significa que cada qual aplica seu próprio esquema de descoberta de topologia e toma suas próprias decisões de roteamento. $O$ resultado é que tais redes afetam umas as outras negativamente, geralmente em dois aspectos: (i) pela geração de uma sobrecarga de controle, devido à monitorações redundantes e frequentes na rede física (NAKAO et al., 2003); (ii) e pela criação de gargalos devido ao roteamento para o mesmo enlace físico mesmo quando diferentes enlaces sobrepostos são empregados (JIANG et al., 2005). Tais aspectos não apenas degradam os serviços sobrepostos, como também afetam o desempenho da rede como um todo.

Neste contexto, o objetivo deste trabalho é propor uma arquitetura de middleware capaz de organizar as funcionalidades das redes sobrepostas para uma provisão eficiente de seus serviços, e um protocolo de middleware através do qual os componentes distribuídos desta arquitetura cooperam para implementar um serviço de multidifusão sobreposta; isto com base no modelo de referência OSI ligeiramente adaptado proposto em (STEEN; TANENBAUM, 2007). Através de uma análise de desempenho, comparamos o protocolo de middleware aqui proposto com o esquema de transmissão tradicional por unidifusão, e com uma transmissão por multidifusão IP. Uma análise funcional evidencia uma das maiores vantagens da multidifusão sobreposta: a possibilidade de implantação prática de um serviço de multidifusão interdomínio em redes públicas de larga escala.

Portanto, este trabalho mostra que uma infraestrutura de multidifusão sobreposta bem definida é capaz de superar os problemas mais críticos da multidifusão IP:

1. O sistema de middleware desenvolvido (um protótipo que implementa a arquitetura e o protocolo de comunicação) provê um serviço de multidifusão interdomínio sobre redes IP de melhor esforço sem qualquer suporte de multidifusão nativa, de forma transparente para as aplicações multimídia, e com desempenho aceitável, próximo daquele apresentado pela multidifusão IP;

2. Por ser independente da camada de rede, não há necessidade de substituição ou adição de novos elementos de rede, sendo uma solução de baixo custo de implantação e manutenção, visto que seus elementos são agentes de software 
instalados em servidores;

3. A implantação pode ser feita gradativamente sem haver "zonas de sombra"4, e sua evolução implicará diretamente na melhoria do desempenho;

4. A arquitetura adotada possibilita interoperabilidade entre sistemas autônomos e flexibilidade na aplicação de políticas, o que permite a criação de um modelo de cobrança viável na Internet.

\subsection{Escopo}

Este trabalho foi desenvolvido no contexto do Grupo de Trabalho em Redes de Serviços Sobrepostos (GT-Overlay) ${ }^{5}$ da Rede Nacional de Ensino e Pesquisa (RNP). O problema em questão era: como expandir a Rede de Vídeo Digital (RVD) para possibilitar sua interconexão com outras redes acadêmicas? Além de resolver este problema, a solução aqui proposta também permite incluir novos serviços de rede avançada (UCHôA; SILVEIRA, 2007).

A RVD é uma Rede de Distribução de Conteúdo ${ }^{6}$ (CDN - Content Delivery Network) construída sobre a rede Ipê da RNP para transportar fluxos de áudio e vídeo de aplicações de vídeo ao vivo, vídeo sob demanda, e vídeo agendado (ou canais). A rede Ipê ${ }^{7}$ é a rede acadêmica brasileira, que usa a mesma tecnologia IP da Internet, mas com atribuição controlada e estruturada dos blocos de endereço.

Dessa forma, nossa solução se enquadra na distribuição de streaming de vídeo em uma rede com topologia implícida conhecida a priori. A arquitetura do middleware proposto nesta dissertação define um componente responsável pelas informações de topologia, mas no cenário de implementação tais informações são cadastradas pelo administrador da rede através de uma interface gráfica apropriada, como apresentado em (UCHôA et al., 2007).

\footnotetext{
${ }^{4} \mathrm{~A}$ multidifusão IP tradicional exige roteadores com tal suporte para o atendimento de uma certa região, e sua ausência implica na ausência do serviço.

${ }^{5}$ Detalhes sobre este Grupo de Trabalho em http://www.rnp.br/pd/gts2008-2009/gt_oerlay2.html

${ }^{6}$ Um sistema de computadores interligados em rede que cooperam de forma transparente para fornecer conteúdo de mídia.

${ }^{7} \mathrm{O}$ mapa desta rede pode ser consultado em http://www.rnp.br/en/backbone/index.php .
} 


\subsection{Organização}

Este trabalho está organizado como segue. No capítulo 2 o cenário atual da multidifusão na Internet é esboçado, ilustrando as duas estratégias existentes, e apresentando o estado da arte da técnica de multidifusão sobreposta. Junto com esta revisão da literatura, os trabalhos relacionados são apontados. Este levantamento serve como base para a arquitetura proposta no Capítulo 3, a qual define uma arquitetura de middleware para multidifusão sobreposta. Em seguida, o Capítulo 4 propõe um protocolo de middleware para controle da multidifusão sobreposta, definindo suas entidades, troca de mensagens, e cenários de operação. A validação da proposta é realizada no Capítulo 5, onde são analisados tanto o desempenho quanto as funcionalidades implementadas no sistema de middleware. Por fim, as conclusões finais, trabalhos futuros e as contribuições deste trabalho são apontados no Capítulo 6. 


\section{Um Novo Paradigma: A Multidifusão Sobreposta}

Para superar os problemas da multidifusão IP, surge um novo paradigma: a multidifusão sobreposta. As funcionalidades de multidifusão são deslocadas dos roteadores para uma nova rede virtual construída em nível de aplicação sobre as redes tradicionais. Este capítulo esboça o cenário atual da multidifusão na Internet, apresentando as principais estratégias e alternativas. São discutidos os conceitos básicos de multidifusão e a implementação destes conceitos na camada de rede e na camada de aplicação. Nosso objetivo aqui é investigar tais estratégias na busca de um modelo de multidifusão escalável para redes públicas como a Internet.

\subsection{Evolução das Arquiteturas para Multidifusão}

As arquiteturas de rede tradicionais distinguem entre dois tipos de entidades: sistemas finais (hospedeiros) e os elementos de rede (comutadores e roteadores). Enquanto que os elementos de rede compõem o núcleo da rede, provendo grande capacidade de comunicação, os sistemas finais posicionam-se em torno deste núcleo, definindo a periferia ou borda da rede, onde oferecem grande capacidade de processamento. Uma das decisões arquiteturais mais importantes é a divisão de funcionalidades entre os sistemas finais e a rede (UCHôA; SILVEIRA, 2007).

$\mathrm{Na}$ arquitetura da Internet, a camada de rede IP oferece um serviço mínimo para a entrega de dados, ou seja, um serviço de unidifusão ${ }^{1}$ dos dados onde não existem garantias sobre: (i) a efetivação da entrega; (ii) a ordenação dos dados; (iii) e o instante de entrega. Por estas características, este tipo de serviço é conhecido como serviço de melhor esforço. Consequentemente, fica a cargo dos sistemas finais implementar

\footnotetext{
${ }^{1}$ As diferenças entre o roteamento por unidifusão e por multidifusão são discutidas na Seção 2.3.1.
} 
todas as outras funcionalidades importantes, tais como controle de erro, controle de congestionamento, e controle de fluxo. Esta decisão de projeto mostrou-se bastante acertada, provavelmente sendo a principal razão técnica para o grande crescimento da Internet (BUSH; MEYER, 2002).

Entretanto, esse crescimento também desencadeou uma demanda crescente por aplicações de mídias contínuas, capazes de ampliar a comunicação e experiência do usuário. O termo mídia contínua refere-se ao fato de que seus dados devem ser reproduzidos dentro de um intervalo de tempo bem definido. Por conseguinte, tais aplicações caracterizam-se por apresentar uma sensibilidade ao atraso e à variação deste atraso, onde falhas no cumprimento destes requisitos de tempo degradam substancialmente a qualidade da mídia percebida, mesmo que todos os seus dados tenham sido corretamente entregues. Dessa forma, as aplicações de mídia contínua exigem alguma melhoria sobre o serviço de entrega de melhor esforço. Portanto, exatamente a abordagem minimalista das redes IP responsável pelo sucesso da Internet tornou-se também um obstáculo para o desenvolvimento de novas aplicações.

Após muitos anos de estudos, uma questão-chave de arquitetura ainda permanece: que novas funcionalidades devem ser incorporadas à camada IP? A multidifusão, a qualidade de serviço (QoS), e segurança são as três características mais importantes que vêm sendo adicionadas à camada IP. Segurança é uma funcionalidade que não pode ser provida apenas por sistemas finais, e dessa forma precisa ser também suportada pela camada IP, além dos enlaces e camada física. Apesar de sistemas finais serem capazes de prover alguns requisitos de QoS de aplicação (tais como vazão, latência, disponibilidade ou continuidade de serviço), um amplo suporte a QoS passa necessariamente pela adição de novas funcionalidades também nas camadas mais baixas. Entretanto, este não é o caso da multidifusão, onde é possível que sistemas finais implementem serviços de multidifusão sobre o serviço de unidifusão IP de melhor esforço apenas na camada de aplicação.

Existem duas considerações conflitantes que devem ser combinadas na decisão entre implementar serviços avançados na camada IP ou nos sistemas finais. De acordo com os argumentos fim-a-fim (SALTZER et al., 1984), uma funcionalidade deve ser (a) levada às camadas altas se possível, (b) a menos que sua implementação em camadas mais baixas possa alcançar benefícios de desempenho que compensem o custo de complexidade adicional gerado por esta decisão. Considerando o caso da multidifusão, Deering argumentou que o desempenho deveria prevalecer à complexidade, e a multidifusão deveria ser implementada na camada IP (DEERING, 1988). Sua visão foi 
amplamente aceita, sendo hoje implementada em quase todos os roteadores.

No entanto, apesar de possuir méritos inegáveis, a multidifusão IP ainda está longe de ser implantada de forma ampla como um serviço aberto na Internet devido a várias razões técnicas e mercadológicas (DIOT et al., ; ALMEROTH, 2000). As mais críticas ainda são (LAO et al., 2007): (1) falta de um protocolo de roteamento interdomínio escalável; (2) problema da escalabilidade de estado quando se tem um grande número de grupos; (3) e o requisito de implantação global de roteadores com capacidade de multidifusão IP. Estes problemas, aliados a falta de um modelo de cobrança, a dificuldade de configuração dos roteadores, e principalmente à necessidade de cooperação entre os sistemas autônomos ${ }^{2}$, fazem com que os provedores de serviço de Internet (ISP) relutem em implantar e prover serviços de multidifusão.

Atualmente, a facilidade de multidifusão é apenas encontrada em redes privadas, onde todas as partes interessadas obtêm o serviço de um mesmo provedor. Somente dessa forma é que os provedores estão conseguindo superar os problemas da multidifusão IP, completando suas lacunas com soluções proprietárias. Porém, em geral, tais soluções não apresentam boa flexibilidade e não são interoperáveis, "engessando" assim o modelo de negócios e limitando a abrangência deste serviço nas redes.

A falta de um serviço aberto de multidifusão na Internet levou à idéia da utilização de sistemas hospedeiros com o objetivo de oferecer capacidades similares sem suporte especial da camada de rede. Através da organização dessas máquinas em uma estrutura de entrega virtual onde cada hospedeiro atua como um nó de redirecionamento em uma árvore de escoamento, um serviço de multidifusão pode ser obtido através do repasse das mensagens aos membros da estrutura, utilizando o serviço de entrega por unidifusão da rede implícita.

Dessa forma, supera-se os problemas da multidifusão IP definida na camada de rede através da sobreposição do roteamento por multidifusão no nível de aplicação. Estas redes virtuais criadas sobre as redes reais são denominadas redes sobrepostas ${ }^{3}$. De forma geral, as alternativas à multidifusão IP construídas em nível de aplicação recebem o nome de multidifusão sobreposta (EL-SAYED, 2004). Nos últimos anos, várias pesquisas têm mostrado a viabilidade deste tipo de estratégia (CHU et al., 2000; FRANCIS, 2007; CHAWATHE et al., 2000; JANNOTTI et al., 2000; PENDARAKIS et al., 2001; CASTRO et al., 2002; CHAWATHE, 2003; HUA et al., ; LAO et al., 2007;

\footnotetext{
${ }^{2}$ Os conceitos de sistemas autônomos e roteamento interdomínio são explorados no Capítulo 4.

${ }^{3} \mathrm{Um}$ modelo de rede sobreposta é apresentado no Capítulo 3.
} 
UCHôA et al., 2007; UCHôA; SILVEIRA, 2007; UCHôA et al., 2008, 2009).

Para acompanhar esta evolução e melhor compreender as diversas técnicas e sistemas de multidifusão atualmente existentes na Internet, este trabalho propõe uma taxonomia da multidifusão discutida a seguir.

\subsection{Taxonomia da Multidifusão na Internet}

Atualmente, podemos classificar as estratégias de multidifusão na Internet de acordo com sua localização na pilha de protocolos, resultando em duas classes amplas:

1. Multidifusão nativa em rede;

2. Multidifusão sobreposta.

A multidifusão sobreposta pode ainda ser categorizada com base em sua arquitetura, de acordo com a utilização ou não de nós intermediários no redirecionamento dos dados de aplicação. Dessa forma, classificamos a multidifusão sobreposta em: (i) mediada; e (ii) direta, respectivamente. O termo interação direta é usado para enfatizar o fato de que a troca de informações é realizada apenas entre os dispositivos de usuário final, sem a participação de servidores intermediários dedicados (ANDROUTSELLISTHEOTOKIS; SPINELLIS, 2004).

De fato, as soluções de multidifusão têm evoluído de baixo para cima na pilha de protocolos (LAO et al., 2005), conforme mostra a Figura 2.1, resultando nas três possíveis arquiteturas para multidifusão:

(a) multidifusão nativa em rede, representada pela multidifusão IP (DEERING, 1988; PERLMAN et al., 1999; HOLBROOK; CHERITON, 1999; STOICA et al., 2000), e assim implantada nos roteadores;

(b) multidifusão sobreposta direta (CHU et al., 2000; FRANCIS, 2007; PENDARAKIS et al., 2001; CASTRO et al., 2002; SOBEIH et al., 2004), implementada de forma descentralizada nos sistemas finais seguindo um modelo de comunicação P2P (do inglês, Peer-to-Peer); 


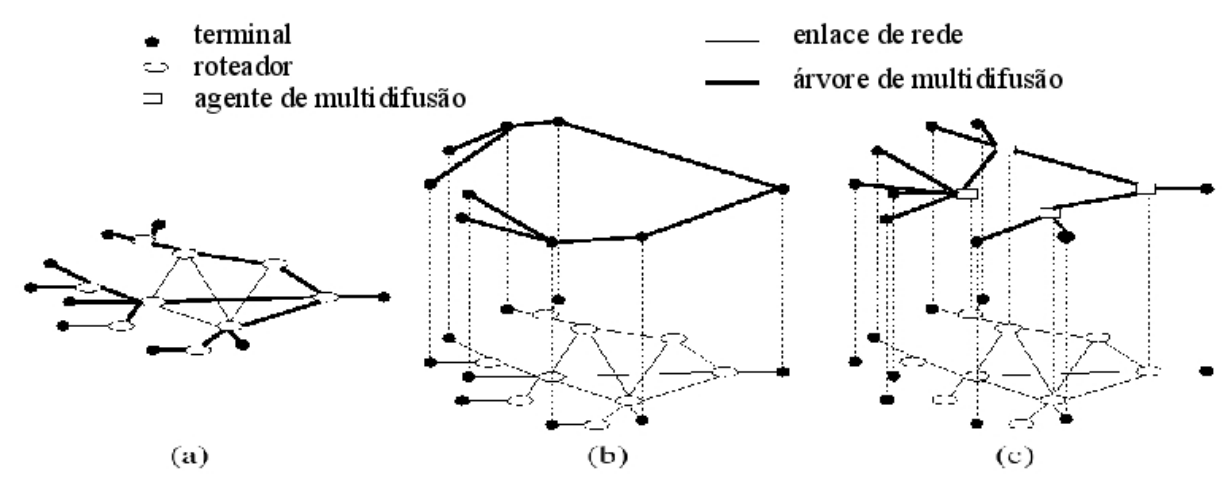

Figura 2.1: Estratégias para multidifusão: (a) multidifusão nativa em rede; (b) multidifusão sobreposta direta; (c) multidifusão sobreposta mediada (figura adaptada de (LAO et al., 2005)).

(c) multidifusão sobreposta mediada (CHAWATHE et al., 2000; JANNOTTI et al., 2000; SHI et al., 2001; BANERJEE et al., 2002; CHAWATHE, 2003; HUA et al., ; LAO et al., 2007; UCHôA et al., 2009), uma solução híbrida que combina os benefícios de ambas abordagens, a qual suporta funcionalidades relacionadas à multidifusão através do uso de nós de serviço intermediários (representantes) especialmente implantados em uma rede sobreposta ou rede por sobreposição ${ }^{4}$.

Apesar de similares na idéia geral, as várias estratégias de multidifusão são bastante diferentes. A próxima seção ilustra conceitos importantes da multidifusão nativa em rede, os quais também são utilizados na multidifusão sobreposta. Damos um breve enfoque na multidifusão nativa em rede, por já se tratar de um tema bastante estabelecido na literatura. Leitores mais interessados podem consultar alguma outra referência, tal como (EDWARDS et al., 2002).

\subsection{Multidifusão Nativa em Rede}

A idéia de multidifusão foi proposta primeiramente por (DEERING, 1988). O conceito de multidifusão proposto era construir uma estrutura de entrega em árvore composta de roteadores que conectam todos os membros do grupo, e assim os dados seriam enviados ao longo desta árvore de multidifusão. Os pacotes destinados a um grande número de sistemas finais viajariam apenas uma vez através dos caminhos comuns

\footnotetext{
${ }^{4}$ Utilizaremos daqui por diante o termo redes sobrepostas como tradução para o termo em inglês overlay networks.
} 


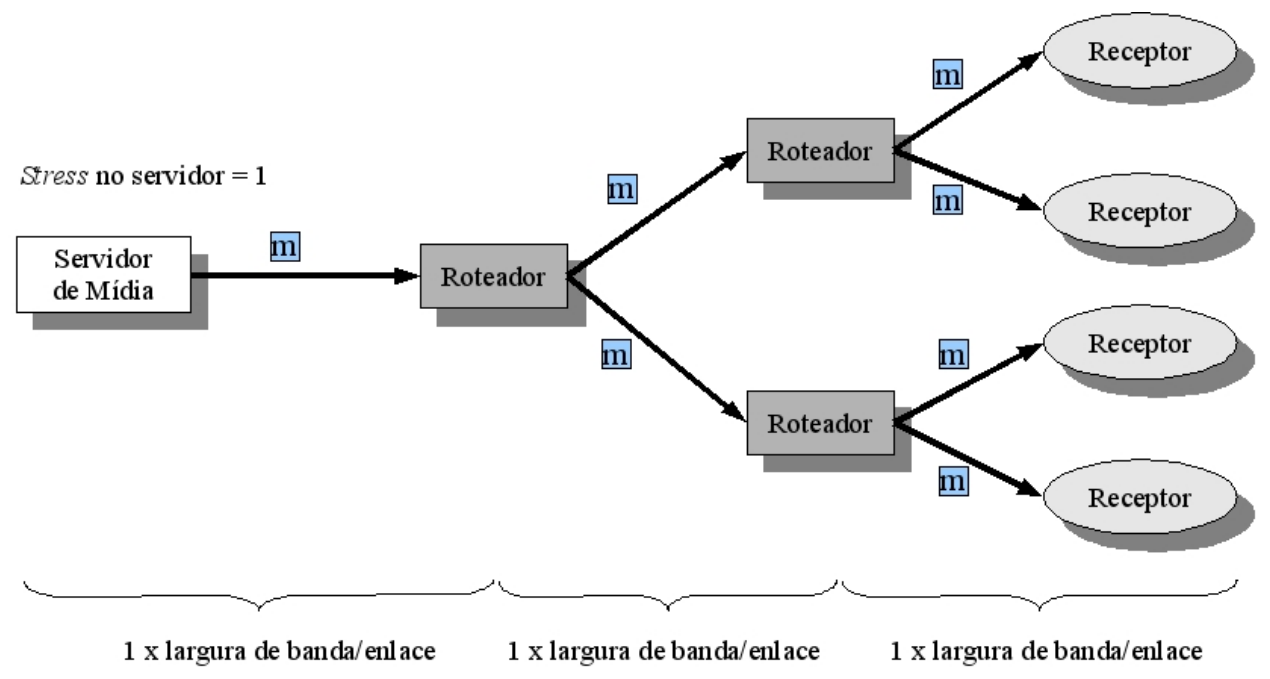

Figura 2.2: Transmissão de fluxo contínuo para quatro receptores utilizando o mecanismo de entrega por multidifusão (figura redesenhada de (LEE, 2005)).

da rede, com replicação apenas nos nós de divisão em cada braço da árvore. Dessa forma, todos os enlaces intermediários no caminho da fonte até os receptores carregam apenas um único fluxo, e múltiplos receptores são atendidos simultaneamente, como ilustra a Figura 2.2.

Ao contrário do modelo de entrega por difusão (ausente na Internet), onde um transmissor envia dados para todos os receptores (como acontece em um ambiente de TV, por exemplo), a utilização da árvore de entrega na multidifusão permite a transmissão de dados apenas para os receptores interessados (os quais formam um grupo). Os enlaces que conectam receptores não interessados nesse fluxo não carregam esse tráfego. Este método oferece o uso de recursos de forma mais eficiente, visto que o tráfego flui apenas nos enlaces que conectam os sistemas finais que expressam o desejo de receber os dados.

Cada subrede que contém pelo menos um receptor interessado é uma folha da árvore. Quando um novo receptor "sintoniza" em uma transmissão, um novo nó de divisão é criado, fazendo com que essa folha participe da árvore. Quando um receptor decide não mais participar da transmissão, seu nó de divisão é "cortado" da árvore. Quando um caminho na árvore se divide, os roteadores replicam os dados e enviam abaixo um único fluxo em cada braço da divisão. Dessa forma, nenhum enlace carrega fluxo de pacotes duplicados. A carga de processamento e a quantidade de largura de banda consumidos pelo transmissor permanecem constantes, independente do número de receptores interessados. 
A multidifusão nativa em rede, representada pela multidifusão IP, é implementada através de três tipos de protocolo:

Protocolos de acesso: que definem a negociação entre os dispositivos do usuário e seus roteadores de borda responsáveis por atendê-los;

Protocolos de roteamento intradomínio: os quais definem a troca de informações entre roteadores com suporte à multidifusão IP em um mesmo sistema autônomo;

Protocolos de roteamento interdomínio: os quais definem a comunicação entre roteadores com suporte à multidifusão IP em sistemas autônomos diferentes.

Não é escopo deste trabalho discutir os protocolos de multidifusão IP. Maiores detalhes podem ser obtidos em (EDWARDS et al., 2002).

A seguir, revisaremos alguns conceitos importantes ligados à multidifusão IP. Tais conceitos são abordados por serem também empregados nas estratégias de multidifusão sobreposta, porém implementados em nível de aplicação.

\subsubsection{Redirecionamento pelo Caminho Reverso (RPF)}

O roteamento por multidifusão envolve uma mudança significativa de paradigma quando comparado ao roteamento por unidifusão. Em geral, roteadores de unidifusão tomam decisão de roteamento com base no endereço de destino do pacote. Quando um pacote de unidifusão chega, o roteador busca o endereço de destino do pacote em sua tabela de roteamento. Esta tabela indica ao roteador por qual interface este deve redirecionar os pacotes para cada rede de destino. Pacotes de unidifusão são então roteados da fonte ao destino.

$\mathrm{Na}$ multidifusão, os roteadores configuram estado de redirecionamento em direção contrária à unidifusão, partindo do receptor até a fonte, chamada de raiz da árvore de distribuição. Os roteadores executam um redirecionamento pelo caminho reverso (RPF - Reverse Path Forwarding), buscando determinar a interface topologicamente mais próxima da raiz da árvore (veja Figura 2.3). RPF é um conceito central no roteamento para multidifusão, presente também na estratégia de multidifusão sobreposta. 
1. Servidor A envia pacotes de dados para um grupo de multidifusão específico, porém nesse ponto o Roteador B não tem conhecimento de nenhum hospedeiro interessado em recebê-los, e então descarta-os.

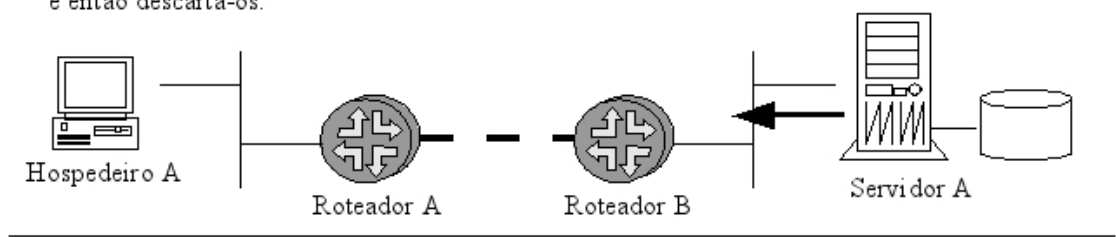

2. Hospedeiro A anuncia ao Roteador A o seu interesse em receber do Servidor A pacotes de dados de multidifusão que estão destinados para o grupo de multidifusão especifíco.

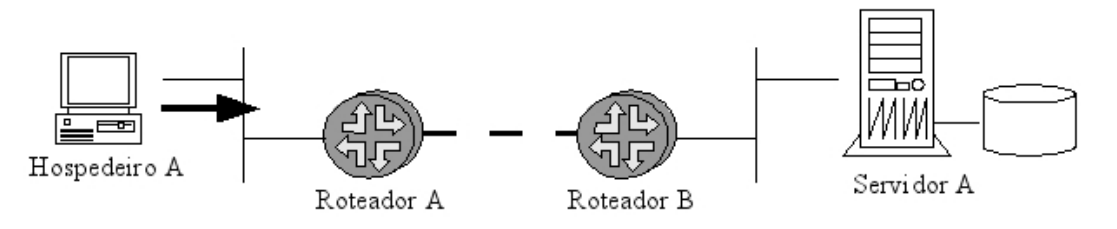

3. Roteador A realiza uma busca RPF pelo endereço do Servidor A, revelando que o Roteador $B$ é o vizinho RPF para o endereço do Servidor A. Roteador A solicita ao Roteador B que redirecione os pacotes de dados para o grupo de multidifusão.

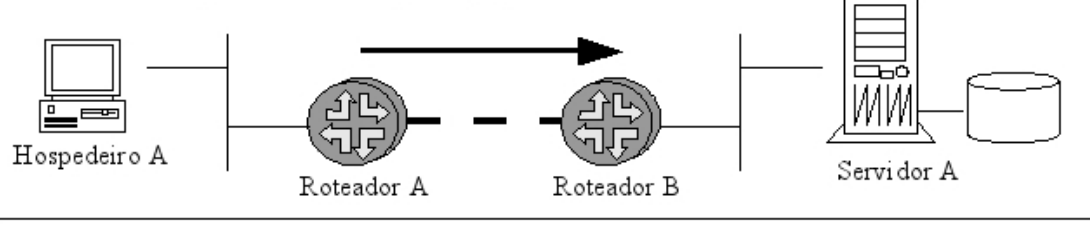

4. Agora ambos roteadores conhecem as interfaces de saída corretas para redirecionar os pacotes de dados. Os pacotes são entregues com sucesso do Servidor A para o Hospedeiro A.

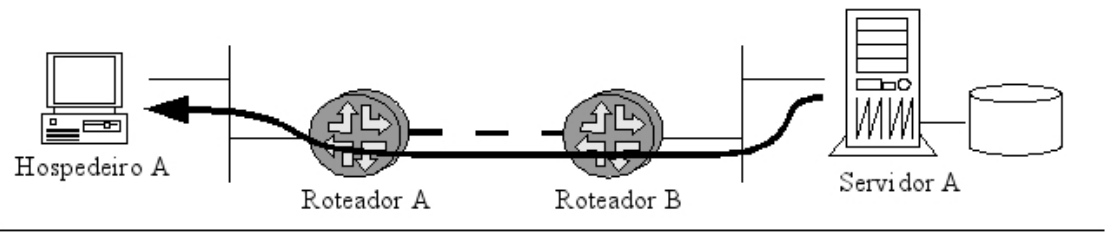

Figura 2.3: Redirecionamento pelo caminho reverso (adaptado de (EDWARDS et al., 2002)).

Na verificação de $R P F$, o roteador consulta a tabela de roteamento para determinar sua interface $R P F$, a qual é a interface de roteamento topologicamente mais próxima da raiz. A interface RPF é a interface de entrada para o grupo, através da qual o roteador receberá os fluxos de multidifusão.

\subsection{2 Árvore de Caminho mais Curto (SPT)}

Em uma árvore de caminho mais curto (SPT - Shortest Path Tree), a raiz da árvore de distribuição é a fonte de transmissão. Se um roteador aprende que um receptor interessado em participar de um grupo está diretamente conectado em uma de suas 
interfaces, ele tenta fazer parte da árvore para aquele grupo.

Como exemplo, suponha que de alguma forma o roteador $\mathrm{C}$ da Figura 2.4 conheça o endereço IP da fonte para tal grupo. Para construir uma SPT, ele executa uma verificação RPF varrendo sua tabela de roteamento para o endereço fonte. A verificação RPF diz ao roteador qual é a interface mais próxima para a fonte. O roteador agora sabe que pacotes de multidifusão provenientes dessa fonte para esse grupo devem fluir pelo roteador através da interface RPF.

O roteador envia adiante uma mensagem Join pela interface RPF para indicar ao próximo roteador no fluxo de subida que deseja receber pacotes para esse grupo a partir dessa fonte. $O$ roteador que recebe uma mensagem Join adiciona a interface pela qual a mensagem foi recebida na sua lista de interfaces de saída (OIL - Outgoing Interface List) para grupo e executa uma verificação RPF para a fonte. Este roteador no fluxo de subida envia uma mensagem Join pela interface RPF para a fonte informando a seu roteador no fluxo de subida que deseja participar do grupo.

Cada roteador no fluxo de subida repete este processo, propagando mensagens Join pela interface RPF até que este novo nó de divisão da árvore: (a) alcance o roteador diretamente conectado à fonte; ou (b) alcance um roteador que já possua estado de redirecionamento por multidifusão para este par fonte-grupo. Dessa forma, um novo nó de divisão da árvore é criado do receptor para a fonte. Uma vez criado este nó de divisão, e cada roteador possuindo estado de redirecionamento para o par fontegrupo, pacotes de multidifusão podem fluir ao longo da árvore, partindo da fonte ao receptor.

\subsection{Multidifusão Sobreposta}

A proposta da multidifusão sobreposta é deslocar a facilidade de multidifusão da camada de rede para o nível de aplicação, onde esta funcionalidade pode ser implementada de forma completa e com desempenho satisfatório, justificável pela simplicidade - de acordo, portanto, com os argumentos fim-a-fim (SALTZER et al., 1984). O nível específico da camada de aplicação que recebe tal responsabilidade é denominado camada sobreposta. Se por um lado a camada de rede trata questões como endereçamento, roteamento e modelo de serviço para prover comunicação entre sistemas finais, a camada sobreposta constrói uma rede virtual de nós e enlaces lógicos 


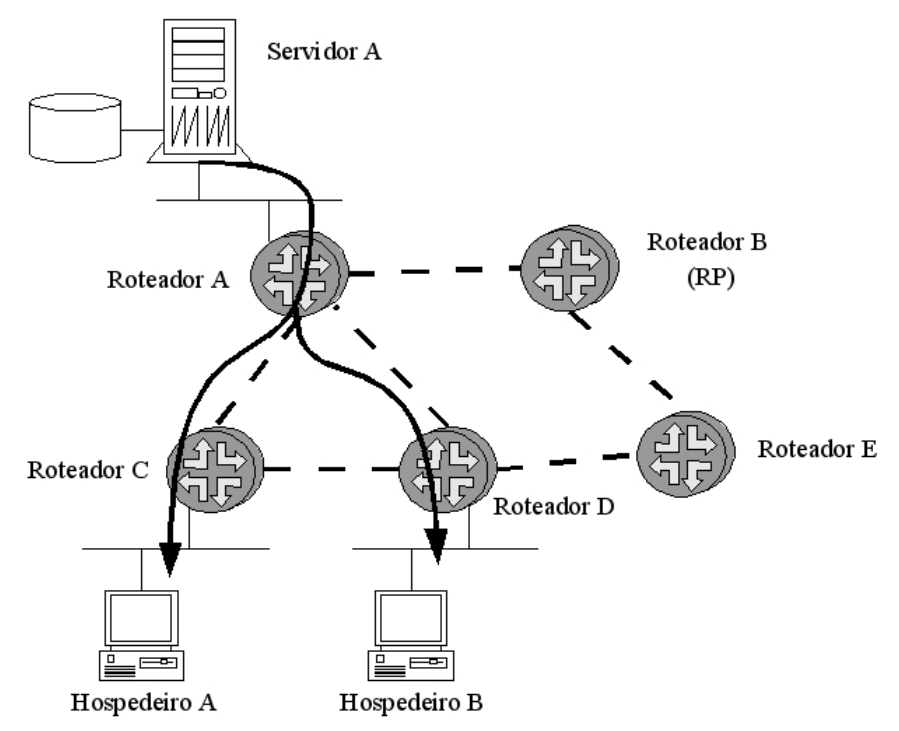

Figura 2.4: Exemplo de uma árvore de caminho mais curto - SPT (adaptado de (EDWARDS et al., 2002)).

sobre a rede física ${ }^{5}$ existente, com o propósito de implementar em nível de aplicação um serviço de rede não disponível de forma nativa na rede implícita. Esta rede virtual é denominada estrutura de entrega.

A estrutura de entrega é construída através da organização dos sistemas finais, onde cada hospedeiro atua como um nó de redirecionamento. Esta construção é ilustrada pela Figura 2.5. Dessa forma, um serviço de multidifusão é obtido através do repasse das mensagens aos membros da estrutura, utilizando o serviço de entrega por unidifusão da rede implícita - geralmente, a Internet. Do ponto de vista das aplicações, a multidifusão sobreposta é capaz de injetar um novo serviço de multidifusão na rede física sem modificá-la, tudo isto de forma transparente. Os detalhes do redirecionamento de mensagens para múltiplos pontos simultâneos ao longo da rede são abstraídos pela camada sobreposta.

Esta técnica oferece a possibilidade de uma implantação rápida e gradativa, configuração simplificada, e melhor controle de acesso, com custo adicional (embora pequeno) da carga de tráfego gerada na rede física pela rede virtual (FAHMY; KWON, 2007). Em geral, o desempenho desta estratégia depende do mapeamento e acompanhamento das características da rede implícita, o que possibilita a construção de estruturas de entrega mais eficientes (NAKAO et al., 2003). A estrutura sobreposta deve ser capaz de detectar falhas e se ajustar à topologia da rede implícita.

\footnotetext{
${ }^{5}$ Chamamos de rede física ou rede implícita a rede IP tradicional, a qual oferece o suporte de entrega por unidifusão para as redes sobrepostas.
} 

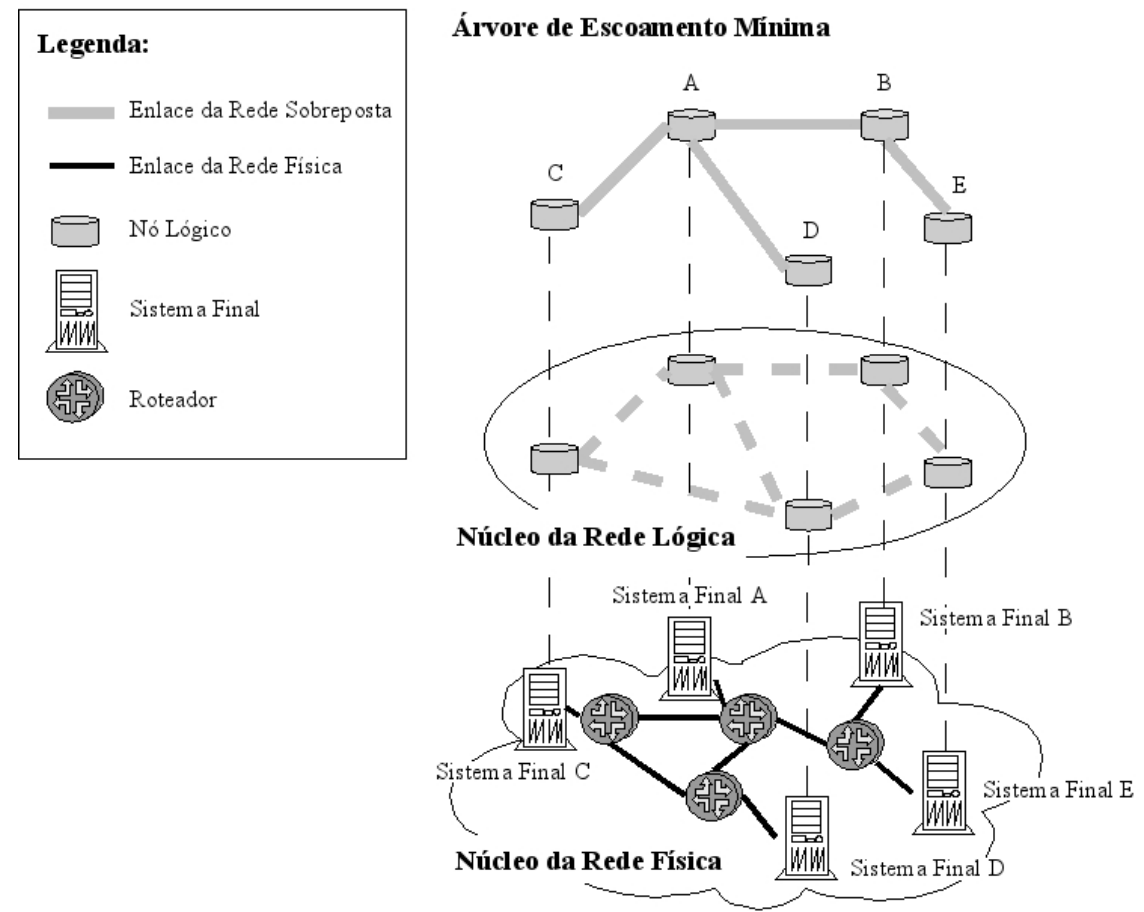

Figura 2.5: Exemplo de construção da estrutura virtual de entrega por multidifusão sobre a rede implícita.

Com base na taxonomia proposta por (YEO et al., 2004), distinguimos pelo menos três critérios de projeto na definição de uma infraestrutura de multidifusão em rede sobreposta : 1) arquitetura de distribuição; 2) topologia sobreposta; 3) modelo de serviço de comunicação em grupo.

\subsubsection{Arquitetura de Distribuição}

A estrutura de entrega pode ser suportada por sistemas finais de usuário interagindo diretamente, ou possuir sistemas finais dedicados no repasse dos dados da aplicação. Entretanto, além da distinção entre uma arquitetura baseada na interação direta dos receptores e uma arquitetura que utiliza uma infraestrutura de nós intermediários, as técnicas de multidifusão sobreposta podem também diferir quanto à criação e manutenção da estrutura virtual de entrega. Isto determinará a presença e o papel de um controlador central na sua arquitetura.

As funções de tal controlador incluem um serviço centralizado para a construção das árvores, um diretório central para todos os membros, o gerenciamento da relação de grupos - tal como processos de entrada e saída nas sessões -, e a execução de mecanismos de recuperação de falhas na estrutura de entrega. Dessa forma, depen- 
dendo da organização destas funcionalidades, as técnicas sobrepostas podem ser divididas em: centralizada; distribuída; e híbrida.

\section{Abordagem Direta ou Mediada}

$\mathrm{Na}$ abordagem direta, a construção da camada sobreposta inclui apenas sistemas finais de usuários, com todas as funcionalidades investidas nessas máquinas. Consequentemente, o controle dos grupos, a construção da estrutura de entrega e o redirecionamento dos dados, são controlados apenas pelas aplicações participantes nos hospedeiros dos usuários; não há suporte algum por parte de nós intermediários ou representantes.

Já a abordagem mediada desloca a facilidade de multidifusão dos roteadores da rede para servidores intermediários dedicados denominados nós de serviço, estrategicamente distribuídos ao longo da rede. Assim, o controle dos grupos, a construção da estrutura de entrega e o redirecionamento dos dados, são controlados por estes nós de serviço. Para ganhar acesso aos serviços sobrepostos, as máquinas de usuário final formam agrupamentos (clusters) em torno dos nós de serviço "mais próximos", onde estes atuarão em seu favor, sendo seus representantes. Portanto, a interação entre os clientes finais é mediada por nós intermediários.

O uso de servidores representantes ou nós de serviço intermediários garante algumas vantagens, advindas principalmente da dedicação funcional de seus elementos distribuidores. Por serem dedicados, os nós intermediários se apresentam de forma homogênea e com melhor provisão de recursos do que os sistemas dos usuários finais, e dessa forma a multidifusão sobreposta mediada é mais confiável e robusta à falhas. Os nós de serviço são persistentes, quando comparado ao tempo de engajamento dos sistemas dos usuários (que podem ser desligados a qualquer momento), o que simplifica bastante a manutenção das estruturas de entrega.

A eficiência da abordagem mediada dependerá do bom provisionamento dos nós de serviço na rede. O posicionamento dos nós pode ser definido segundo uma coalocação junto aos roteadores da rede física, ou por sua localização em pontos de alta atividade. Recentemente, alguns algoritmos que definem o provisionamento destes nós foram propostos por (LAO et al., 2007) e (FAHMY; KWON, 2007). Nosso modelo analítico de validação proposto no Capítulo 5 também sugere heurísticas para este provisionamento. 
Entretanto, a inclusão destes nós ao longo da rede pode apresentar problemas de aceitação e de implantação, por ser intrusivo ao domínio administrativo dos sistemas autônomos. Quando comparado aos sistemas P2P, a infraestrutura intermediária possui uma menor responsividade à mudanças nas condições do ambiente, visto que o posicionamento dos representantes é usualmente estático.

\section{Abordagem Centralizada, Distribuída, ou Híbrida}

Uma abordagem centralizada para o problema da criação da estrutura de entrega consiste em investir todas as responsabilidades de gerenciamento de grupo, cálculo da estrutura sobreposta, e otimizações, à um controlador central. Este controlador mantém informação sobre grupos, trata da relação de pertinência aos grupos, coleta medições a partir de todos os membros de um grupo, calcula caminhos ótimos na estrutura de entrega, e dissemina as rotas ou tabelas de roteamento para todos os membros.

A centralização da topologia simplifica seu gerenciamento, evitando problemas de coerência da estrutura, garante uma maior eficiência no seu processo construtivo, já que o RP pode criar uma topologia ótima através do conhecimento das características dos nós, e ainda uma maior robustez, já que o RP pode eleger nós para o repasse que historicamente apresentam comportamento mais estável.

Dessa forma, a abordagem centralizada apresenta grande simplicidade nos algoritmos de roteamento, uma gerência mais simples e eficiente dos grupos, e a provisão de um mecanismo confiável para prevenção de falhas na estrutura de entrega e para evitar laços de roteamento. Entretanto, sua natureza centralizada limita sua escalabilidade e impõe outros problemas de confiabilidade, como o problema de um ponto único de falhas.

Como o próprio nome sugere, a abordagem distribuída distribui as responsabilidade sobre a pertinência à grupos e o cálculo da estrutura sobreposta para outros nós da rede virtual. Portanto, esta abordagem é relativamente mais robusta à falhas, visto que uma falha em um nó individual não terá impacto no restante do grupo (evita ponto único de falha). $O$ fato de não possuir um controlador centralizado como gargalo torna esta abordagem mais escalável. Entretanto, uma abordagem completamente distribuída causa sobrecargas excessivas, e não é tão otimizada e eficiente na construção da estrutura sobreposta. 
Deve-se notar que a abordagem distribuída requer a manutenção de estado para todos os seus vizinhos na estrutura por cada membro do grupo. Além disso, a distribuição torna o processo de construção da estrutura de entrega bastante complexo, dificultando seu gerenciamento e atrasando o tempo de estabelecimento das sessões.

Uma abordagem híbrida é aquela onde um controlador de peso leve ainda é utilizado para facilitar algumas das funções de gerenciamento de grupos (processo de participação, por exemplo), de definição da estrutura de entrega, e recuperação de falhas, enquanto que a construção propriamente dita da estrutura de entrega é deixada para um algoritmo distribuído. Tal abordagem pode ser capaz de combinar os benefícios das outras duas abordagens citadas.

\subsubsection{Topologia Sobreposta}

A estrutura de entrega deve ser construída de forma a otimizar a eficiência da rede sobreposta e facilitar o gerenciamento dos grupos. Nesse sentido, algumas configurações de topologia da estrutura de entrega podem ser definidas. Os nós da camada sobreposta podem ser logicamente organizados em duas topologias: uma topologia de controle e uma topologia de dados.

A topologia de controle carrega dados de controle, tais como mensagens para acompanhamento de atividade, mensagens de atualização de estado, medições na rede e seus dados resultantes; enquanto que a topologia de dados compreende os caminhos de entrega de dados da aplicação para os múltiplos destinos. Note que os nós da topologia de controle não precisam ser necessariamente membros do grupo de multidifusão. Portanto, a topologia de controle é um superconjunto da topologia de dados.

A topologia de controle pode assumir uma estrutura lógica separada sob a forma de malha, ou pode compartilhar a mesma estrutura da topologia de dados. A maioria das técnicas adotam como norma uma estrutura em árvore para a topologia de dados em face de sua fácil construção e eficiência.

De acordo com a abordagem escolhida, a topologia sobreposta resultante pode ser classificada em três diferentes contextos (YEO et al., 2004): (i) árvore; (ii) malhaárvore; e (iii) estrutura embutida. Os projetos em árvore e malha-árvore podem ser 
categorizados como projeto consciente de topologia, enquanto que os projetos que usam uma estrutura embutida estão na categoria agnóstica de topologia (YEO et al., 2004).

O projeto de redes sobrepostas conscientes de topologia utiliza medidas ativas para inferir propriedades da rede, provendo informações básicas para a construção de uma topologia de dados eficiente, tentando combinar o máximo possível com a topologia da rede física. Já as abordagens agnósticas de topologia ignoram características da rede. Portanto, algoritmos conscientes de topologia possuem a vantagem de minimizar a ineficiência da sobreposição do roteamento, porém ao custo de um aumento na sobrecarga de gerenciamento, e possivelmente, de uma potencial redução de escalabilidade quando comparado à contra-partida agnóstica.

A topologia sobreposta pode ainda ser categorizada de acordo com os níveis de abstração empregados na topologia, resultando em uma topologia plana ou uma topologia hierárquica. Uma topologia plana é aquela onde há apenas uma única camada sobreposta localizada sobre a rede física. Todos os nós na camada sobreposta estão no mesmo nível lógico. Uma topologia hierárquica introduz um projeto de hierarquia na camada sobreposta, formando multicamadas sobrepostas. Os nós formam aglomerados no nível mais baixo, onde cada agrupamento possui um líder. Os líderes por sua vez formam aglomerados no próximo nível, e assim por diante.

As duas principais vantagens de se utilizar uma sobreposição hierárquica são: 1) sua capacidade de escalar, já que seu projeto em camadas possibilita que cada nó armazene uma pequena quantidade de informação de manutenção de estado; e 2) baixa sobrecarga de gerenciamento, já que monitorações e troca de informações de controle são realizadas sobre pequenos grupos. Isto é alcançado com o custo da eficiência, já que não é permitida a criação de enlaces virtuais entre nós filhos situados em agrupamentos diferentes, além da sobrecarga adicional para a manutenção dos aglomerados.

A seguir, discutimos um pouco mais sobre as topologias sobrepostas. 


\section{Árvore}

Membros de um grupo de multidifusão se organizam em uma estrutura em árvore através da escolha de uma raiz para cada novo grupo. Os nós na árvore podem estabelecer e manter conexões virtuais de controle uns com os outros, além dos caminhos lógicos utilizados pela árvore de entrega de dados. Portanto, esta abordagem utiliza como topologia de controle uma estrutura em árvore compartilhada com a topologia de dados. A vantagem de tal escolha é a simplicidade e potencial eficiência na construção de árvores de escoamento. Entretanto, o algoritmo de construção da árvore precisa prevenir laços e tratar partições, visto que a falha em um único nó da árvore pode causar uma partição na topologia sobreposta.

As abordagens em árvore tradicionais utilizam uma arquitetura de distribuição centralizada para controle da estrutura virtual de entrega por multidifusão. O ponto central é o RP, que controla a relação de membros de grupos e ajuda tais membros na construção de árvores de entrega eficientes. Ele orienta a organização dos nós sobrepostos, elegendo a raiz e definindo novos pais e filhos na árvore. Diferentes mecanismos para arbitrar a posição dos nós na árvore podem ser adotados. Basicamente, a participação de novos nós na árvore pode ser definida de forma centralizada ou distribuída.

$\mathrm{Na}$ escolha centralizada, o RP define a participação dos nós na árvore calculando árvores de escoamento com custo mínimo a partir do conhecimento local ou global da topologia. Já na forma distribuída, os nós se auto-organizam na estrutura de entrega. Geralmente, o RP passa uma orientação de posicionamento inicial na estrutura, e os próprios nós podem atualizar sua localização na árvore através da observação de sua vizinhança. Tanto no esquema centralizado como distribuído, as métricas utilizadas na definição do posicionamento podem ser tempo de ida-e-volta (Round-Trip-Time RTT) ou largura de banda disponível nos enlaces lógicos, ambos medidos sobre a rede física.

\section{Malha-Árvore}

A abordagem malha-árvore estabelece a topologia sobreposta segundo um processo de construção em dois passos. É comum que os membros do grupo de multidifusão primeiramente se auto-organizem de maneira distribuída em uma topologia sobreposta de controle denominada malha. Posteriormente, um protocolo de roteamento 
é executado sobre esta topologia de controle, definindo caminhos sobrepostos únicos para cada um dos membros, levando em consideração todos os nós. Dessa forma, árvores de distribuição de dados centradas em qualquer um dos membros são então construídas sobre a estrutura em malha segundo algum protocolo padrão de roteamento por multidifusão. Este foi o processo de construção apresentado na Figura 2.5, no início deste capítulo.

Novamente, é comum que uma entidade central, o RP, inicie o procedimento de participação em sessão por um novo membro, tal como na abordagem em árvore. Depois, os sistemas finais (dedicados ou não) são então organizados em uma estrutura de entrega através de um protocolo distribuído. Quando um novo nó deseja participar de um grupo de multidifusão, ele pode, por exemplo, primeiro obter uma lista de todos os membros da malha já estabelecidos no grupo. Tipicamente, esta informação pode ser obtida a partir do RP, o qual mantém estado sobre todos os membros participantes do grupo de mutidifusão. Através de algum processo decisório, este novo nó escolhe um subconjunto desta lista, e tenta participar da malha como vizinho dos membros selecionados. O procedimento de participação no grupo finaliza com sucesso quando pelo menos um destes membros aceita o novo nó como seu vizinho na malha.

Comparada ao projeto apenas em árvore, a abordagem malha-árvore é mais complexa. No entanto, ela possui várias vantagens ( $\mathrm{CHU}$ et al., 2000), listadas como segue:

1. as funções de gerenciamento de grupo são abstraídas e tratadas na malha, ao invés de replicadas ao longo de múltiplas árvores (uma por fonte);

2. heurísticas distribuídas para reparo de partição e para otimização da malha são enormemente simplificadas, visto que a eliminação de laços não é mais um fator limitante;

3. possibilidade de utilização de algoritmos de roteamento padronizados para a construção das árvores de entrega de dados, simplificando assim a construção e manutenção da topologia de dados sobreposta, dado que os mecanismos de detecção e eliminação de laços já estão embutidos nestes protocolos de roteamento;

4. maior robustez, visto que a estrutura em malha é mais resiliente à falhas de membros do que uma estrutura em árvore (existência de caminhos redundantes), e também os pesados mecanismos de reparo de partição são invocados com menor frequência. 


\section{Estrutura Embutida}

$\mathrm{Na}$ abordagem estrutura embutida, os membros recebem endereços lógicos na rede sobreposta a partir de algum espaço coordenado abstrato, e constroem a estrutura de entrega com a ajuda destes endereços lógicos. Através da inserção de mapeamento de vizinhança embutido no endereço dos membros, o roteamento de mensagens em cada salto pode ser realizado sem a necessidade de protocolos de roteamento rebuscados, tais como aqueles utilizados na multidifusão IP. Além disso, cada membro precisa manter conhecimento apenas sobre um pequeno subconjunto de membros, permitindo que os protocolos sejam altamente escaláveis.

Como exemplo, imagine um espaço de nomes circular de $n$ bits, o qual pode ser usado para identificar nós na rede sobreposta. Dessa forma, os possíveis identificadores dos nós variam na faixa de 0 a $2^{n}-1$. Um desses identificadores pode ser atribuído a um nó quando este solicita participação no grupo de multidifusão. O identificador pode ser escolhido de forma aleatória, assumindo-se uma distribuição uniforme dentro do espaço de nomes do anel. Neste sistema, o roteamento pode ser realizado de forma bastante simples: ao receber uma mensagem e o identificador de seu destino, um nó da estrutura repassa a mensagem para o vizinho cujo identificador seja mais próximo do identificador do nó destino que se deseja alcançar. Este exemplo está ilustrado na Figura 2.6.

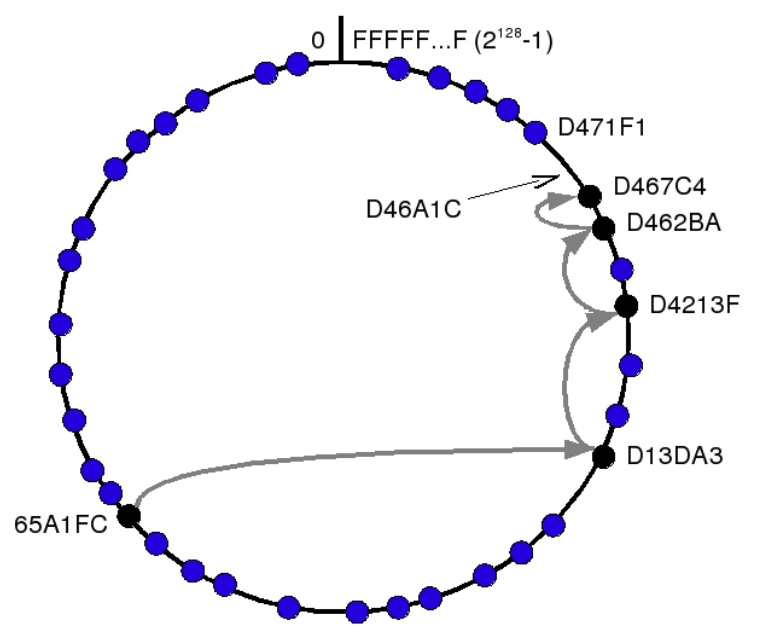

Figura 2.6: Roteando uma mensagem a partir do nó 65A1FC com chave D46A1C (adaptado de (ROWSTRON; DRUSCHEL, 2001)). Os pontos representam nós ativos em um espaço de nomes circular de 128 bits.

É importante notar que, em contraste com as abordagens baseadas em árvore ou malha, muitos dos protocolos que utilizam a abordagem de estrutura embutida impõem regras nas relações de vizinhança, ditadas pela atribuição de endereços aos 
sistemas finais, sem levar em consideração o desempenho. Dessa forma, pode haver uma penalidade de desempenho na construção das topologias sobrepostas, desde que as relações de vizinhança normalmente não se confirmam na topologia da rede física. Portanto, várias topologias sobrepostas construídas com estrutura embutida se enquadram como agnósticas de topologia, com exceção daqueles que possuem características implícitas que possibilitam um melhor mapeamento entre os vizinhos na estrutura sobreposta com os vizinhos na rede implícita, os quais se caracterizam como conscientes de topologia.

\subsubsection{Modelo de Serviço de Comunicação em Grupo}

Dependendo da maneira pela qual os dados vão sendo entregues à múltiplos destinos simultâneos, as soluções sobrepostas poderão ser classificadas em: entrega de melhor esforço ou entrega confiável; e modelo de entrega com fonte específica ou modelo de entrega com fonte qualquer (YEO et al., 2004).

O modelo de serviço determinará os tipos de aplicações que as várias técnicas de multidifusão poderão suportar. Aplicações de mídias contínuas, tais como difusão de dados multimídia em tempo real e certas aplicações colaborativas de áudio/videoconferência, por exemplo, são tolerantes à perdas, e um serviço de entrega de melhor esforço pode ser suficiente se mecanismos de ordenação e marcas temporais forem empregados. Já serviços de replicação requerem integridade de seus dados, e dessa forma necessitam de uma transferência confiável. Normalmente, para distribuição de conteúdos um modelo de entrega com fonte específica é suficiente, enquanto que aplicações colaborativas utilizam um modelo de entrega com fonte qualquer.

\section{Melhor Esforço ou Transferência Confiável}

Por transferência confiável, entendemos como o uso de uma confiabilidade fim-a-fim na transmissão dos dados. Note que esta é uma definição um pouco mais rigorosa, a qual inclui mais do que apenas utilizar o protocolo TCP para transferência dos dados. O TCP apenas assegura uma confiabilidade salto-a-salto, a qual previne perdas devido à erros de transmissão e congestionamento da rede, com o custo da impossibilidade de cumprimento dos requisitos temporais na entrega (YEO et al., 2004). 
Para a recuperação de erros oriundos de transições na árvore de entrega e falha de nós, técnicas de recuperação de erros como duplicação de dados e retransmissões precisam ser incorporadas. Estas técnicas, assim como a transferência TCP saltoa-salto ${ }^{6}$, impõem uma pressão de volta à fonte, visto que a fonte precisa tratar das solicitações de retransmissão, além de sua própria limitação de taxa, para evitar estouro do buffer ${ }^{7}$. Neste sentido, os nós da rede sobreposta podem ajudar a aliviar essa pressão na fonte se estes possuírem capacidade de "bufferização" e/ou de limitação de taxa, de forma que o controle de fluxo e as retransmissões possam ser tratados localmente.

\section{Entrega com Fonte Específica ou Fonte Qualquer}

O serviço de comunicação das técnicas de multidifusão sobreposta podem também ser classificadas em: modelos de fonte específica e modelos de fonte qualquer. $O$ primeiro constrói uma árvore de entrega de dados centrada (ou enraizada) em uma única fonte, com uma árvore para cada fonte, enquanto que o último modelo constrói uma árvore compartilhada por grupo, onde qualquer membro na árvore pode ser uma fonte. No modelo de fonte específica é empregada uma entrega um-para-muitos, também denominada simplex, enquanto que o modelo de fonte qualquer emprega uma entrega muitos-para-muitos, também denominada multiplex.

A árvore compartilhada geralmente é centrada na fonte dominante, embora possa ser centrada em qualquer nó, conforme definido por seus algoritmos de construção da árvore. Árvores centradas na fonte são simples, possuindo uma reconhecida vantagem de latência sobre as árvores compartilhadas por grupo, embora os estados de roteamento associados com a árvore centrada na fonte cresçam linearmente com o número de fontes de dados, visto que esta abordagem precisa lidar com uma sobrecarga de manutenção e otimização de múltiplas árvores. No entanto, esta é uma preocupação menor em sistemas finais do que em roteadores (YEO et al., 2004). Por outro lado, árvores compartilhadas por grupo reduzem a ineficiência de roteamento, e incorrem em uma menor sobrecarga na construção e gerenciamento da árvore, porém não são otimizadas para fontes individuais e são susceptíveis à falha no ponto central.

\footnotetext{
${ }^{6}$ Entre os nós da rede sobreposta, ou seja, fim-a-fim com cada sistema final intermediário, conectados através do protocolo TCP.

${ }^{7}$ Memória de contingência.
} 


\subsection{Trabalhos Correlatos}

Os protocolos de multidifusão sobreposta normalmente se tornam específicos, já que precisam levar em consideração os requisitos de cada aplicação. Dessa forma, surge na literatura uma grande variedade de sistemas e protocolos. Discutiremos agora algumas destas propostas, onde os conceitos envolvidos explorados anteriormente, para cada caso, são resumidos na Tabela 2.1 .

\section{ALMI}

Um bom exemplo de solução que constrói uma topologia plana em árvore de forma centralizada é o Application Level Multicast Infrastructure (ALMI) (PENDARAKIS et al., 2001). Tal esquema utiliza uma entidade central que ajuda os nós a se autoorganizarem em uma estrutura de entrega com interação direta entre os sistemas dos usuários finais.

Consequentemente, ALMI calcula uma árvore de escoamento mínimo (minimum spanning tree - MST), a qual consiste de conexões ponto-a-ponto entre sistemas finais. A latência entre os membros é utilizada como custo de enlace da MST. Portanto, o ALMI otimiza a topologia sobreposta para uma baixa latência, alcançada através de medidas de RTT sobre a rede física.

\section{BTP}

O Banana Tree Protocol (BTP) (HELDER; JAMIN, 2002) constrói a árvore de escoamento de forma descentralizada e auto-organizada, com interação direta entre os sistemas finais de usuário. O primeiro nó a solicitar participação no grupo se torna a raiz da árvore. Novos membros subsequentes aprendem sobre o nó raiz através do RP, e são instruídos a se posicionarem na árvore. No entanto, cada nó membro também possui autonomia para decidir trocar de lugar na árvore caso descubra uma configuração que melhor atenda suas expectativas.

Para tomar tal decisão, o BTP emprega uma técnica denominada comutação de árvore, a qual visa obter uma árvore com custo mais baixo. Periodicamente, cada nó 
solicita ao nó logo acima no fluxo de subida (denominado nó pai) uma lista de nós vizinhos. Através de medições em cada máquina da lista, ele determina se existe um nó "mais próximo" de si do que o seu pai atual, e com melhores condições. Em caso afirmativo, este nó decide trocar de pai.

\section{Host Multicast}

De forma similar ao BTP, no Host Multicast (ZHANG et al., 2002) o RP também elege um nó como raiz e permite que novos membros descubram este nó raiz. No entanto, o processo de adaptação da árvore é feito de forma interativa.

Este processo interativo pode ser descrito da seguinte forma:

1. um novo membro descobre o nó raiz através do RP, considerando-o então como um pai em potencial;

2. ele então solicita deste possível pai uma lista de filhos já estabelecidos (irmãos em potencial), e escolhe como novo pai em potencial o nó "mais próximo" de si, considerando os irmãos e o pai em potencial;

3. este processo se repete árvore abaixo, até que o novo membro perceba que seu atual pai em potencial é realmente o nó mais próximo de si;

4. o novo nó envia para seu pai em potencial uma solicitação de participação no grupo. Se este pai em potencial não esgotou seu limite de número de filhos, ele aceita o pedido e se torna o pai efetivo. Caso contrário, o novo nó retrocede um nível acima na hierarquia da árvore e repete o processo de busca.

É importante observar que apenas alguns membros são designados para participarem do processo de construção da árvore compartilhada. Estes membros são denominados de Designated Members (DM), e são eleitos para atuar em benefício dos membros de uma ilha de mutidifusão. O DM se comunica com sua ilha através de multidifusão local. Como os DMs não são hospedados em servidores dedicados, e sim em sistemas finais de usuários, o Host Multicast emprega uma multidifusão sobreposta direta. 


\section{OMNI}

Um outro sistema que utiliza um processo interativo semelhante na construção da estrutura sobreposta é o Overlay Multicast Network Infrastructure (OMNI) (BANERJEE et al., 2006). Entretanto, tal processo é dividido em duas fases: uma fase de inicialização "desligada" - antes que a entrega dos dados comece; e uma fase "ligada" - processo dinâmico de auto-organização realizado durante a entrega dos dados.

Antes do início da transmissão, na fase "desligada", a raiz da árvore monitora e ordena a lista de nós em ordem crescente de latência de unidifusão, a partir da própria raiz. A raiz então constrói a árvore sempre escolhendo os nós mais próximos de si em cada nível. Dessa forma, a raiz organiza os nós em uma árvore de entrega de dados inicial, onde os clientes entram e saem da árvore dinamicamente, e a raiz é conectada à fonte. Note que esta é uma fase centralizada.

Esta estrutura em árvore irá se autotransformar para se adaptar às mudanças nas condições da rede durante a transmissão, ou seja, na fase "ligada". Uma prioridade dinâmica é atribuída a cada nó, baseada no tamanho de seu conjunto de serviço (isto é, número de clientes em atendimento). Com base nessa propriedade dinâmica, os nós se auto-organização de forma interativa, visando otimizar a topologia sobreposta.

A estrutura sobreposta construída por OMNI utiliza servidores representantes dedicados ao repasse de dados e distribuídos ao longo da rede, o que classifica-o como uma abordagem de multidifusão sobreposta mediada. Tais elementos sobrepostos são denominados Multicast Service Nodes (MSNs). OMNI é projetado para distribuição de dados em larga escala onde exista apenas uma fonte, como aplicações webcast, por exemplo.

\section{Overcast}

O Overcast (JANNOTTI et al., 2000) também utiliza um processo interativo similar ao Host Multicast. Porém, Overcast tem como objetivo maximizar a largura de banda a partir da fonte para todos os membros (com o custo de um aumento no atraso). Consequentemente, em vez de medir sua latência até os membros da lista (incluindo o pai em potencial), um novo nó Overcast mede sua largura de banda para estes nós. A largura de banda é obtida através da observação da troca de 10 kbytes de dados 
entre os nós. Assim, exceto pelo custo utilizado na construção da árvore, o processo interativo é realizado conforme explicado para o Host Multicast.

Overcast organiza um conjunto de representantes, chamados nós overcast, em uma árvore de distribuição enraizada na fonte (fonte específica), para oferecer uma multidifusão confiável. Como estes nós overcast são hospedados em servidores dedicados, este esquema se utiliza de uma multidifusão sobreposta mediada.

\section{Narada}

O Narada (CHU et al., 2000) foi um dos primeiros sistemas a demonstrar a possibilidade de implementação de funcionalidades de multidifusão em nível de aplicação. Este sistema utiliza o protocolo End System Multicast (ESM), o qual define uma arquitetura distribuída de multidifusão sobreposta direta.

O Narada utiliza um projeto de topologia sobreposta plana em malha-árvore, onde o RP inicia o procedimento de participação em sessão por um novo membro. Os sistemas finais dos usuários são então organizados em uma estrutura de entrega através de um protocolo distribuído, o ESM. A construção da estrutura de entrega é realizada em dois passos: (1) primeiramente, uma topologia de controle em malha é construída ao longo dos nós participantes; (2) subsequentemente, uma topologia de dados é construída sobre essa malha através da auto-organização dos membros em árvores de multidifusão centradas na fonte usando protocolos padrão de roteamento, tal como o Distance Vector Multicast Routing Protocol (DVMRP) (WANG; CROWCROFT, 1995), por exemplo.

Quando um novo nó deseja participar de um grupo de multidifusão, ele primeiro obtém uma lista de todos os membros da malha já estabelecidos no grupo. Tipicamente, esta informação pode ser obtida a partir do RP, o qual mantém estado sobre todos os membros participantes do grupo de mutidifusão. De forma aleatória, este novo nó escolhe um subconjunto desta lista, e tenta participar da malha como vizinho dos membros selecionados. O procedimento de participação em sessão finaliza com sucesso quando pelo menos um destes membros aceita o novo nó como seu vizinho na malha.

Os membros do grupo executam um protocolo de roteamento para cálculo dos caminhos de unidifusão para todos os pares na malha. Dessa forma, caminhos para 
entrega de dados por multidifusão com qualquer um dos membros como fonte específica podem ser calculados usando esquemas conhecidos de checagem de caminho reverso mais curto (RPF), similar aos mecanismos empregados em protocolos de multidifusão IP, conforme visto na Seção 2.3.

Após participar da malha, o novo membro inicia uma troca de mensagens de atualização periódica com seus vizinhos de malha. Sempre que um novo nó entra ou um nó existente abandona o grupo, esta informação de mudança no grupo é propagada através da malha para todos os outros membros. Dessa forma, cada membro no grupo mantém estado sobre todos os outros membros que fazem parte desse grupo. Esta informação também é periodicamente atualizada.

\section{Scattercast}

De forma similar ao Narada, o Scattercast (CHAWATHE, 2003) também adota a abordagem malha-árvore com topologia plana para a construção da rede sobreposta. Porém, a diferença está na utilização explícita de uma infraestrutura de nós de serviço (representantes ou proxies) estrategicamente implantados ao longo da rede e especialmente dedicados para o repasse de dados na topologia sobreposta, o que caracteriza uma arquitetura de multidifusão sobreposta mediada.

O Scattercast utiliza o protocolo distribuído Gossamer para auto-organizar seus ScatterCast proXies (SCXs) (os elementos intermediários) na malha, sobre a qual um algoritmo global de roteamento é utilizado para construir uma árvore de entrega de dados centrada na fonte, usando a latência como métrica de roteamento. Assim como o Narada, cada membro também precisa manter estado completo e tabelas de roteamento para todos os outros membros.

\section{TOMA}

Uma outra solução que utiliza servidores dedicados para o repasse dos dados é o Two-Tier Overlay Multicast Architecture (TOMA) (LAO et al., 2007). Em sua arquitetura, TOMA defende a noção de um Serviço de Multidifusão em Rede Sobreposta (Multicast Service Overlay Network - MSON ) (DUAN et al., 2002) como o núcleo de domínio do serviço. Um serviço MSON é uma rede sobreposta formada a partir de nós de 
serviços estrategicamente implantados ao longo da rede, através dos quais árvores de distribuição são construídas para entrega dos dados de aplicação com base em protocolos de roteamento por multidifusão.

O TOMA utiliza um projeto de topologia malha-árvore com abordagem hierárquica em dois níveis. TOMA é caracterizado como uma solução híbrida por empregar uma abordagem distribuída dentro do núcleo de domínio do serviço MSON, e uma abordagem centralizada para os agrupamentos fora do MSON. Em seu núcleo, quando um representante de membro decide lançar uma solicitação de participação em um grupo, ele envia uma mensagem para o representante hospedeiro. Este representante hospedeiro realiza uma busca de batimento grupo-árvore, encontrando ou calculando um árvore compartilhada, e confirmando para o representante de membro. Se este representante de membro ainda não participa desta árvore de entrega, ele se enxertará à árvore enviando uma mensagem através de seu representante hospedeiro, e os representantes ao longo do caminho de propagação vão atualizando suas tabelas de roteamento adequadamente.

Fora do MSON, um sistema terminal recebe uma lista de candidatos a representantes de membro através de um servidor DNS MSON. Através de medições RTT, o sistema terminal elege seu representante. Sistemas finais associados ao mesmo representante de membro formam aglomerados. Em cada aglomerado, TOMA adota uma abordagem de núcleo-base para construir as árvores de mutidifusão P2P. TOMA tem como foco aplicações colaborativas, onde pode haver mais de uma fonte por grupo, caracterizando uma entrega de dados com fonte qualquer utilizando um serviço de entrega de melhor esforço.

\section{YOID}

Uma solução diferente de todas as propostas malha-árvore vistas até aqui é o YOID (FRANCIS, 2007), o qual cria as topologias em malha e em árvore separadamente. Primeiro ele constrói diretamente uma árvore de dados compartilhada, e só depois constrói uma malha de controle. A topologia em árvore não é um subconjunto da topologia em malha. Elas são completamente independentes e construídas para diferentes propósitos.

A árvore é otimizada para eficiência da distribuição, enquanto que a malha provê robustez, servindo para descoberta e recuperação de árvores particionadas, detecção 
e notificação de membros inatingíveis, verificação da recepção de conteúdos, etc. A construção da árvore é feita de forma similar ao BTP, como descrito anteriormente. Porém, cada membro mantém informação sobre um pequeno número de nós vizinhos, como forma de garantir uma topologia sem partições. Consequentemente, a topologia em malha consiste apenas desses nós vizinhos.

\section{ALM-CAN}

A solução Application-Level Multicasting using Content-Addressable Networks (ALMCAN) (RATNASAMY et al., 2001b) faz uso de uma infraestrutura de roteamento em nível de aplicação denominada Content-Addressable Networks (CAN) (RATNASAMY et al., 2001a) como base de suporte para provisão de um serviço de multidifusão em nível de aplicação chamado Application-Level Multicast (ALM).

A infraestrutura CAN é uma rede P2P estruturada cujos nós constituintes formam um espaço coordenado abstrato, onde cada membro possui sua própria porção individual neste espaço. Essencialmente, a rede CAN é uma tabela hash distribuída (Distributed Hash Table - DHT) na escala da Internet que mapeia nomes de arquivo em sua localização na rede, através do suporte a operações de inserção, localização, e deleção de pares (chave, valor) na tabela.

Cada nó individual da rede CAN armazena uma parte (referenciada como "zona") da tabela DHT, assim como informações sobre um pequeno número de zonas adjacentes na tabela. Solicitações de inserção, localização, ou deleção de uma chave particular são roteadas através das zonas intermediárias até o nó que mantém a zona referente a esta chave. O espaço coordenado utilizado é completamente lógico e não possui nenhuma relação com a rede física implícita. Este espaço coordenado nos oferece um nível de abstração, já que agora podemos falar em armazenar conteúdos em um "ponto" no espaço, ou rotear entre "pontos" no espaço. Por "ponto" no espaço, nos referimos a um nó CAN que administra uma zona que contém aquele ponto.

Portanto, ALM-CAN utiliza a rede CAN como topologia de controle. A topologia para a multidifusão dos dados é definida implicitamente através da realização de uma inundação direta (RATNASAMY et al., 2001b). As regras para redirecionamento de dados de aplicação podem ser resumidas da seguinte forma: a fonte repassa um pacote de dados a todos os seus vizinhos na topologia de controle; ao receber os pacotes, os vizinhos por sua vez repassam os dados para todos os seus próprios vizinhos, exceto 
o vizinho a partir do qual ele recebeu.

Note que não há necessidade de construção de nenhuma árvore explícita. Cada membro CAN mantém uma tabela de roteamento para seus vizinhos, assim como um cache de pacotes para identificar e descartar duplicatas. Vizinhos são definidos como os membros que possuem zonas contíguas no espaço coordenado. Portanto, para um espaço coordenado de dimensão $d$, um nó membro mantém estado para $2 d$ nós adicionais (seus vizinhos contíguos), independente do número de fontes no grupo. Para uma dimensão $d=2$, por exemplo, um nó membro manterá estado para 4 nós, ou seja, o mesmo número de vizinhos contíguos.

\section{ALM-DT}

Uma outra proposta similar ao ALM-CAN é o Application Layer Multicasting using Delaunay Triangulations (ALM-DT) (LIEBEHERR; SI, 2002). ALM-DT também atribui a cada membro um par de coordenadas lógicas $(x, y)$ em um plano. As coordenadas podem ser atribuídas através de algum mecanismo externo, tal como GPS (Global Position System) ou algum mecanismo de entrada pelo usuário, e selecionadas de forma a refletir a localização geográfica dos nós. Através destas coordenadas, uma topologia de controle, a qual essencialmente compreende combinações de triangulações de Delaunay (Delaunay Triangulations - DT), é construída através de cálculos e comparações com base nas propriedades da DT. Detalhes desta construção podem ser vistos em (LIEBEHERR; SI, 2002).

Uma vez construída a topologia de controle, a árvore de multidifusão de dados centrada na fonte é embutida na DT sem a necessidade de protocolo de roteamento, desde que a informação para redirecionamento do pacote está codificada nas coordenadas de um nó. A técnica de roteamento compassado (LIEBEHERR; SI, 2002) é utilizada para determinar a árvore de roteamento por multidifusão, onde os nós calculam seus nós filhos nessa árvore de forma distribuída. Cada nó pode determinar localmente seus nós filhos para um grupo utilizando suas próprias coordenadas, as coordenadas de seus vizinhos, e as coordenadas do transmissor fonte. 


\section{Bayeux}

Também similar ao ALM-CAN, Bayeux (ZHUANG et al., 2001) utiliza uma infraestrutura de roteamento e localização em nível de aplicação denominada Tapestry (ZHAO et al., 2003). Nesta infraestrutura, os nós são embutidos em um espaço de endereçamento virtual independente de sua localização na rede. A arquitetura de Tapestry é baseada em uma variação da técnica de busca distribuída conhecida como malha de Plaxton (PLAXTON et al., 1997). Cada nó mantém um mapa de vizinhos com múltiplos níveis, cada nível $l$ contendo apontadores para nós cujo identificador precisa combinar em $l$ dígitos. Cada entrada no mapa de vizinhos corresponde a um apontador para o nó mais próximo na rede cujo identificador "bate" com o número no mapa de vizinhos, até uma posição de dígitos.

Ao contrário do ALM-CAN e ALM-DT, Bayeux tem que construir explicitamente uma árvore de multidifusão centrada na fonte sobre a topologia de controle Tapestry. A árvore de dados Bayeux compreende tanto os nós Tapestry atuando como roteadores em software como os receptores da multidifusão.

\section{NICE}

O NICE (BANERJEE et al., 2002) é um protocolo de multidifusão sobreposta direta com uma arquitetura distribuída, e que apresenta um projeto de topologia hierárquica. Nesta topologia, os membros são organizados em uma hierarquia multicamadas, podendo assim alcançar uma alta escalabilidade. Um protocolo de agrupamento distribuído em cada camada particiona estes membros em um conjunto de aglomerados com o limite de tamanho especificado. O protocolo escolhe um líder do aglomerado, o qual é o centro deste agrupamento na camada $L_{i}$, para participar da camada $L_{i+1}$.

Esta disposição permite que novos membros localizem rapidamente sua posição na hierarquia com um mínimo de consultas à outros membros. Um novo membro é redirecionado para os hospedeiros na camada mais alta da hierarquia $\left(L_{i}\right)$ pelo RP. O nó solicitante contacta estes membros e seleciona aquele mais próximo de si em termos de latência. Este nó selecionado informará ao nó que deseja participar do grupo a respeito de seus pares na camada $L_{i-1}$. Interativamente, o nó recém-chegado identifica o membro mais próximo de si em cada camada até que ele localize seu agrupamento na camada $L_{0}$. 
A hierarquia NICE dos membros é utilizada tanto para definir as topologias de controle quanto de dados. A topologia de dados é uma árvore embutida centrada na fonte, definida por uma regra de redirecionamento na topologia de controle sem a necessidade de construí-la explicitamente ou de se utilizar qualquer algoritmo complexo de roteamento. Uma fonte envia os dados de aplicação para todos os interessados na topologia de controle. Um hospedeiro receptor irá apenas repassar os dados para seus pares se, e somente se, ele for o líder do agrupamento.

NICE é um projeto consciente de topologia, visto que ele escolhe os pares sobrepostos com base em sua localidade na rede, ainda que sua topologia de dados esteja implícita na hierarquia NICE. Resultados de simulação mostram que este esquema causa uma redução da largura de banda necessária para o tráfego de controle, e estruturas virtuais hierárquicas absorvem mudanças melhor que estruturas planas (JAIN et al., 2000).

\section{SCRIBE}

Uma outra forma de se construir uma estrutura embutida é fazendo uso de um sistema de notificação de eventos em larga escala. O sistema de multidifusão SCRIBE (CASTRO et al., 2002) é um exemplo, onde os dados são disseminados em um esquema publica-subscreve para grupos baseados em tópicos. SCRIBE constrói uma árvore de multidifusão compartilhada centrada na fonte sobre uma infraestrutura embutida.

A infraestrutura de suporte do SCRIBE é a rede P2P Pastry (ROWSTRON; DRUSCHEL, 2001), usada para localização e roteamento na Internet. Assim como Tapestry, Pastry utiliza um prefixo de roteamento similar à malha de Plaxton para construir uma rede sobreposta auto-organizável de forma descentralizada, onde cada par roteia solicitações de clientes e interage com instâncias locais de uma ou mais aplicações (LUA et al., 2005).

A cada nó em Pastry, é atribuído um identificador de nó de 128 bits. Este identificador é usado para posicionar o nó em um espaço de nomes circular, o qual pode variar de 0 a $2^{128}-1$. O identificador é atribuído aleatoriamente quando um nó solicita participação no sistema, assumindo-se uma distribuição uniforme ao longo do espaço de nomes, conforme ilustrado anteriormente na Figura 2.6. O roteamento é realizado da seguinte forma: dado uma mensagem e uma chave de destino, Pastry roteia a mensagem para o nó cujo identificador é numericamente mais próximo da chave. 
O SCRIBE, portanto, utiliza a topologia de controle do Pastry. Um nó Pastry que deseja participar de um grupo SCRIBE simplesmente roteia uma mensagem de participação utilizando o identificador de tópico como sua chave de destino. Todos os membros neste caminho que ainda não participam da árvore de multidifusão dos dados para o grupo desejado também adicionam-se à árvore. Portanto, um nó SCRIBE mantém uma tabela de filhos para o grupo contendo uma entrada (endereço IP e identificador do nó) para cada um de seus filhos na árvore de multidifusão.

\section{SMCP}

Com base nestes trabalhos relacionados, esta dissertação propõe um protocolo de controle para multidifusão em redes sobrepostas denominado Simple Multicast Control Protocol (SMCP) ${ }^{8}$. A proposta é criar um protocolo simples, baseado em padrões internacionais, para uma transmissão multimídia eficiente através de diferentes Redes com Serviço de Multidifusão Sobreposta (MSON), provendo portanto uma multidifusão interdomínio.

Tais requisitos levam a escolha de uma arquitetura mediada e híbrida, neste ponto similar às propostas do OMNI e TOMA. O uso de servidores dedicados intermediários simplifica o protocolo, pois a provisão mais homogênea e permanente dos recursos inerentemente torna o sistema mais confiável e robusto. Uma entidade central localizada na MSON executa algoritmos de roteamento com base em informações da topologia da rede, definindo os caminhos de entrega intradomínio. Essa centralização simplifica o gerenciamento e permite a criação de uma topologia sobreposta ótima. Para o roteamento entre mais de uma MSON, algumas entidades atuam de forma distribuída para garantir a multidifusão interdomínio, o que faz do SMCP uma abordagem com arquitetura híbrida.

Além disso, o SMCP emprega uma topologia hierárquica multicamadas, uma para cada MSON ao longo do caminho de entrega; neste sentido, de forma semelhante ao NICE. Isto confere ao SMCP uma alta escalabilidade, visto que se trabalha com um conjunto com tamanho limitado especificado em cada MSON. Para que sua estratégia seja eficiente, torna-se necessário um conhecimento prévio da topologia da rede, o que enquadra o SMCP como uma abordagem consciente de topologia. Entretanto, para garantir sua simplicidade e flexibilidade, não é escopo do SMCP definir como se dá a construção da topologia sobreposta. Dessa forma, qualquer uma das aborda-

\footnotetext{
${ }^{8}$ Adotamos um termo em inglês para facilitar nas publicações.
} 
gens já discutidas podem ser empregadas, a saber: árvore, malha-árvore ou estrutura embutida. Na prática, a abordagem malha-árvore confere ao SMCP uma série de vantagens, conforme já discutido na Seção 2.4.2.

Um exemplo de como o SMCP pode construir a estrutura de entrega é dado a seguir. Dentro de uma MSON, o processo de construção da estrutura de entrega pode ser realizado em dois passos, similar ao Narada (porém de forma centralizada). Primeiramente, uma entidade central constrói uma estrutura em malha com base nas informações de topologia. Então, para cada nova solicitação de participação em sessão, esta entidade pode executar algoritmos de roteamento sobre a malha, e assim calcular uma estrutura em árvore enraizada na fonte, para todos os elementos de borda. Dessa forma, cada novo cliente que deseja participar da sessão é então redirecionado para receber o fluxo a partir de um nó de serviço "mais próximo" de si, já com a informação dos outros nós da árvore até a fonte. Neste momento, cada nó intermediário se encarrega de obter o fluxo e repassá-lo, até que o novo participante comece a receber os dados.

O resultado é um protocolo simples e leve, mas ainda mantendo sua eficiêcia e robustez. Além disso, o SMCP é o único protocolo baseado em um padrão internacional (International Telecommunication Union (ITU) - International Organization for Standardization (ISO/IEC), 2004) e o único que provê uma multidifusão interdomínio (UCHôA et al., 2009).

O protocolo SMCP será discutido em detalhes no Capítulo 4, mas antes o Capítulo 3 propõe uma arquitetura de middleware capaz de organizar as funcionalidades das redes sobrepostas, provendo o suporte necessário para garantir a eficência dos serviços construídos sobre estas redes. 


\section{Quadro-Resumo}

A Tabela 2.1 resume as características de cada uma das propostas discutidas, incluindo o SMCP que será discutido no Capítulo 4.

\begin{tabular}{|l||l|l|l|}
\hline Solução & Arquitetura & Topologia & Serviço de comunicação \\
\hline \hline ALMI & Direta, centralizada & Árvore, plana, consciente & Confiável, fonte qualquer \\
\hline BTP & Direta, distribuída & Árvore, plana, consciente & Melhor esforço, fonte qualquer \\
\hline Host Multicast & Direta, híbrida & Árvore, plana, consciente & Melhor esforço, fonte qualquer \\
\hline OMNI & Mediada, híbrida & Árvore, plana, consciente & Melhor esforço, fonte qualquer \\
\hline Overcast & Mediada, distribuída & Árvore, plana, consciente & Confiável, fonte específica \\
\hline Narada & Direta, distribuída & Malha-árvore, plana, consciente & Melhor esforço, fonte específica \\
\hline YOID & Direta, híbrida & Malha-árvore, plana, consciente & Melhor esforço, fonte qualquer \\
\hline ScatterCast & Mediada, distribuída & Malha-árvore, plana, consciente & Confiável, fonte específica \\
\hline TOMA & Mediada, híbrida & Malha-árvore, hierárquica, consciente & Melhor esforço, fonte qualquer \\
\hline ALM-CAN & Direta, distribuída & Estrutura embutida, plana, agnóstica & Melhor esforço, fonte qualquer \\
\hline ALM-DT & Direta, híbrida & Estrutura embutida, plana, agnóstica & Melhor esforço, fonte qualquer \\
\hline Bayeux & Mediada, distribuída & Estrutura embutida, plana, consciente & Confiável, fonte específica \\
\hline NICE & Direta, distribuída & Estrutura embutida, hierárquica, consciente & Melhor esforço, fonte específica \\
\hline SCRIBE & Direta, distribuída & Estrutura embutida, plana, consciente & Melhor esforço, fonte qualquer \\
\hline SMCP & Mediada, híbrida & Malha-árvore, hierárquica, consciente & Melhor esforço, fonte específica \\
\hline
\end{tabular}

Tabela 2.1: Resumo da classificação das propostas de multidifusão sobreposta. 


\section{Proposta de Middleware para Redes Sobrepostas}

A proposta deste trabalho é a construção de um middleware para multidifusão em nível de aplicação, capaz de estender os serviços de entrega das redes de melhor esforço para atender à demanda das aplicações de mídias contínuas sobre redes de larga escala. Entretanto, os serviços de rede avançada que desejamos oferecer sobre as redes físicas podem ser implementados somente se os requisitos da aplicação forem levados em conta. Consequentemente, entendemos que esta é uma forte razão para implementarmos as facilidades de comunicação necessárias em um alto nível, deslocando assim tais funcionalidades da camada de transporte para uma camada de middleware.

\subsection{Middleware para Comunicação em Rede}

A necessidade de atendimento de requisitos de comunicação específicos de aplicação pode ser contornada através da implementação de novos serviços de comunicação em uma camada intermediária, entre a camada de transporte e a camada de aplicação. Esta abordagem resulta em um modelo de referência para comunicação ligeiramente adaptado, como mostra a Figura 3.1 (STEEN; TANENBAUM, 2007).

Em comparação com o modelo OSI, as camadas de sessão e apresentação foram substituídas por uma única camada de middleware que contém protocolos independentes de aplicação. Esses protocolos não pertencem às camadas mais baixas, como a camada de transporte ou rede. Na proposta deste trabalho, a camada de middleware cria uma abstração da rede física denominada rede sobreposta. Nesta rede, nós de serviço são ligados através de enlaces lógicos, que serão estabelecidos mais abaixo pela camada de transporte. 


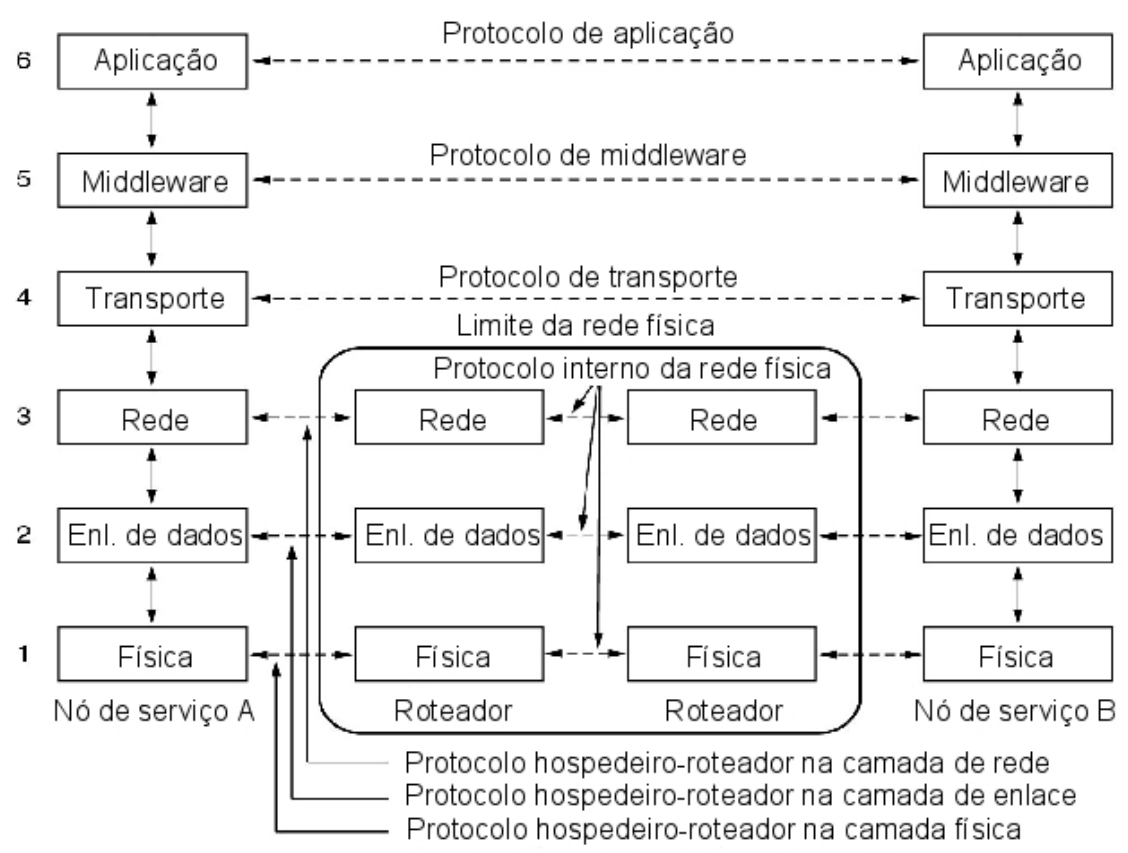

Figura 3.1: Modelo de referência adaptado para um middleware de comunicação em redes sobrepostas.

\subsection{Modelo de Rede Sobreposta}

A técnica de redes sobrepostas visa mediar a demanda por serviços de rede avançada das aplicações multimídia com a potencialidade atual das redes de suporte. Aplicações multimídia, por exemplo, demandam serviços de entrega com capacidades de comunicação em grupo ou multidifusão (JANNOTTI et al., 2000; ROCA; EL-SAYED, 2001; PENDARAKIS et al., 2001; ZHUANG et al., 2001; CHAWATHE, 2003; BANERJEE et al., 2006; LAO et al., 2007), qualidade de serviço (QoS) oferecida na entrega dos dados (SUBRAMANIAN et al., 2003, 2004; CASTRO et al., 2004; LI, 2005; LAO et al., 2006), segurança (KEROMYTIS et al., 2002), informações de contexto e políticas (AL-OQILY; KARMOUCH, 2007), enquanto que a maioria das redes de suporte em larga escala oferecem apenas o serviço de entrega de melhor esforço, o qual não oferece nenhuma garantia de entrega, ordenação e atraso.

Uma rede sobreposta pode ser construída através do uso de nós de serviço, isto é, sistemas finais, dedicados ou não (proxies ou máquinas dos clientes), estrategicamente distribuídos ao longo da rede. Estes hospedeiros se comunicam com os dispositivos de rede e entre si, conforme mostrado na Figura 3.1. Em cada nó de serviço, agentes de middleware são implantados, cada qual responsável por estender o serviço de meIhor esforço para um serviço avançado específico. Dessa forma, teremos agentes para multidifusão, agentes para QoS, e etc. Estes agentes compõem um núcleo de 


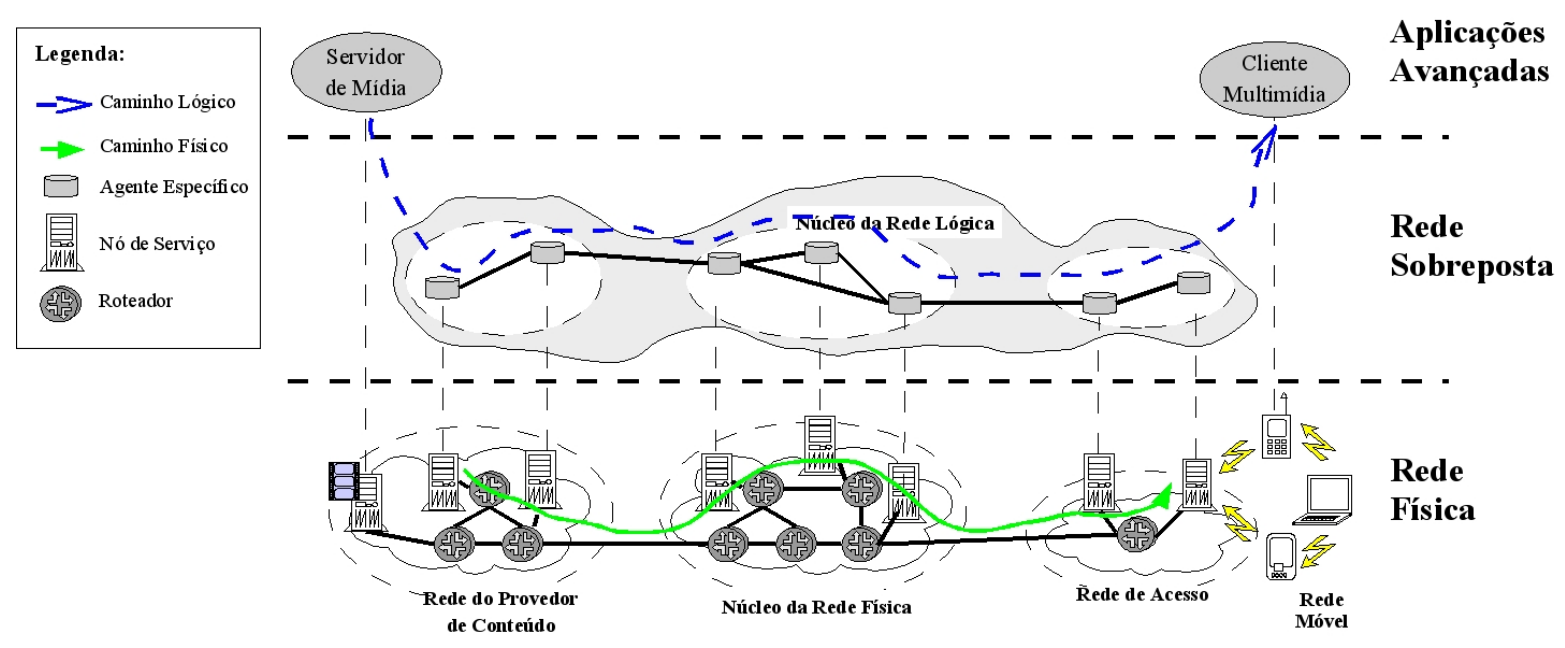

Figura 3.2: Rede sobreposta para extensão do serviço de melhor esforço para um serviço de rede avançada.

rede sobreposta, capaz de prover serviços avançados sobre os ambientes da Internet atual, os quais não oferecem tal suporte por parte de seus roteadores. Estas idéias estão ilustradas na Figura 3.2, cuja descrição vem a seguir.

A arquitetura da Figura 3.2 foi organizada em três camadas. A camada superior representa as aplicações demandantes por serviços de rede avançada. A camada inferior mostra as redes de suporte que compõem uma rede pública, com seus elementos de rede e as máquinas hospedeiras. Para preencher a lacuna entre o serviço de entrega desejado pelas aplicações e o serviço realmente oferecido pelas redes, propõe-se a inclusão de uma camada intermediária sobreposta à rede de suporte, capaz de estender o serviço de entrega de melhor esforço para atender os requisitos das aplicações avançadas. Consequentemente, de acordo com o modelo de comunicação adaptado proposto em (STEEN; TANENBAUM, 2007), propõe-se aqui um middleware para comunicação em redes sobrepostas.

Os serviços avançados são implementados em nível de aplicação através da cooperação entre componentes de software distribuídos em máquinas finais estrategicamente alocadas ao longo da rede - componentes do middleware. Dessa forma, a rede de suporte é denominada rede física, e estes componentes de software distribuídos que atuam na rede são denominados agentes de middleware. Tais agentes representam nós lógicos de serviço, e a comunicação entre os agentes é realizada através de protocolos de middleware, e abstraída sob a forma de enlaces lógicos estabelecidos através de protocolos da camada de transporte. Consequentemente, cria-se uma rede lógica que é sobreposta à rede física, conforme ilustrado na Figura 3.2. 


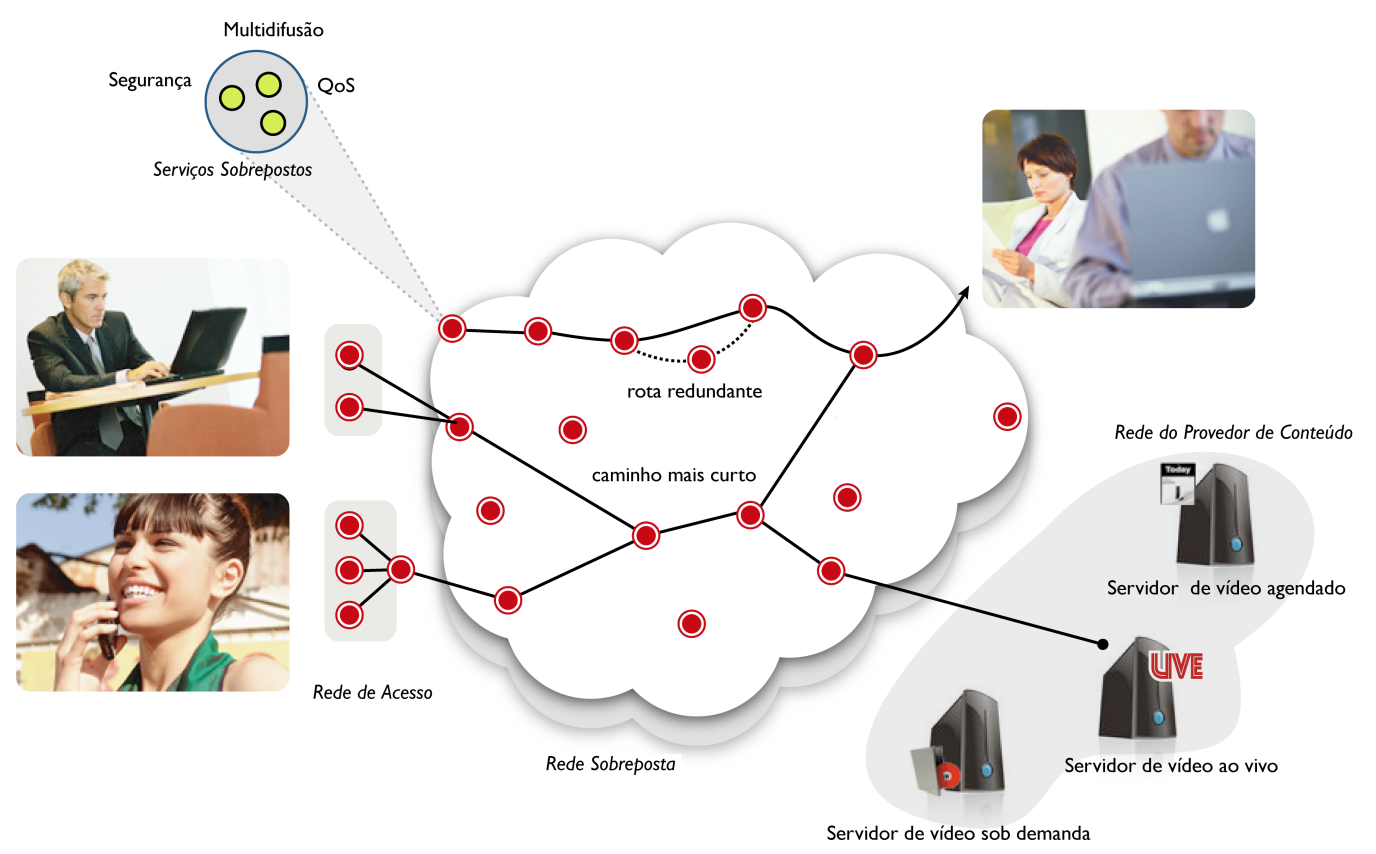

Figura 3.3: Rede de serviços sobrepostos para aplicações multimídia.

Para ganharem acesso a esta rede lógica, os sistemas terminais dos usuários formam aglomerados em torno de cada nó de serviço. Dessa forma, a topologia física da rede é abstraída na forma de um grafo lógico no qual Redes de Serviços Sobrepostos (SON - Service Overlay Network) constroem uma estrutura de entrega de dados. Através do uso desta infraestrutura intermediária é possível reduzir a complexidade de gerenciamento e a sobrecarga de controle, já que um número menor e fixo de nós deve ser gerenciado. A Figura 3.3 apresenta apenas o plano sobreposto, ilustrando os agentes de middleware que podem ser implantados em cada nó do núcleo da rede sobreposta. Note que cada agente implementa um serviço sobreposto específico.

\subsubsection{Vantagens e Desvantagens}

A utilização de uma camada intermediária para implantação de serviços avançados oferece uma alta escalabilidade e heterogeneidade, ainda que tal solução se mantenha simples e leve. A escalabilidade advém da ampliação de recursos, já que recursos avançados são deslocados dos roteadores para nós de serviço distribuídos, o que possibilita a criação de um maior número de grupos com um maior número de usuários recebendo serviços, e da implementação em nível de aplicação, o que resulta em uma maior integração e interoperabilidade entre sistemas autônomos, ampliando a abrangência dos serviços. A heterogeneidade da rede física é abstraída pela rede sobreposta, permitindo que usuários finais percebam o sistema de distribuição como 
um sistema único e coerente. A camada intermediária abstrai para as aplicações toda a complexidade do sistema.

Como desvantagens, podemos citar uma possível perda de desempenho quando comparado com soluções nativas na camada de rede, apesar deste ser um argumento discutível (FAHMY; KWON, 2007). Outra característica é sua natureza intrusiva, onde nós de serviço precisam ser implantados na rede. Porém, nas redes sobrepostas com interação direta este problema não acontece (ver Capítulo 2, Seção 2.4.1). Precisamos considerar também um grande aumento de complexidade no desenvolvimento das aplicações em redes sobrepostas. Como estas aplicações precisam construir estruturas de entrega de dados em nível de aplicação, elas precisarão implementar estratégias eficientes para o gerenciamento da entrega, o que aumenta sua dificuldade de desenvolvimento e manutenção. Este fato também pode ser evitado adotando-se uma organização e arquitetura para redes sobrepostas, o que é exatamente o que propomos a seguir.

\subsection{Arquitetura para Redes Sobrepostas}

Visando simplificar e padronizar o desenvolvimento de aplicações e serviços em redes sobrepostas, e ainda assim aumentando a eficiência e escalabilidade do sistema, nesta seção propomos uma organização e arquitetura para redes sobrepostas. Para isso, compartilhamos a mesma idéia de (NAKAO et al., 2003), e postulamos que uma arquitetura para redes sobrepostas deve aderir a dois princípios de alto nível:

1. Primeiro, ela precisa levar em consideração o custo, medido em termos de monitorações na rede física;

2. Segundo, ela precisa ser dividida em camadas de forma que SONs especializadas possam ser construídas a partir de um conjunto de primitivas básicas.

Tais princípios leva a um projeto de arquitetura onde as camadas mais baixas expõem em larga escala informações estáticas com baixo nível de detalhe, enquanto que as camadas mais altas realizam medições mais frequentes sobre um conjunto limitado de nós, produzindo informações dinâmicas. 
Consequentemente, aplicações avançadas, tais como vídeoconferência, vídeo sob demanda, vídeo ao vivo, vídeo agendado, Internet TV, jogos interativos, e etc., combinam serviços SON para compor um portfólio que inclui multidifusão, QoS e segurança, sem suporte nativo da camada de rede. Esta arquitetura foi denominada Scalable and Effective Architecture for OVERlay Networks (OVERSEA) ${ }^{1}$.

Portanto, neste trabalho reforçamos a necessidade de uma camada baixa sobreposta capaz de prover serviços básicos de sobreposição para uma camada mais alta de redes de serviços sobrepostos. Esta camada básica é denominada Serviços Sobrepostos Básicos (BOS - Basic Overlay Services ), e a camada superior é denominada Rede Sobreposta de Serviços (SON - Service Overlay Network). Acreditamos que esta é a melhor forma de se garantir eficácia e escalabilidade na provisão de serviços de Internet de valor agregado sobre redes de melhor esforço.

\subsubsection{OVERSEA: Uma Arquitetura Escalável e Eficaz para Redes Sobrepostas}

Como explicado na seção anterior, redes sobrepostas criam uma topologia virtual sobre o nível do protocolo básico de transporte, facilitando o gerenciamento das relações dos nós sobrepostos entre si, e com a rede implícita. As redes sobrepostas introduzem uma camada de rede semântica sobre o nível do protocolo básico de transporte que organiza a topologia da rede de acordo com o interesse de alguma entidade central ou dos próprios nós. Neste sentido, podemos organizar uma rede sobreposta conforme mostrado na Figura 3.4, cujas camadas são listadas a seguir.

- Rede: a camada de rede é a mais baixa da arquitetura, podendo representar uma rede IP de melhor esforço. É sobre esta camada que implantamos serviços de rede avançada em nível de aplicação. Pode-se aproveitar algum suporte de rede mais rico caso exista alguma região de rede que possua esta capacidade nativamente ("ilhas" de serviços avançados na Internet (MAMBRETTI; SCHMIDT, 1999)). O protocolo da camada de rede transporta unidades de dados do protocolo da camada de transporte.

- Transporte: acima da camada de rede, temos a camada de Transporte, representando um serviço básico de transmissão fim-a-fim. Aqui, podemos conside-

\footnotetext{
${ }^{1}$ Alguns termos daqui por diante serão definidos na língua inglesa para simplificar a escrita de artigos e a disseminação e possível adoção da arquitetura proposta.
} 


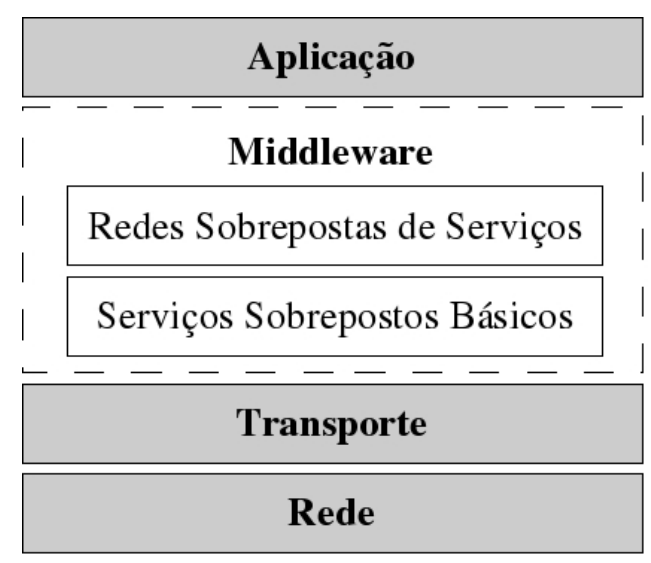

Figura 3.4: Proposta de arquitetura para redes sobrepostas.

rar a camada de transporte da pilha TCP/IP (SOCOLOFSKY; KALE, 1991), com a diferença de que o fluxo de dados não vem direto da aplicação, mas passa por uma camada intermediária cujo objetivo é melhorar o serviço de entrega de dados. Dessa forma, a camada de transporte oferece serviços tais como multiplexação das sessões, checagem de erros, e a possibilidade de transporte confiável (através da utilização do protocolo TCP (Transmission Control Protocol) (University of Southern California, 1981) ). O protocolo da camada de transporte transfere unidades de dados dos protocolos de middleware (ver Figura 3.1).

- Middleware: logo acima, na pilha de protocolos, temos a camada de Middleware. Esta é uma camada intermediária que provê serviços sobrepostos comuns às redes sobrepostas em geral, e serviços diferenciados para redes sobrepostas específicas. As redes de serviços sobrepostos se caracterizam como uma forma efetiva para se implantar serviços de rede avançada que não poderiam ser diretamente incorporados na camada de rede, tais como multidifusão (PENDARAKIS et al., 2001; LAO et al., 2007), QoS (SUBRAMANIAN et al., 2004), e segurança (KEROMYTIS et al., 2002), mesmo que a rede física não ofereça tal suporte nativamente. Apesar da arquitetura proposta prever a inclusão de outros serviços sobrepostos, esta dissertação foca apenas na multidifusão. Em (UCHôA; SILVEIRA, 2007), mostramos como seria o uso da arquitetura para os outros serviços.

- Aplicação: a camada mais alta do modelo representa a camada de Aplicação. As aplicações desenvolvidas nesta camada se beneficiam de toda esta infraestrutura para melhorar sua qualidade de transmissão das mídias contínuas. As aplicações enxergam um conjunto ampliado de serviços de rede, já que a camada de Middleware estende os serviços de entrega de dados oferecidos. Dessa forma, é possível que aplicações usufruam completamente de um serviço de multidifusão, desfrutando ainda de algum nível de QoS e segurança, ou ainda outros serviços 
avançados.

A seguir, ilustramos um cenário de utilização da arquitetura OVERSEA, para facilitar seu entendimento.

\subsubsection{Cenário de Utilização da Arquitetura OVERSEA}

Observe que o oferecimento de serviços avançados para a camada de aplicação, conforme discutido na seção anterior, possibilita a implementação de aplicações avançadas, tais como aplicações de vídeo agendado, vídeo ao vivo, e vídeo sob demanda, por exemplo. Este cenário é ilustrado na Figura 3.5. No exemplo, a camada de middleware estende o serviço de entrega da camada de rede criando uma nova configuração ou uma nova visão de rede, definindo novos elementos e novos relacionamentos.

Para tanto, a camada de middleware precisa se espalhar ao longo da rede, e isso é realizado através da implantação de agentes de middleware em máquinas hospedeiras, ou nós de serviço, distribuídos na rede. Estes agentes de middleware criam, portanto, múltiplos pontos de vantagem de rede. Perceba que a camada de middleware é uma aplicação distribuída implementada como uma rede ou um conjunto de redes sobrepostas. Os agentes de middleware se comunicam através de um protocolo de middleware com uma parte central denominada sistema de middleware, que implementa o núcleo da camada de middleware. O resultado da interação entre estes elementos é o surgimento de um novo serviço, como a multidifusão sobreposta, por exemplo.

Observe que aplicações de distribuição de mídia e de monitoração de rede podem estar integradas aos agentes de middleware nos nós de serviço, resultando em uma entrega específica para cada aplicação final. Além disso, a figura apresenta uma aplicação de publicação de conteúdos, mais em destaque, e aplicações de consumo de mídia nas máquinas dos usuários. Todas estas aplicações interagem com a camada de middleware para distribuir informações de metadados, conteúdos de vídeo e dados de monitoração, obtendo do middleware os serviços sobrepostos.

Para compreendermos como é possível estender os serviços de entrega de dados da camada de rede, a seguir discutiremos em detalhes a camada de middleware, descrevendo sua composição e os serviços oferecidos para a camada de aplicação. Conforme já explicitado anteriormente, a descrição a seguir tem como foco apenas 


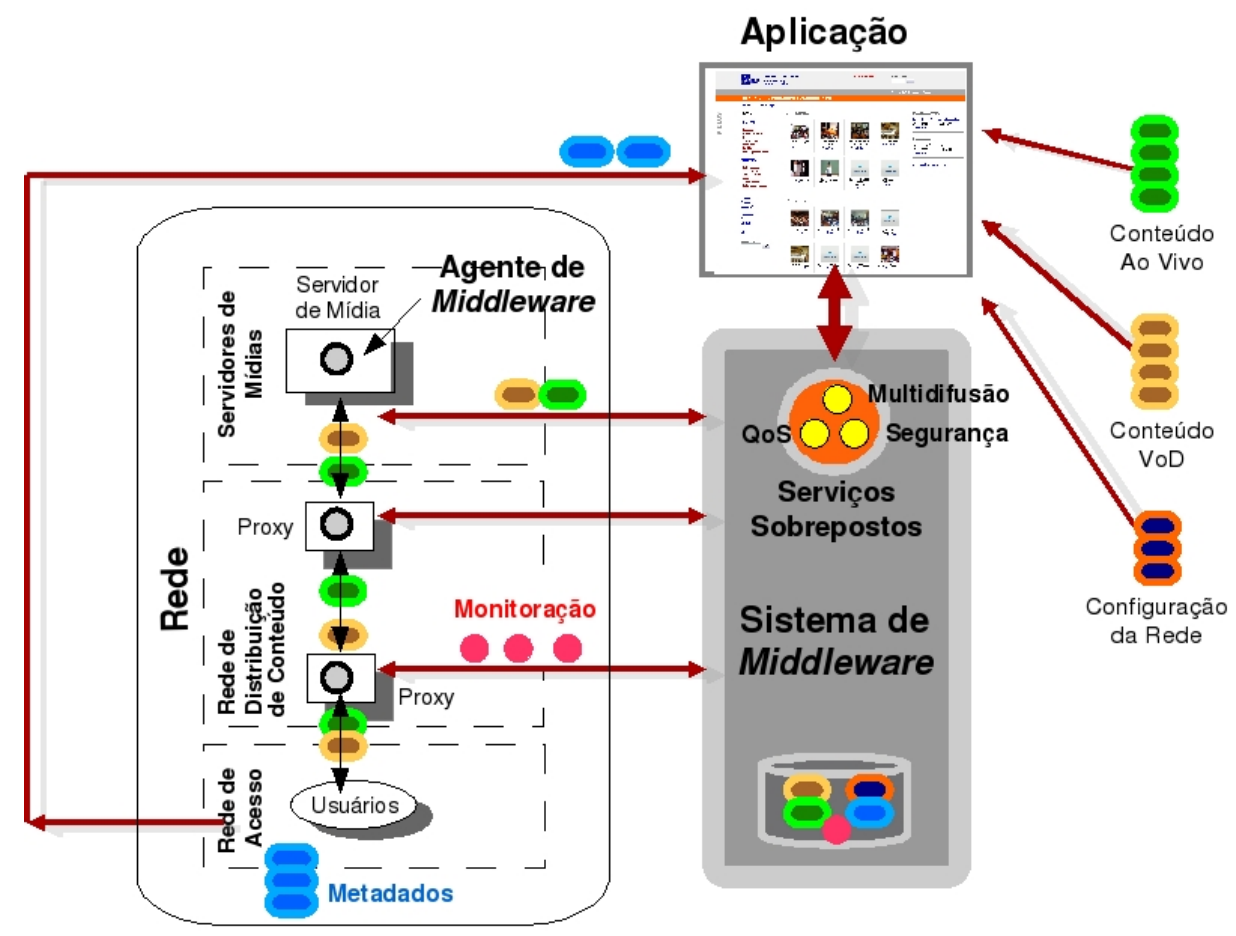

Figura 3.5: Exemplo de implementação de serviços sobrepostos pelo sistema de middleware.

um serviço de multidifusão sobreposta.

\subsection{Camada de Middleware}

Nesta seção discutiremos a organização interna da camada de middleware, a qual é dividida em duas subcamadas:

- Serviços Sobrepostos Básicos (BOS);

- Rede Sobreposta de Serviços (SON).

\subsubsection{Serviços Sobrepostos Básicos (BOS)}

A camada de Serviços Sobrepostos Básicos, ou camada BOS (Basic Overlay Services), é a subcamada de mais baixo nível da camada de middleware. A idéia é 
prover serviços sobrepostos comuns à redes sobrepostas, evitando que desenvolvedores reimplementem tais serviços de maneira ad-hoc. A camada BOS define componentes sobrepostos independentemente do domínio do serviço que será oferecido pela rede sobreposta. A seguir, listaremos os serviços presentes nesta camada.

\section{Serviço de Comunicação}

Os componentes da camada BOS oferecem uma infraestrutura de programação distribuída, focando na alocação, agendamento e coordenação dos diversos recursos fim-a-fim envolvidos nas aplicações distribuídas. Dessa forma, desenvolvedores de serviços em redes sobrepostas podem se concentrar na lógica do seu serviço, evitando o uso direto de características de baixo nível do middleware para construir códigos de comunicação para componentes distribuídos.

Dentre os serviços de comunicação oferecidos na camada BOS, podemos citar o endereçamento dos nós sobrepostos, comunicação orientada a mensagens e comunicação orientada a fluxos, e primitivas básicas para o redirecionamento e adaptação de fluxos de dados.

\section{Serviço de Topologia}

Como já evidenciado em (NAKAO et al., 2003; UCHôA; SILVEIRA, 2007), manter um bom nível de congruência entre a topologia física e a topologia sobreposta é de fato um desafio, e também o fator-chave para um bom desempenho da rede sobreposta (FAHMY; KWON, 2007; LAO et al., 2005). Assim, redes sobrepostas com frequência monitoram a rede física, em um esforço para aprender algo sobre a topologia da rede implícita, permitindo a construção de topologias sobrepostas mais eficientes.

Neste sentido, a idéia da camada BOS é evitar que cada rede sobreposta seja construída de forma independente, e mais ainda, evitar que elas monitorem de forma descontrolada os elementos da rede física, o que resultaria em altas sobrecargas na rede. Dessa forma, a camada BOS coleta e reúne informações sobre a topologia da rede física, e cuida de criar topologias sobrepostas eficientes. As camadas superiores consultam a camada BOS ao tomarem decisões de roteamento específico para aplicação. 
Dentre os serviços de topologia oferecidos na camada BOS, podemos citar a localização de nós sobrepostos, o encontro de vizinhos "mais próximos" a um nó, encontro dos caminhos disjuntos entre dois nós, e construção de uma estrutura sobreposta para roteamento. Com base nestes serviços, a camada SON constrói uma estrutura de entrega específica para a aplicação usuária.

\section{Serviço de Monitoração}

Para oferecer informações de topologia de maneira consistente para as camadas superiores, a camada BOS precisa implementar e especializar serviços básicos de monitoração. Neste sentido, a camada BOS oferece três níveis de monitoração: monitoração de rede, monitoração de sistema, e monitoração dos agentes de middleware.

Na monitoração de rede, o objetivo é acompanhar métricas relacionadas aos enlaces da rede física, tais como status operacional (up/down), utilização de banda, atraso, perda e jitter, por exemplo. A monitoração de sistema é baseada na monitoração SNMP (CASE et al., 1990), e o objetivo é acompanhar métricas relacionadas aos nós de serviço, tais como tempo em serviço, utilização de CPU e memória, vazão e taxa de erro nas interfaces de rede, por exemplo. Já na monitoração dos agentes de middleware, as informações básicas podem ser de status operacional (up/down), número de conexões, fluxo agregado de entrada, fluxo agregado de saída, e etc.

Note que as informações de monitoração em cada nível podem ser combinadas, produzindo informações de altíssimo valor. Dessa forma, as redes de serviços sobrepostos na camada SON podem agendar testes nos caminhos de sua estrutura de entrega, verificando antecipadamente informações como atraso unidirecional, atraso bidirecional, perda e jitter, podendo alterar ou não as rotas em função dos resultados, visando um melhor atendimento para a aplicação usuária.

\section{Serviços de Utilidade}

Além dos serviços de comunicação, topologia e monitoração já citados, a camada BOS ainda oferece um conjunto de serviços básicos que agrupamos aqui como serviços de utilidade. Dentre estes serviços, podemos citar configuração dos nós, notificação de eventos, persistência de informações, e registros, por exemplo. 
É importante frisar que não temos a pretensão de definir aqui todos os possíveis serviços da camada BOS, tornando-a capaz de suportar qualquer rede sobreposta. Vários outros serviços de camada BOS podem e devem ser incluídos, e suas necessidades surgirão da implementação de vários serviços sobrepostos na camada SON.

\subsubsection{Rede Sobreposta de Serviços (SON)}

Na camada de Rede Sobreposta de Serviços, ou camada SON, implementamos um serviço de domínio específico, como um serviço de multidifusão, por exemplo. Dessa forma, o roteamento dos dados será realizado de forma apropriada para uma aplicação ou conjunto de aplicações. Pode-se testar se, a priori, uma determinada rota será capaz de atender certos requisitos de aplicação previamente definidos, por exemplo, e em caso negativo, pode-se definir estratégias de tomada de decisão na tentativa de melhoria ou superação dos problemas encontrados. Para implementar estes serviços específicos, a camada SON se utiliza do conjunto básico de serviços sobrepostos disponibilizados pela camada BOS.

Basicamente, todas as redes sobrepostas precisarão tomar decisões de roteamento, e por isso a camada BOS oferece primitivas e serviços básicos para este roteamento em nível de aplicação. No entanto, os critérios de roteamento dependerão do foco do serviço sobreposto oferecido, e das classes de aplicação que ele pretende servir. Dessa forma, cada serviço de camada SON precisará especializar seu roteamento de forma satisfatória. Portanto, não poderemos listar os serviços realizados pela camada SON sem antes definir qual serviço sobreposto será oferecido.

No geral, podemos dizer que os serviços da camada SON incluem localização de nós sobrepostos que executam ou implementam o serviço sobreposto desejado, seleção de nós que satisfaçam requisitos de aplicação previamente definidos, construção de estruturas de entrega ajustadas ou otimizadas para certos parâmetros, e repasse especializado de dados de aplicação sobre caminhos virtuais que atravessem redes sobrepostas. 


\section{Camada SON para um Serviço de Multidifusão Sobreposta}

Como o foco deste trabalho é a construção de um middleware para multidifusão em redes sobrepostas, nesta seção apresentaremos os detalhes dos serviços da camada SON específicos para esta finalidade. Dessa forma, para prover uma entrega de conteúdo de forma prática, eficiente e escalável, para múltiplos usuários simultâneos sobre redes de melhor esforço, propomos uma infraestrutura de Rede Sobreposta de Serviço de Multidifusão (MSON - Multicast Service Overlay Network), construída na camada SON da arquitetura OVERSEA.

Esta infraestrutura implementa características para multidifusão em nível de aplicação, estendendo o serviço de entrega de melhor esforço sem modificações na infraestrutura de rede. Dessa forma, criamos um núcleo de domínio de serviço de multidifusão na camada SON, capaz de inicializar e controlar as sessões de multidifusão, gerenciar os membros de grupo, construir estruturas de entrega e repassar os dados de aplicação nesta estrutura. Classificamos todas essas funções básicas como gerência de multidifusão.

No entanto, além de oferecer os mesmos serviços oferecidos pelas estratégias de multidifusão nativa em rede (ver Capítulo 2 , Seção 2.3), queremos demonstrar que uma infraestrutura de multidifusão sobreposta bem definida é capaz de superar um dos problemas mais críticos da multidifusão IP. Dessa forma, vamos também considerar aqui a questão da multidifusão interdomínio. A seguir, descrevemos a arquitetura da nossa rede MSON com foco nos serviços que ela oferece.

\section{Multidifusão Interdomínio}

A infraestrutura para multidifusão aqui proposta é capaz de interconectar MSONs com diferentes autoridades administrativas, provendo assim um serviço de multidifusão interdomínio sem modificação da infraestrutura de rede dos Sistemas Autônomos (ASs) envolvidos. Um AS consiste em um grupo de roteadores submetidos a um mesmo controle administrativo, ou seja, operados pela mesma organização.

O problema de multidifusão interdomínio é tratado através da extensão deste conceito tradicional para a criação de um novo conceito: o de Sistemas Autônomos Sobrepostos (OASs - Overlay Autonomous Systems). Dessa forma, ao invés de considerarmos 
os limites da rede física, usamos limiares lógicos de rede no nível sobreposto. Portanto, podemos construir um ou mais OASs sobre um ou mais ASs reais.

Neste modelo, consideramos uma organização hierárquica da estrutura dos OASs em vários níveis, de forma similar ao protocolo BGP (BATES et al., 2007). Dessa forma, OASs podem ser classificados como stub, transit ou multi-homed. Um OAS stub é um domínio virtual conectado apenas a um outro OAS. Um OAS transit é um OAS com conexões para mais de um OAS, e que permite sua utilização na condução do tráfego de trânsito entre dois OASs. Similar ao OAS transit, o OAS multi-homed também possui conexões com mais de um OAS; entretanto, ele não permite que tráfego de trânsito passe por ele. Note que com este conceito de OASs questões de políticas estão envolvidas, e um gerenciamento de roteamento baseado em políticas torna-se necessário.

\section{Gerência de Multidifusão}

A arquitetura da rede MSON em camadas apresenta algumas vantagens (LAO et al., 2007):

1. Primeiro, a organização da arquitetura OVERSEA permite que um provedor de MSON suporte uma variedade de aplicações de comunicação em grupo simultaneamente, compartilhando informações comuns de topologia e evitando monitoração redundante na rede.

2. Segundo, a desassociação dos provedores de serviços sobrepostos e provedores de serviços de rede permite construir um modelo de negócio bem definido, viabilizando serviços de multidifusão interdomínio em redes como a Internet. Além disso, tal desassociação faz com que os provedores de serviços sobrepostos concentrem seus esforços no planejamento e gerenciamento de suas redes sobrepostas.

3. Em terceiro lugar, a noção de MSON simplifica significativamente o gerenciamento das redes físicas. Provedores de serviços de rede precisam apenas prover serviços a um número limitado de provedores de MSON, ao invés de tratar de milhões ou bilhões de usuários finais individualmente.

4. Finalmente, nossa abordagem adota uma entrega por unidifusão para a transmissão dos dados dentro dos agrupamentos, fora da MSON. A escolha pelo uso 
de unidifusão nos agentes de borda é motivada pelo requisito de evitar que usuários finais tenham que baixar e instalar softwares clientes em suas máquinas para acesso aos serviços do sistema.

Entretanto, para usufruir de todas estas vantagens, um serviço de multidifusão sobreposta precisa superar vários desafios. Em particular, o gerenciamento e provisão eficientes da MSON são as questões mais críticas. Como espera-se que uma MSON acomode um grande número de grupos de multidifusão, torna-se crítico para um provedor de MSON estabelecer e gerenciar eficientemente as árvores de multidifusão. Além disso, diante das características de tráfego do usuário, o provedor de MSON deve prover cuidadosamente a rede sobreposta visando a redução dos custos de operação e a melhoria da qualidade do serviço (LAO et al., 2007).

Para tratar do problema de um gerenciamento eficiente, no próximo capítulo propomos um protocolo de controle para multidifusão sobreposta denominado SMCP (sigla para o termo em inglês Simple Multicast Control Protocol). Este é um protocolo de middleware que coordena os agentes de middleware distribuídos, trocando informações de controle necessárias à construção de estruturas de entrega sobre a rede implícita, fazendo assim a gerência de todas as operações de multidifusão sobreposta.

\section{Serviços de Alto Nível}

Além dos serviços de gerência de multidifusão e multidifusão interdomínio, a implementação do roteamento de dados em nível de aplicação abre possibilidade para um grande leque de novos serviços de entrega. Podemos citar o armazenamento de cópias temporárias dos conteúdos nos nós de serviço, ou seja, otimizações de caching, o que pode aumentar bastante a eficiência do sistema. Também é possível suportar negociação de parâmetros sessão e localização de serviços para aplicações multimídia, como gateways que realizam adaptação de fluxo para redes de baixa largura de banda e dispositivos com diferentes resoluções de tela. 


\subsection{Implantação do Sistema de Middleware}

Para que o sistema de middleware aqui proposto seja implantando, componentes de middleware que implementem os serviços descritos anteriormente precisam ser definidos. A implantação desse sistema foi realizada como atividade do Grupo de Trabalho em Redes de Serviços Sobrepostos (GT-Overlay) da Rede Nacional de Ensino e Pesquisa (RNP), dando origem ao serviço de multidifusão atualmente em produção em dois importantes sistemas multimídia: o Vídeo@RNP e o IPTV USP Experimen$\mathrm{tal}^{2}$.

A instância de middleware criada visa prover dois objetivos principais: (i) gerência dos usuários e dos conteúdos de mídia; e (ii) gerência da distribuição dos conteúdos. Dessa forma, os seguintes aspectos de gerência são contemplados: (1) armazenamento de conteúdo, recuperação e busca; (2) autenticação do usuário e controle de acesso; (3) configuração, monitoramento e controle dos componentes do serviço de rede e dos nós de serviço; (4) configuração, monitoramento e controle dos serviços de distribuição de mídia e das sessões de multidifusão.

Como os componentes desenvolvidos tratam questões que vão além da multidifusão, sua descrição foge do escopo desta dissertação. No próximo capítulo, apresentaremos apenas os componentes relacionados com a multidifusão. A operação do sistema de multidifusão é definida pelo protocolo de middleware SMCP proposto a seguir. Maiores detalhes sobre a implantação completa do sistema podem ser obtidos em (UCHôA et al., 2007), (UCHôA; SILVEIRA, 2007), (UCHôA et al., 2008) e (UCHôA et al., 2009).

\footnotetext{
${ }^{2}$ Estes sistemas estão acessíveis em http://www.video.rnp.br/ e http://iptv.usp.br/, respectivamente.
} 


\section{Protocolo de Middleware para Controle da Multidifusão Sobreposta}

Organizamos as funcionalidades das redes sobrepostas em uma camada de middleware situada entre a camada de transporte e a camada de aplicação. A arquitetura do nosso middleware prevê uma camada básica de serviços gerais para redes sobrepostas, e uma camada para serviços sobrepostos específicos. Dentro dos serviços específicos, este trabalho foca em um serviço de multidifusão, e a idéia é prover uma solução de alta escalabilidade, porém mantendo-se simples e leve. Para isso, um gerenciamento eficiente da Rede Sobreposta de Serviço de Multidifusão (MSON) é imprescindível. Entretanto, não existe ainda nenhum protocolo padrão para prover e gerenciar essa multidifusão sobreposta. Portanto, neste capítulo propomos um protocolo de middleware capaz de coordenar seus componentes na construção de uma MSON.

\subsection{Visão Geral}

Esta seção introduz os conceitos do protocolo de middleware aqui proposto, onde descreveremos de forma geral seu escopo, suas funcionalidades, e sua descrição. $O$ restante do capítulo segue com as definições e entidades do protocolo, o modelo de interação entre estas entidades, a estrutura das mensagens, e, por fim, os cenários de operação considerados.

A necessidade de desenvolvimento deste protocolo se justifica pela carência de um protocolo padronizado para controle da multidifusão em redes sobrepostas. A única iniciativa existente foi realizada pela ITU através da recomendação ITU-T X.603 (International Telecommunication Union (ITU) - International Organization for Standardization (ISO/IEC), 2004), a qual define um arcabouço para construção de protocolos 
de controle para tais redes. Dessa forma, nosso protocolo de middleware foi desenvolvido em acordo com a norma ITU-T X.603, e respeitando a arquitetura OVERSEA (ver Capítulo 3).

\subsubsection{Escopo}

O Simple Multicast Control Protocol (SMCP) é um protocolo de controle em nível de aplicação para a provisão e gerenciamento da multidifusão sobreposta um-paramuitos, tanto intra como interdomínio. Além de seguir a recomendação ITU-T X.603, a estrutura do SMCP é também inspirada nos protocolos ditos de nova geração, tais como o Real-time Transport Protocol (RTP) (SCHULZRINNE et al., 2003) e o Session Initiation Protocol (SIP) (ROSENBERG et al., 2002). Até onde sabemos, o SMCP é a única proposta de protocolo de controle sobreposto para provisão eficiente de multidifusão na Internet que segue uma padronização internacional.

O SMCP é capaz de estabelecer, manter, modificar, finalizar e monitorar sessões de multidifusão sobreposta. Ele também pode adicionar participantes à sessões já existentes, como sessões de multidifusão de vídeo ao vivo ou de TV sobre IP. Mídias também pode ser adicionadas ou removidas de sessões já estabelecidas. O SMCP suporta de forma transparente o mapeamento de nomes e serviços de redirecionamento, provendo mobilidade pessoal, assim como ocorre no SIP. Dessa forma, usuários podem manter um único identificador externamente visível independente da localização de rede.

\subsubsection{Funcionalidades}

Através do SMCP, nosso middleware é capaz de suportar cinco possibilidades no estabelecimento e finalização da comunicação de multidifusão sobreposta:

- Localização do usuário: determinação do agente de middleware mais próximo do usuário, a partir do qual este receberá o encaminhamento dos dados de aplicação por multidifusão. Isto possibilita um melhor redirecionamento dos dados e a possibilidade de adaptação personalizada dos fluxos multimídia, resultando em uma melhor qualidade de serviço vista pelo usuário. 
- Disponibilidade de agentes: determinação do status de atividade dos agentes de middleware como forma de avaliação de seu engajamento no redirecionamento dos dados. Esta característica resulta em uma maior robustez no serviço de entrega, além de possibilitar um melhor atendimento através da escolha de agentes com maior potencialidade de atendimento em um determinado instante.

- Capacidade dos usuários: determinação do contexto do usuário, tal como capacidade do seu terminal e de sua conexão de acesso, da mídia e de seus parâmetros, o que permite uma negociação de parâmetros de sessão, aumentando a probabilidade de sucesso e a qualidade das sessões estabelecidas.

- Estabelecimento de sessão: construção de estruturas sobrepostas de entrega, estabelecimento de parâmetros de controle de sessão e requisitos de QoS. Tais serviços são essenciais para o controle da entrega de dados, garantindo um entrega eficiente e eficaz.

- Gerência de sessão: inclui transferência e finalização de sessões, modificação de parâmetros de sessão, manutenção da relação de membros, monitoração das sessões ativas, e invocação de serviços. Tais características são cruciais para a escalabilidade e eficiência da solução adotada.

É importante ressaltar que o protocolo SMCP oferece as primitivas básicas para a implementação destes serviços, mas o completo funcionamento depende da implementação do middleware, o qual precisará também lançar mão de outros protocolos para isso. A construção e manutenção da topologia, por exemplo, é um fator crítico para o desempenho do serviço de multidifusão, mas não é definido aqui no SMCP. Algum outro protocolo de descoberta de topologia da camada BOS deve alimentar a base de dados que será consultada no momento da construção da estrutura de entrega.

Portanto, o SMCP não pretende ser um sistema de comunicação verticalmente integrado. Ao invés disto, ele pode ser utilizado em conjunto com os padrões MPEG7 (Internationl Organization for Standardization ISO/IEC, 2002), MPEG-21 (ISO/IEC, 2004), os protocolos SIP (ROSENBERG et al., 2002), Session Description Protocol (SDP) (HANDLEY et al., 2006), Service Location Protocol (SLP) (GUTTMAN et al., 1999), e protocolos adotados pelo Internet Streaming Media Alliance (ISMA) (FUCHS; FÄRBER, 2005), para a construção de um ambiente multimídia completo, onde a entrega, monitoração e controle de conteúdos multimídia se torna viável. 


\subsubsection{Descrição}

O SMCP define agentes de multidifusão ${ }^{1}$, denominados Multicast Agents (MAs), nos nós de serviço ${ }^{2}$ para suportar características relacionadas à multidifusão, mesmo quando a camada de rede não oferece tal suporte.

De fato, um núcleo sobreposto é alcançado através da distribuição estratégica dos MAs ao longo da rede, para garantir que dados de multidifusão possam transpor mesmo regiões de rede que contemplem apenas uma entrega por unidifusão. Dessa forma, dados de aplicação podem ser transmitidos simultaneamente para vários usuários, partindo da fonte até os receptores.

Além dos MAs, a recomendação ITU-T X.603 (International Telecommunication Union (ITU) - International Organization for Standardization (ISO/IEC), 2004) define uma entidade central capaz de gerenciar todas as operações do protocolo, incluindo o estabelecimento e monitoração de sessões. Tal entidade é denominada Session Manager, e atua como um gerente de sessões.

O Session Manager atua como uma espécie de Rendezvous Point (RP), ou seja, uma entidade que faz com que os MAs se encontrem, se descubram, para juntos criarem o caminho de entrega. Dessa forma, o Session Manager é encarregado de coordenar os MAs para garantir que dados da aplicação possam entrar no núcleo sobreposto de uma Rede Sobreposta de Serviço de Multidifusão (MSON - Multicast Service Overlay Network) a partir de um nó de serviço de ingresso, e encontrar seus respectivos nós de serviço de egresso, ao longo dos quais os sistemas finais dos clientes formam aglomerados para recebimento dos fluxos que deixam o núcleo sobreposto, fora do MSON.

Para representar os dispositivos dos usuários, o SMCP define User Agents, que solicitam conteúdos de vídeo e apresentam à seus usuários. Para receber os pedidos dos User Agents, uma entidade chamada Publishing Manager precisa anunciar as sessões de multidifusão. Já no lado do servidor de mídia, o SMCP também define uma entidade para controlar a fonte, chamada Source Agent. Estas três últimas entidades citadas não são definidas pela recomendação ITU-T X.603.

\footnotetext{
${ }^{1}$ Os agentes de multidifusão são agentes de middleware especializados para uma entrega de dados por comunicação em grupo.

${ }^{2}$ Os nós de serviço podem ser servidores representantes ou proxies, ou ainda sistemas terminais de usuário.
} 


\subsection{Definições e Entidades}

A seguir, discutimos detalhadamente as definições e entidades envolvidos no SMCP.

\subsubsection{Definições}

Listamos abaixo um conjunto de definições necessárias ao entendimento do protocolo SMCP.

Rede física rede real construída através da interconexão de equipamentos de rede, como switches e roteadores. Tradicionalmente, rede IP de melhor esforço.

Rede Sobreposta de Serviços (SON) rede virtual construída em nível de aplicação sobre uma rede física, com o intuito de incorporar serviços de rede avançada na rede real, sem modificações na sua infraestrutura. Neste caso, é dito que a rede física fica implícita à rede SON. Algumas vezes referimo-nos a uma rede SON apenas como rede sobreposta.

Nós de serviço nós de serviço são servidores representantes (proxies) estrategicamente implantados ao longo da rede física para atuarem como sistema de suporte para redes SON. Alternativamente, sistemas terminais de usuário também podem ser utilizados. São as máquinas que hospedam os nós das redes sobrepostas.

Nó sobreposto é a abstração que representa um nó de serviço em uma rede sobreposta.

Enlace sobreposto representa uma relação de ligação (comunicação direta em nível sobreposto) entre dois nós sobrepostos. A realização desta comunicação dá-se em nível de transporte, podendo o enlace sobreposto ser implementado através de uma conexão TCP ou datagramas UDP. 
Núcleo sobreposto núcleo da rede sobreposta formado através da conexão dos nós sobrepostos através de enlaces sobrepostos. É a parte de maior tráfego da rede, interligando as regiões periféricas, podendo ser considerada a espinha dorsal da rede sobreposta.

Fonte primária de mídia servidor de armazenamento que contém a versão original da mídia, a qual será transmitida através de uma sessão de multidifusão.

Receptores de mídia cliente de mídia hospedado no sistema final do usuário, que solicita, recupera, e exibe as mídias para os usuários que participam de uma sessão de multidifusão.

Agentes de multidifusão agentes de software que atuam nos nós sobrepostos realizando operações de roteamento, repasse de dados, e controle da multidifusão entre nós sobrepostos. Tais agentes são, portanto, responsáveis pelo repasse dos dados de aplicação da fonte primária de mídia até os receptores de mídia, atravessando regiões de rede de unidifusão ou multidifusão nativa.

Serviços de distribuição de mídia são entidades responsáveis pelo transporte dos dados para aplicações multimídia. São proxies ou brokers que atuam nos nós de serviço ora em nome da fonte de mídia, ora em nome dos receptores de mídia, aplicando estratégias eficientes no repasse dos dados multimídia. Enquanto os agentes de multidifusão são responsáveis tanto pelos canais de controle como pelos canais de dados em alto nível, os serviços de distribuição de mídia implementam um conjunto básico de serviços de transporte, como o suporte comum à transmissões para aplicações de vídeo sob demanda, vídeo ao vivo, e vídeo agendado, por exemplo.

Sessão de multidifusão relação de membros de uma comunicação em grupo para transmissão de fluxos por multidifusão, ou seja, para vários usuários simultaneamente. A sessão de multidifusão é composta pela fonte primária de mídia, pelos agentes de multidifusão que repassam estes dados ao longo da rede, e pelos receptores de mídia, todos envolvidos na mesma transmissão. 
Nó de redirecionamento nó sobreposto participando ativamente de uma sessão de multidifusão.

Malha sobreposta grafo conectado cujos vértices são nós sobrepostos que possuem agentes de multidifusão capazes de atender a uma sessão de multidifusão, e cujos arcos são enlaces sobrepostos que interligam estes nós.

Árvore de escoamento sobreposta estrutura hierárquica de entrega interligando nós de redirecionamento através de enlaces sobrepostos, com a finalidade de escoamento dos dados de aplicação em uma sessão de multidifusão através do núcleo da rede sobreposta.

Caminho de redirecionamento caminho na árvore de escoamento sobreposta que interliga através de enlaces sobrepostos um conjunto de nós de redirecionamento envolvidos em uma sessão de multidifusão.

Fluxo de descida sentido do caminho de redirecionamento que vai da fonte primária de mídia até o receptor de mídia.

Fluxo de subida sentido do caminho de redirecionamento que vai do receptor de mídia até a fonte primária de mídia.

Representante é o agente de multidifusão mais próximo do receptor de mídia, sendo um agente de borda do núcleo da rede sobreposta.

Salto do usuário é o último passo no caminho de redirecionamento, ligando o usuário a seu representante. 
Aglomerado conjunto de receptores de mídia que mantém uma relação direta com seu representante, ou seja, que estabelecem um enlace sobreposto com o mesmo representante. Normalmente, um representante atende vários receptores de mídia simultaneamente, em uma mesma sessão ou em sessões diferentes. Chamamos de aglomerado esta associação entre um conjunto de receptores de mídia e seu representante.

Região de cobertura área de rede sobreposta gerenciada por uma entidade especial de controle.

Sistema autônomo real definição tradicional de sistemas autônomos, como um grupo de roteadores submetidos a um mesmo controle administrativo.

Sistema autônomo sobreposto (OAS) compreende um grupo de nós de serviço submetidos a um mesmo controle administrativo, ou seja, operados pela mesma organização. Dessa forma, ao invés de considerarmos os limites da rede física de um sistema autônomo real, usamos limiares lógicos de rede no nível sobreposto.

OAS stub um OAS stub é um domínio virtual conectado apenas a um outro OAS.

OAS transit um OAS transit é um OAS com conexões para mais de um OAS, e que permite sua utilização na condução do tráfego de trânsito entre dois OASs.

OAS multi-homed similar ao OAS transit, o OAS multi-homed também possui conexões com mais de um OAS; entretanto, ele não permite que tráfego de trânsito passe por ele. 


\subsubsection{Entidades}

Após formalizarmos os vários conceitos envolvidos no SMCP, podemos definir as entidades envolvidas neste protocolo. Tais entidades são listadas e explicadas como segue.

User Agents (UAs) são abstrações dos clientes em software para realização das requisições por serviço, implantados nos sistemas finais dos usuários em qualquer lugar da Internet. User Agents utilizam o SMCP para localizar o agente de multidifusão "mais próximo", através do qual receberá fluxos de dados e negociará parâmetros de sessão. Alternativamente, podem também ser hospedados em servidores Web, sendo acessados remotamente, evitando a necessidade de instalação de software cliente nos sistemas finais dos usuários.

Source Agents (SAs) são abstrações em software de fontes geradoras de fluxo multimídia, e são implantados nos servidores de mídia em qualquer lugar da Internet. As fontes primárias de mídia possuem os conteúdos originais das mídias, e geram os fluxos para os Multicast Agents (MAs), quando autorizadas pelo Publishing Manager. Dessa forma, os SAs são utilizados para oferecer suporte SMCP para as fontes de mídia, provendo gerenciamento nestes servidores. Note que para melhorar a eficiência da distribuição, podemos ter diversos SAs distribuídos ao longo da rede, cada um gerenciando um conjunto de cópias primárias dos conteúdos multimídia. Além disso, os MAs podem também aplicar otimizações de caching ao longo do caminho de entrega.

Multicast Agents (MAs) são entidades lógicas implantadas ao longo da Internet atuando como nós de multidifusão do núcleo sobreposto. Tais agentes desempenham funções de roteamento e multidifusão em nível de aplicação. Estes nós de multidifusão são responsáveis pelo repasse dos dados de aplicação a partir do Source Agent (SA) para os User Agents (UAs). Dessa forma, dados de aplicação trafegam tanto através de regiões de rede de unidifusão quanto de regiões com multidifusão nativa, para prover um serviço de comunicação de grupo abrangente e eficiente.

Os MAs podem desempenhar vários papéis, e de acordo com sua situação corrente 
eles podem ser classificados como:

- User Multicast Agent (UMA): é o representante do usuário. UAs se aglomeram em torno de um UMA para ganharem acesso ao serviço.

- Source Multicast Agent (SMA): é um agente de multidifusão anexado ao um Source Agent. Recebe o fluxo de dados diretamente da fonte primária.

- Gateway Multicast Agent (GMA): é um agente de borda em um sistema autônomo sobreposto (OAS), responsável por suportar as funcionalidades associadas à interconexão de domínios virtuais distintos. Em conjunto com outros GMAs e outros Session Manager, garante uma multidifusão sobreposta interdomínio.

- Relay Multicast Agent (RMA): é um agente de multidifusão envolvido em uma transmissão. SMAs, GMAs e/ou UMAs que participam de uma sessão são também RMAs para esta sessão.

Session Manager é uma entidade especial encarregada de prover e gerenciar características relacionadas à multidifusão em nível de aplicação. Ele é responsável pela inicialização e finalização das sessões, pelo gerenciamento da relação de grupos, e monitoração de status das sessões. O Session Manager coordena a configuração da hierarquia da árvore de escoamento sobreposta, elegendo os melhores MAs que devem redirecionar dados em cada sessão de multidifusão. Para isso, ele pode utilizar uma base de dados alimentada com medições realizadas na rede física, melhorando a eficiência da entrega.

Publishing Manager é uma entidade SMCP especial que recebe registros dos conteúdos, informações sobre sua descrição e localização corrente, e armazena estas informações dentro de uma base de dados. O Publishing Manager é responsável pela gerência de armazenamento e gerência de anúncio dos conteúdos de mídia. Com relação à gerência de armazenamento, o Publishing Manager pode sugerir fontes primárias de mídia para a postagem dos conteúdos por seus provedores. Além disso, ele é também responsável por estratégias que possam salvar recursos de rede através da manipulação dos conteúdos, tais como replicação automática, melhorias de QoS, e otimizações de caching. Com relação à gerência de anúncios, o Publishing Manager anuncia as sessões de multidifusão, inicializa transmissões agendadas, e agenda solicitações dos usuários, caso seja necessário. 
Dessa forma, estas são as cinco entidades envolvidas em nosso modelo para multidifusão sobreposta: User Agents, Source Agents, Multicast Agents, Session Manager e Publishing Manager. A seguir, discutiremos seus relacionamentos.

\subsubsection{Modelo de Interação}

O modelo de interação entre estas entidades pode ser entendido como segue. Um cliente desejando um conteúdo de mídia específico ganha acesso a todo o sistema através de seu User Agent. O User Agent obtém informações sobre a disponibilidade dos conteúdos de mídia através do Publishing Manager, o qual controla as transmissões das fontes de mídia fora do núcleo sobreposto. Dado a seleção de um conteúdo de mídia por parte do usuário, seu User Agent sempre envia uma solicitação de participação em sessão para o Session Manager.

Diante de tal solicitação, o Session Manager constrói uma estrutura de entrega hierárquica para o repasse dos dados de aplicação, partindo do Source Agent na fonte primária de mídia até o User Agent interessado neste conteúdo. Esta estrutura de entrega é chamada árvore de escoamento sobreposta, e é composta pelos Multicast Agents (MAs) estrategicamente eleitos pelo Session Manager para prover o controle do repasse dos dados. Estes MAs irão cooperar para realizar uma entrega eficiente do conteúdo de mídia, compartilhando os fluxos e aplicando otimizações de caching quando necessário.

A forma como o Session Manager constrói esta árvore de escoamento sobreposta não é definida pelo protocolo SMCP. Ao invés disso, o SMCP apresenta a flexibilidade de permitir que estratégias e algoritmos sejam definidos pelos serviços de multidifusão sobreposta que o utilizam. Discutimos várias possibilidades de construção da árvore de escoamento sobresposta no Capítulo 2, Seção 2.5. A idéia é construir a cada nova sessão uma árvore de entrega associada, eliminando laços e escolhendo-se as melhores rotas para o repasse um-para-muitos dos dados da aplicação. Um exemplo de árvore de escoamento é ilustrado pela Figura $4.1^{3}$.

Os MAs podem ser monitorados pelo Session Manager, e estratégias de recuperação de falhas podem ser empregadas. A estrutura do núcleo sobreposto pode variar com o tempo, dependendo das condições de tráfego e de falha nos nós, sendo que tais

\footnotetext{
${ }^{3}$ Neste caso, obtido da forma como descrito na Seção 2.5, na subseção que introduz o SMCP.
} 


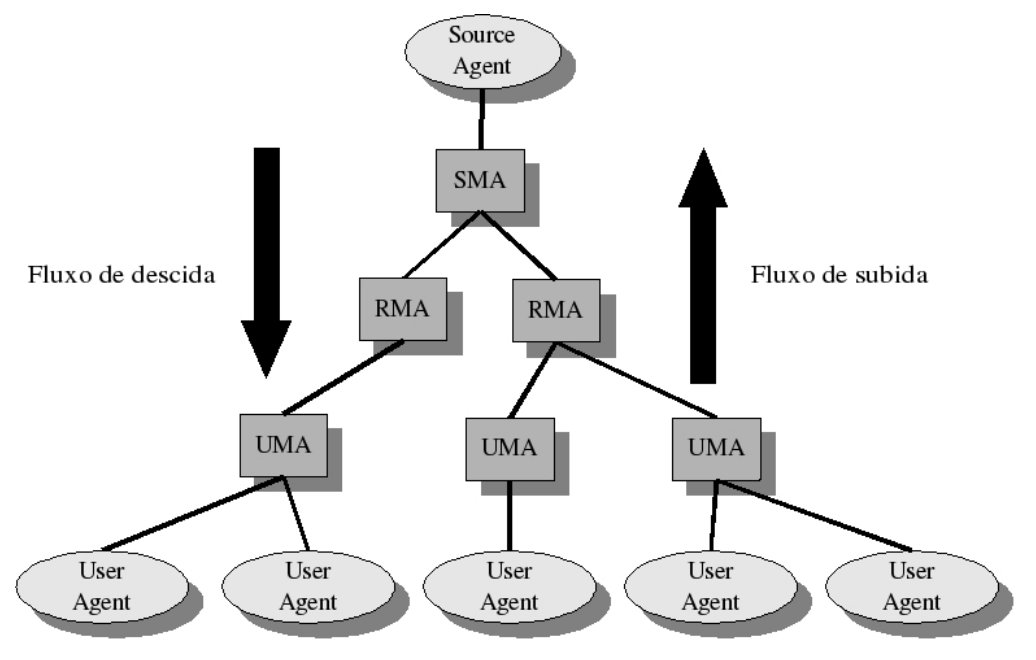

Figura 4.1: Exemplo de árvore de escoamento construída pelo Session Manager para multidifusão dos dados de aplicação.

mudanças podem ser automaticamente refletidas na próxima construção de árvore de escoamento quando se utiliza o SMCP. Mecanismos para adaptação da árvore durante uma sessão já estabelecida também são possíveis. O SMCP define mensagens entre suas entidades que permitem a implementação destes serviços a partir de suas primitivas básicas.

Como resposta à solicitação de participação em sessão, após a criação da árvore de escoamento sobreposta, o Session Manager informa ao User Agent seu representante para esta sessão, a partir do qual o User Agent receberá o fluxo de dados. Este representante é definido pelo Session Manager como o Multicast Agent com melhores condições para atender este cliente. Questões como localização na rede, capacidade de transmissão e número de clientes em atendimento devem ser levadas em consideração.

A Figura 4.2 ilustra o modelo de interação entre as entidades SMCP, cujos passos podem ser resumidos como segue:

Passo 1 No primeiro passo o User Agent (UA) do usuário obtém informações sobre mídias disponíveis através do Publishing Manager. Ao selecionar um conteúdo, o Publishing Manager redireciona este UA para o Session Manager desta região de cobertura.

Passo 2 O passo dois ilustra a solicitação de participação em sessão que o UA envia para o Session Manager. Ao receber este pedido, o Session Manager elege MAs ao longo do caminho de redirecionamento entre o Source Agent (SA) anexado 


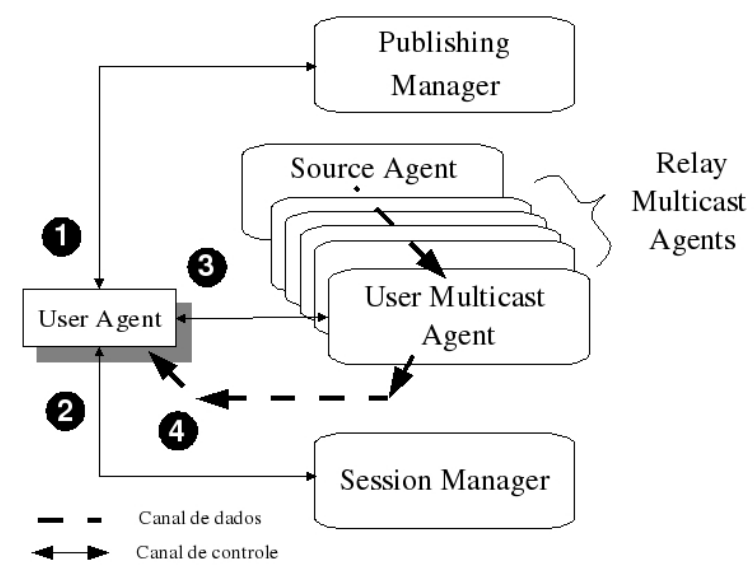

Figura 4.2: Modelo de interação entre as entidades SMCP.

à fonte de mídia e o MA mais próximo do usuário, denominado User Multicast Agent (UMA). Tal caminho é escolhido pelo Session Manager após a construção da árvore de escoamento, com base nas informações de topologia fornecidas pela camada BOS. A resposta do Session Manager indica ao UA seu representante, ou seja, seu UMA.

Passo 3 O terceiro passo ilustra a interação entre o UA e seu UMA. Eles combinam os parâmetros de sessão, e o UMA se encarrega de obter o fluxo de dados e repassá-lo ao UA. No caso em que não exista nenhum MA já envolvido na sessão solicitada, o pedido de estabelecimento de canal de dados pode ser repassado ao longo do fluxo de subida até alcançar o SA da fonte.

Passo 4 O quarto e último passo ilustra o estabelecimento do canal de dados, e finalmente a transmissão dos objetos de mídia solicitados, e sua recepção por parte do UA do cliente.

A Figura 4.3 mostra a troca de mensagens entre o Session Manager e os MAs. A interação entre estas entidades é extremanente necessária para a construção de árvores de escoamento eficientes. É dessa forma que o Session Manager toma conhecimento da existência dos MAs, e de sua situação atual. Além disso, a Figura 4.3 apresenta de forma mais clara o caminho de redirecionamento estabelecido para um UA, como uma melhor visualização do passo 4 da Figura 4.2.

Observe que os MAs podem também aplicar políticas de cache, de forma que clientes subsequentes obtenham o fluxo de mídia a partir de nós de redirecionamento, ao invés da solicitação chegar até a fonte de mídia primária. Podemos perceber que a técnica de caching é capaz de reduzir o atraso ao acesso da mídia e os custos de transporte. 


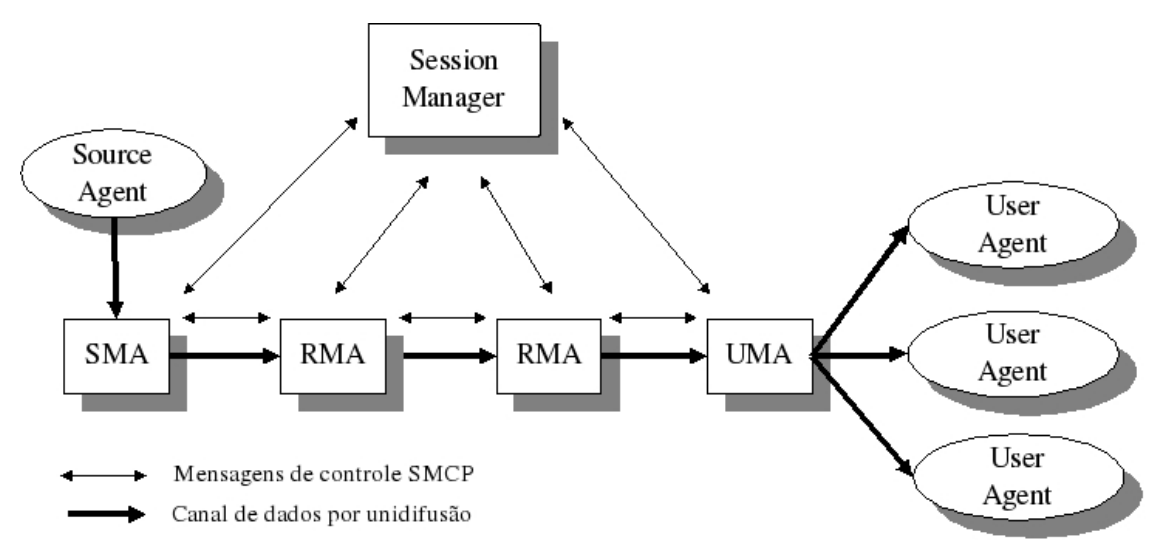

Figura 4.3: Um aglomerado de UAs em torno de um mesmo representante para uma mesma sessão.

\subsection{Estrutura das Mensagens}

A comunicação utilizando SMCP, ou seja, a sinalização para inicialização, monitoração e controle das sessões de multidifusão, é realizada pela troca de uma série de mensagens textuais, semelhantes às mensagens HTTP (FIELDING et al., 1999). As mensagens SMCP são enviadas entre suas entidades para que o protocolo execute sua função. As mensagens podem ser transportadas de forma independente pela rede, utilizando, por exemplo, o protocolo da camada de transporte UDP, ou serem transmitidas de forma confiável através do protocolo TCP.

As mensagens SMCP podem ser classificadas de duas formas: solicitações, se iniciadas pela entidade ora atuando como cliente, e enviadas para a entidade ora atuando como o servidor; ou respostas, se enviadas pela entidade ora atuando como servidor, para a entidade ora atuando como cliente. Fica claro que as entidades não têm papel principal definido, podendo atuar tanto como cliente quanto como servidor, dependendo do contexto.

Solicitações são usualmente utilizadas para inicializar algum tipo de ação ou informar o conteúdo do pedido por alguma coisa. Respostas são usadas para confirmar que uma solicitação foi recebida e processada, e contém o status do processamento.

As mensagens SMCP são baseadas em texto usando a sintaxe ABNF $^{4}$ (CROCKER; OVERELL, 1997), com codificação de oito bits, utilizando um conjunto de caracteres UTF-8, e fim de linha CRLF ${ }^{5}$. As mensagens consistem de uma linha inicial, um ou

\footnotetext{
${ }^{4}$ Augmented Backus-Naur Format

${ }^{5}$ Carriage Return Line Feed
} 
mais cabeçalhos, uma linha em branco indicando o fim dos campos de cabeçalho (CRLF), e um corpo de mensagem opcional. Todos as linhas devem ser terminadas com um caracter de retorno seguido de um caracter de fim de linha (CRLF).

$\begin{aligned} \text { mensagem SMCP genérica }= & \text { linha inicial } \\ & \text { cabeçalhos de mensagem } \\ & \text { CRLF } \\ & \text { [corpo da mensagem }]\end{aligned}$

Exceto pela diferença no conjunto de caracteres, muito da sintaxe das mensagens SMCP e campos de cabeçalho são semelhantes às mensagens HTTP e SIP.

Alternativamente, também é prevista a construção das mensagens SMCP utilizando estruturas hierárquicas bem definidas, como documentos $\mathrm{XML}^{6}$, seguindo a tendência dos protocolos mais modernos. A seguir, apresentamos uma mensagem SMCP como texto simples, e logo depois, uma outra mensagem em versão XML.

Uma mensagem SMCP típica tem a forma representada logo abaixo. A primeira linha indica que esta mensagem é uma solicitação SMCP JOIN, utilizada para participação em sessão por um novo cliente ou nova entidade SMCP. JOIN é o nome do método que indica o desejo de participar da sessão. O identificador de recursos uniforme (URI Uniform Resource Identifier) na primeira linha, smcp: source://mediaserver@cerbero . iptv.usp.br, é chamado Request URI, ou seja, a URI de solicitação, e, neste caso, contém a URI da fonte de mídia primária, a qual armazena o conteúdo desejado. Neste caso, será o hospedeiro cerbero.iptv.usp.br.

\footnotetext{
${ }^{6} \mathrm{~A}$ linguagem de marcação extensível (XML) foi desenvolvida em 1996 pelo XML Working Group do Consórcio World Wide Web (W3C). Trata-se de uma tecnologia aberta para descrever dados, amplamente suportada, cujo formato tornou-se padrão para trocas de dados entre aplicações em rede.
} 
JOIN smcp:source://mediaserver@cerbero.iptv.usp.br SMCP/1.0

Via: SMCP/1.0/RMI rmi://192.168.57.10:1099/smcp/user/alice

Next-Hop: smcp:multicast://firstagent@192.168.106.150

Next-Hop: smcp:multicast://secondagent@192.168.106.151

Max-Hops : 10

To: smcp: source://mediaserver@cerbero.iptv.usp.br

From: smcp:user://alice@192.168.57.10

Session-ID: overmediaxZm1I87mUPjsvD6W1ybzt22vSR_vYYDFgD4zZULupGE \& \& type=video

CSeq: 0 JOIN

Contact: rmi://192.168.57.10:1099/smcp/user/alice

Content-Length: 147

(Descrição de sessão não apresentada)

Uma mensagem SMCP pode conter um ou mais campos de cabeçalho "Next-Hop" e "Via". Os campos "Next-Hop" representam o caminho no fluxo de subida até a fonte primária, determinando quais elementos serão acionados para que este novo participante seja integrado à sessão. É o Session Manager quem preenche estes campos após a construção da estrutura de entrega para esta sessão. Cada MA ao longo do fluxo de subida que ainda não redireciona a sessão indicada em "SessionID" deve retirar o campo "Next-Hop" cujo valor refere-se a si, e redirecionar o pedido para o próximo "Next-Hop" da lista.

Já o campo "Via" é usado para armazenar o caminho do pedido, permitindo que servidores intermediários possam retransmitir as respostas pelo mesmo caminho. No caso da solicitação JOIN, esta sequência reflete o caminho no fluxo de descida através do qual os canais de dados deverão ser estabelecidos para atender este novo participante. Cada MA que redireciona o pedido acrescenta seu próprio endereço na mensagem e o número da porta através da qual espera receber respostas de controle.

Estes são os únicos campos onde os valores devem estar em ordem sequencial, já que serão reutilizados por outras entidades considerando-se sua ordem. Como esta mensagem possui apenas um campo "Via", pode-se dizer que o User Agent está sendo executado no hospedeiro 192.168.57.10, e que ele aguarda respostas na porta 1099, através do protocolo Java Remote Method Invocation (RMI) ${ }^{7}$.

\footnotetext{
${ }^{7}$ Detalhes sobre o protocolo RMI estão disponíveis em: http://java.sun.com/j2se/1.3/docs/guide/rmi/spec/rmiprotocol.html.
} 
O campo "Max-Hops" define o número máximo de tentativas ("saltos") realizadas para localização dos fluxos dessa sessão. Este campo deve ser inicializado com um valor padrão, e decrementado pelos MAs à cada salto que se sucede.

Os campos "From" e "To" identificam o originador (novo participante) e o destino (fonte primária de mídia) da solicitação de participação em sessão. "Session-ID" contém um identificador globalmente único para a sessão que se deseja participar, normalmente associado ao identificador da mídia.

"CSeq" é utilizado para manter a ordem de seqüência dos pedidos, pois como sabemos, as mensagens podem chegar fora de ordem caso transportadas via UDP. Dessa forma, este campo é usado para manter o controle de fluxo e controlar retransmissões. Assumindo-se "CSeq" = 1 para o JOIN inicial, poderia-se supor que esta seria uma mensagem retransmitida.

O campo de cabeçalho "Contact" contém o endereço IP e a porta na qual o originador da solicitação está esperando futuros pedidos enviados pela parte chamada, além do protocolo que será utilizado.

O cabeçalho da mensagem é separado do corpo principal por uma linha em branco. O corpo de uma mensagem JOIN pode conter uma descrição do tipo de sessão que precisa ser estabelecida, e para isso um outro protocolo além do SMCP precisa ser utilizado. O corpo da mensagem é apenas transportado pelo SMCP como um objeto opaco, representando unidades de dados de outro protocolo que não são observadas pelo SMCP.

Além da forma de texto simples, uma mensagem SMCP pode também ser escrita em linguagem XML da seguinte forma: 


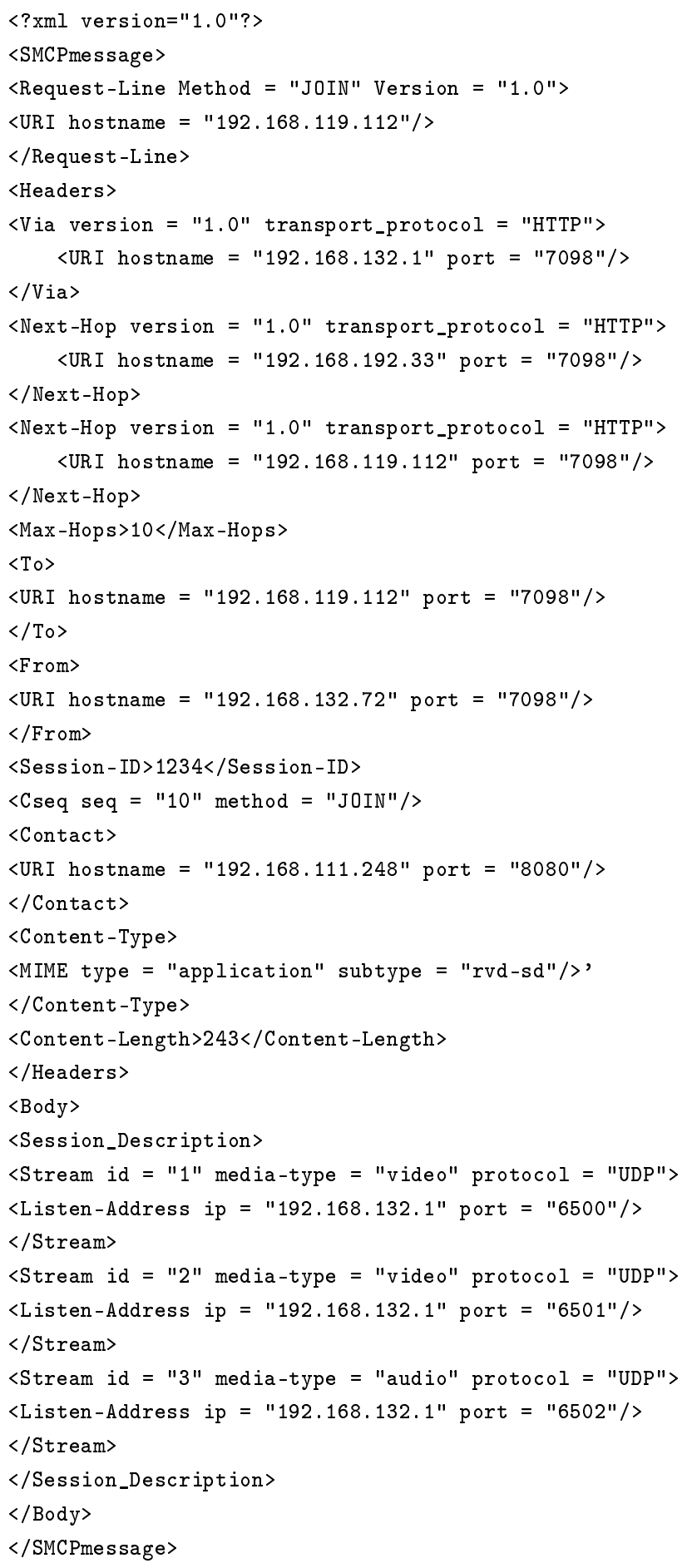

\subsubsection{Solicitações}

As solicitações SMCP diferem de suas repostas por apresentarem uma Linha de Solicitação como linha inicial. A Linha de Solicitação contém o nome do método (Method), uma URI de solicitação (Request-URI), e a versão do protocolo (SMCP ver- 
sion), com cada elemento separado por caracter de espaço simples (SP):

Linha de Solicitação $=$ Method SP Request-URI SP SMCP Version SP CRLF

onde cada componente pode ser explicado como segue:

- Method: será um dos 8 métodos definidos a seguir;

- Request-URI: URI geral de acordo com a RFC 2396 (BERNERS-LEE et al., 1998). Indica o usuário ou serviço para o qual este pedido está endereçado;

- SMCP Version: versão do protocolo em uso.

\section{Métodos}

A seguir, listamos os métodos SMCP utilizados na implementação do cenário de multidifusão proposto nesta dissertação:

ACK : um método ACK é enviado por um agente para confirmar a recepção de uma resposta;

BYE : este método é enviado por um agente quando este deseja finalizar uma sessão;

CANCEL : este método deve ser enviado quando se deseja interromper a transmissão antes de receber uma resposta do agente chamado;

JOIN : é utilizado por um agente que deseja participar de uma sessão;

OPTIONS : é um pedido enviado a uma entidade para descobrir suas capacidades, bem como a lista de mídias suportadas;

REGISTER : é um pedido de novo registro ou de atualização de um registro existente realizado por um agente;

REPORT : é um pedido por envio de relatório de status detalhado. Ao receber este pedido, o agente precisa respondê-lo prontamente. 


\subsubsection{Respostas}

As respostas SMCP diferem das solicitações por possuírem uma Linha de Status como linha inicial. A Linha de Status consiste na versão do protocolo (SMCP Version), seguida de um código numérico de status (Status-Code), e uma frase textual (Reason-Phrase) associada, com cada elemento separado por caracter de espaço simples (SP):

Linha de Status $=$ SMCP Version SP Status-Code SP Reason-Phrase SP CRLF

onde cada componente pode ser explicado como segue:

- SMCP Version: versão do protocolo em uso;

- Status-Code: código resultante inteiro de 3 dígitos que indica a saída de uma tentativa de entendimento e realização do pedido;

- Reason-Phrase: curta descrição textual do código de status.

O SMCP utiliza o Status-Code da Linha de Status para identificar as respostas. Seu primeiro dígito identifica a classe da resposta. Os outros dígitos não possuem nenhum papel categórico. Assim, qualquer resposta cujo código de status esteja entre $100 \mathrm{e}$ 199 é referenciada como resposta classe $1 X X$, entre 200 e 299 como classe $2 X X$, e assim por diante. Previmos seis valores diferentes para o primeiro dígito do código de status:

1XX: Provisional - pedido recebido, continuando o processamento do pedido;

2XX: Success - a ação foi recebida com sucesso, entendida e aceita;

3XX: Redirection - ações adicionais precisam ser tomadas para completar o pedido;

4XX: Client Error - o pedido contém erro de sintaxe ou não pode ser processado neste servidor;

5XX: Server Error - o servidor falhou no processamento de um pedido aparentemente válido; 
6XX: Global Failure - o pedido não pode ser processado em qualquer servidor.

Na próxima sessão vamos demonstrar os cenários de multidifusão montados a partir da interação entre as entidades definidas através da troca de mensagens SMCP.

\subsection{Cenários de Operação}

Nesta dissertação, descreveremos as operações básicas do SMCP considerando cinco cenários de operação: 1) a inicialização da rede sobreposta, 2) participação de um novo cliente, 3) monitoração da estrutura de controle, 4) monitoração da estrutura de entrega, e 5) multidifusão interdomínio.

\subsubsection{Inicialização da Rede Sobreposta}

A fim de construir árvores de escoamento eficientes, o Session Manager precisa ter tanto o conhecimento da topologia da rede física quanto o conhecimento da topologia da rede sobreposta. A eficiência da árvore de escoamento sobreposta depende da capacidade do Session Manager em cruzar estas informações e combiná-las de forma a otimizar a construção da árvore.

Portanto, na inicialização da rede sobreposta o Session Manager pode carregar as informações sobre a topologia da rede física a partir de uma base de dados alimentada por algum protocolo da camada BOS. O SMCP define uma troca de mensagens entre os MAs e o Session Manager para prover a descoberta da topologia sobreposta. Ao ser inicializado, o MA precisa enviar uma mensagem de registro denominada REGISTER, informando sobre sua existência. Após este envio, o MA aguarda confirmação do Session Manager, a qual conterá parâmetros de configuração do SMCP. Tais registros possibilitarão ao Session Manager a descoberta ou atualização da topologia sobreposta. No corpo destas mensagens é possível incorporar informações também sobre a topologia física, de acordo com algum protocolo externo específico para esta finalidade.

Portanto, a inicialização do Session Manager basicamente se dá em 3 passos: 
1. Ele realiza suas configurações básicas (rede e alguns outros parâmetros do SMCP);

2. Carrega informações de topologia física;

3. Aguarda por registros dos MAs.

Lembrando que o passo 2 pode ser ignorado, e em tal caso torna-se necessário o envio de informações sobre a topologia física dentro das mensagens de registro, utilizando-se algum outro protocolo para isso.

Ao inicializar-se, e após concluir suas configurações de rede, cada MA precisa se registrar no Session Manager enviando uma mensagem SMCP REGISTER. A descrição dos serviços de distribuição de mídia controlados por este MA pode ser enviada no corpo da mensagem, como um objeto opaco, ou seja, não manipulado pelo protocolo SMCP. Isto pode ser feito, por exemplo, utilizando o protocolo SLP (GUTTMAN et al., 1999).

Caso este registro falhe, o MA precisa esperar um tempo pré-definido (por configuração) e novamente contactar o Session Manager para obter informações de inicialização. Supondo que o registro seja feito com sucesso, o Session Manager enviará um resposta de confirmação SMCP 200 OK. Nesta confirmação, o Session Manager informa a URI de contato para a atualização dos registros e a periodicidade na qual este MA precisará atualizá-los. No corpo da mensagem, fora do escopo do SMCP, a aplicação Session Manager pode confirmar o serviços de distribuição de mídia registrados e/ou o recebimento de informações pertinentes à topologia física.

Um exemplo ilustrando um evento de inicialização de um MA é apresentado pela Figura 4.4. Assume-se que os MAs conhecem o URI de contato do Session Manager por configuração. A troca de mensagens SMCP entre um MA e o Session Manager é ilustrada através do diagrama de sequência da Figura 4.5.

Nenhuma inicialização especial é exigida para a entidade Publishing Manager. O importante é que para cada conteúdo a ser publicado sejam extraídos os metadados correspondentes, bem como as informações sobre a fonte primária de mídia. Observe que esta não é uma atividade de inicialização de sistema, podendo ser realizada posteriormente. No entanto, uma sessão de transmissão de uma mídia só poderá ser criada após sua publicação no Publishing Manager. 


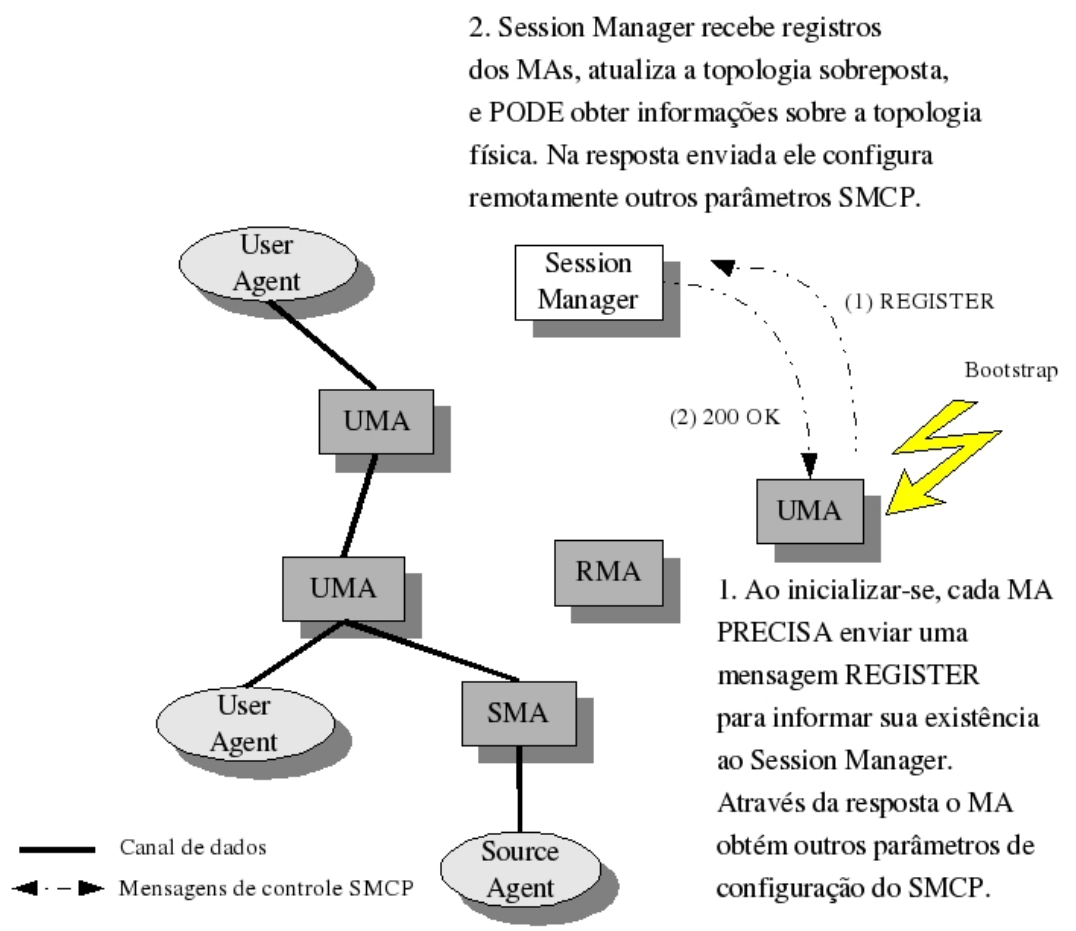

Figura 4.4: Exemplo de evento de inicialização do MA.

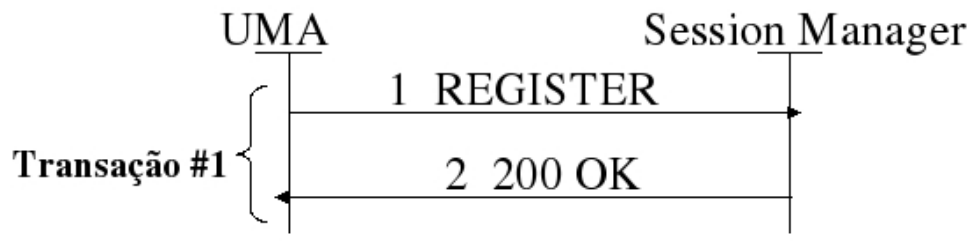

Figura 4.5: Sequência de troca de mensagens SMCP na inicialização de um componente de rede.

\subsubsection{Participação de um Novo Cliente}

Vamos ilustrar este cenário de utilização do SMCP através do exemplo da Figura 4.6. Neste exemplo, um usuário de nome Alice vai utilizar o protocolo SMCP para descobrir e participar de uma sessão de multidifusão anunciada por uma aplicação multimídia que se utiliza do Publishing Manager. Alice está separada do servidor-fonte de mídia por um rede de longa distância sem suporte nativo a multidifusão. Note que na Figura 4.6 já existe uma sessão de multidifusão sobreposta ativa, onde os fluxos de dados são transmitidos de forma eficiente a partir do SA até os UAs B e C.

A função do SMCP neste cenário é:

1. Estabelecer uma sessão de controle para esta transmissão; 


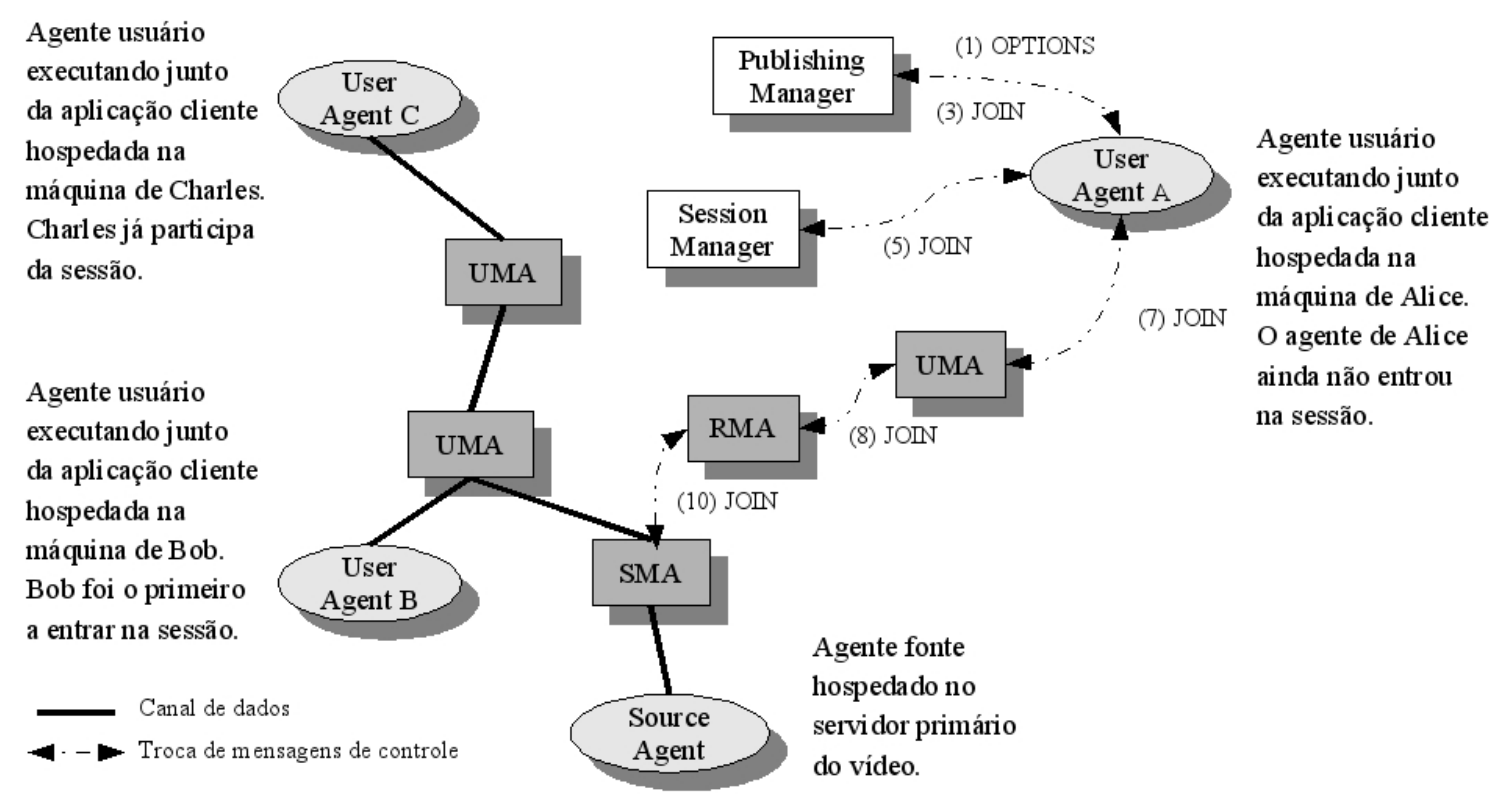

Figura 4.6: Participação em sessão ativa por um novo cliente.

2. Prover mecanismos que permitam a negociação dos parâmetros de sessão e o estabelecimento do fluxo de dados por parte de algum serviço de distribuição de mídia (MDS - Media Distribution Service );

3. Prover mecanismos para que seja possível garantir que uma única cópia do fluxo multimídia trafegue entre os MAs ao longo da rede;

4. Prover mecanismos que torne possível o gerenciamento das sessões de multidifusão.

A seguir, vamos descrever a troca de mensagens SMCP necessárias para a participação de um novo cliente em uma sessão já existente. Entretanto, como preparação para o cenário proposto, precisamos antes descrever como a sessão foi inicialmente criada.

Neste exemplo, a primeira solicitação de participação foi realizada por Bob através do User Agent B. O pedido de transmissão foi repassado no fluxo de subida, até a fonte primária do vídeo, e um canal de dados foi estabelecido no fluxo de descida, partindo da fonte, passando pelos MAs intermediários, até chegar no UA B. Toda a troca de mensagens de controle SMCP se sucedeu, e Bob começou a receber os fluxos de mídia.

Após certo tempo, o usuário Charles decidiu também participar desta sessão, e utilizou mensagens SMCP para informar seu desejo à rede. Dessa vez, o pedido de 
participação em sessão (mensagem SMCP JOIN) repassado no fluxo de subida não precisou chegar até a fonte primária, já que este pedido chegou a um MA que já transmitia os fluxos para o UA de Bob. Dessa forma, o UMA de Bob passou a atuar também como RMA, abrindo um novo braço de transmissão para os elementos no caminho do fluxo de descida até o UA de Charles.

Agora é a vez do usuário Alice pedir para também entrar na sessão, e é neste ponto da comunicação que a Figura 4.6 foi capturada. Para solicitar participação em sessão, primeiro Alice precisa tomar conhecimento sobre as mídias disponíveis. Para isso, previamente, um provedor de conteúdos precisa ter publicado a mídia no Publishing Manager. Então, o UA de Alice envia a mensagem SMCP OPTIONS. No corpo da mensagem SMCP 200 OK de resposta ${ }^{8}$, o UA A recebe a lista das mídias e sua descrição, de acordo com algum outro protocolo apropriado (o SDP (HANDLEY et al., 2006), por exemplo). Neste momento, o software cliente na máquina da Alice apresenta-lhe a lista de mídias e suas opções. Ao clicar na mídia desejada, Alice faz com que seu UA envie a mensagem SMCP JOIN para o Publishing Manager. Esta mensagem informa que Alice quer participar desta sessão.

O Publishing Manager é a entidade responsável pelo conhecimento das mídias, o que também inclui seu local de armazenamento primário, porém ele não tem qualquer conhecimento sobre a rede de distribuição e seus elementos. Dessa forma, a resposta que o Publishing Manager envia para Alice é um pedido para redirecionar a mensagem SMCP JOIN para a entidade capaz de eleger elementos de rede para o redirecionamento dos dados solicitados. Tal entidade é o Session Manager. Esta necessidade de redirecionamento é informada ao UA através de uma mensagem SMCP 306 Use Manager como resposta ao SMCP JOIN. Nesta resposta o Publishing Manager insere informações sobre a fonte primária da mídia, e o UA deve repassar tais informações para o Session Manager.

O UA de Alice então redireciona a mensagem SMCP JOIN para o Session Manager, cujo URI de contato foi informado na resposta SMCP 306 Use Manager. Ao receber tal pedido, o Session Manager constrói uma árvore de entrega por multidifusão, cujos vértices são MAs escolhidos, e cujos arcos são enlaces sobrepostos definidos. Nesta construção o Session Manager tenta otimizar a árvore sobreposta através do conhecimento sobre a fonte primária de mídia, informado indiretamente pelo Publishing Manager através do UA de Alice, do conhecimento sobre o receptor de mídia, extraído a partir do identificador do UA informado na mensagem SMCP JOIN, e do

\footnotetext{
${ }^{8}$ Observe que omitimos as mensagens de resposta na Figura 4.6 para não sobrecarregá-la.
} 
conhecimento da topologia da rede física.

O Session Manager responde para o UA de Alice com uma mensagem SMCP 305 Use Proxy, repassando uma lista com os agentes de multidifusão eleitos para o repasse dos dados de aplicação. Dessa forma, o Session Manager define o caminho "mais curto" para o atendimento desta sessão.

O UA de Alice deve então enviar uma mensagem SMCP JOIN para o primeiro elemento da lista informada pelo Session Manager. Este primeiro elemento é o UMA de Alice. Este agente de multidifusão, por sua vez, verifica se já participa desta sessão. Em caso afirmativo, ele abre um braço de transmissão e envia os dados também para o UA de Alice. No caso negativo, o pedido de participação em sessão SMCP JOIN será repassado no fluxo de subida para o próximo elemento na lista. Este procedimento se repete, até que se alcance um RMA ativo nesta sessão, ou até que se alcance o SMA desta transmissão.

A cada salto em avanço no fluxo de subida, o MA posterior confirma seu empenho em obter o fluxo de dados enviando ao MA anterior uma mensagem SMCP 100 Trying. Assim que o pedido SMCP JOIN atinge um MA que já possui o fluxo, este confirma prontamente a presença do fluxo ao MA anterior no fluxo de subida, enviando uma resposta SMCP 170 Sending. Esta confirmação é repassada ao longo do fluxo de descida. Enquanto isso, o MA que já possui o fluxo vai se preparando para criar um braço de divisão da árvore de dados. Assim que ele estiver pronto para retransmitir o fluxo, ele confirma o pedido de participação SMCP JOIN lançado por seu antecessor no fluxo de subida com uma mensagem de resposta SMCP 200 OK enviada no fluxo de descida. Este antecessor confirma que ainda tem intenção de participar da sessão enviando uma mensagem SMCP ACK. Após esta confirmação, o canal de dados é estabelecido entre os dois.

Observe que nesta tentativa de estabelecimento de canal de dados, as entidades podem combinar parâmetros de sessão através de algum outro protocolo externo, tal como o SDP. Tais mensagens serão enviadas de forma transparente no corpo das mensagens SMCP. Todo este procedimento se sucede ao longo do fluxo de descida, e os canais de dados vão sendo estabelecidos neste mesmo sentido, até que o cliente na máquina de Alice receba o fluxo, o decodifique, e apresente-o para Alice.

Além disso, em cada salto, após o estabelecimento do canal de dados, os MAs confirmam para o Session Manager sua entrada na sessão enviando uma mensagem 


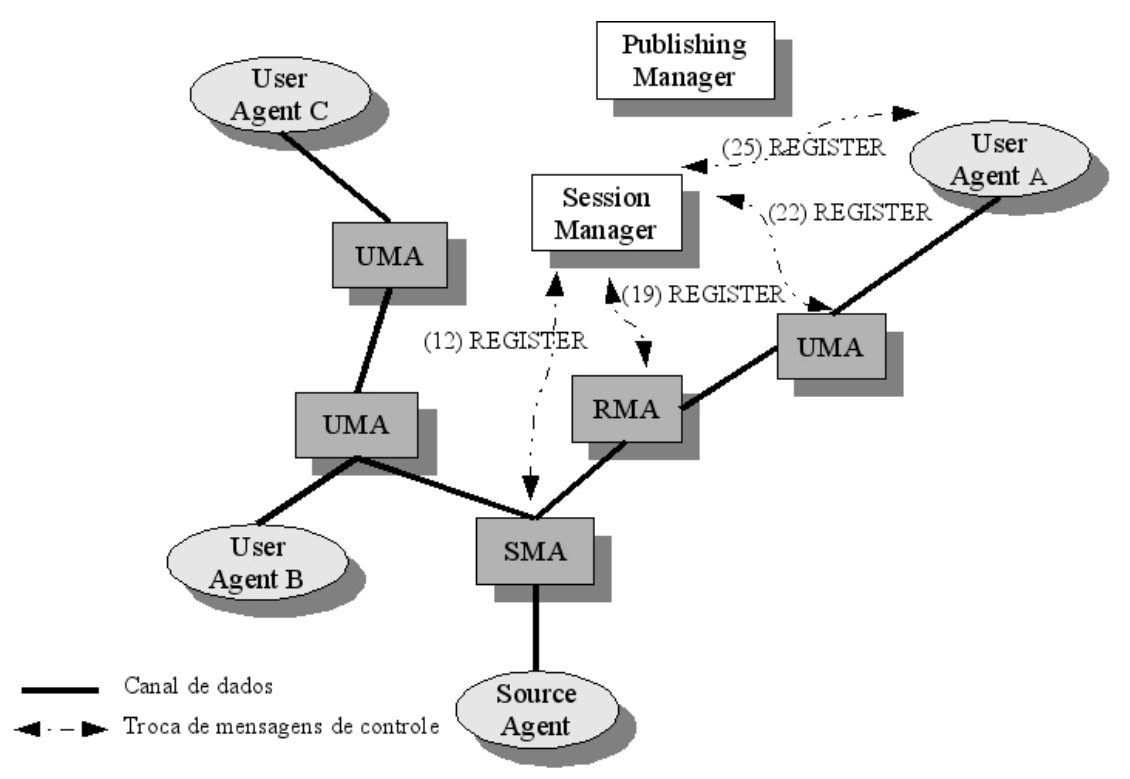

Figura 4.7: Entrada de novos participantes na sessão.

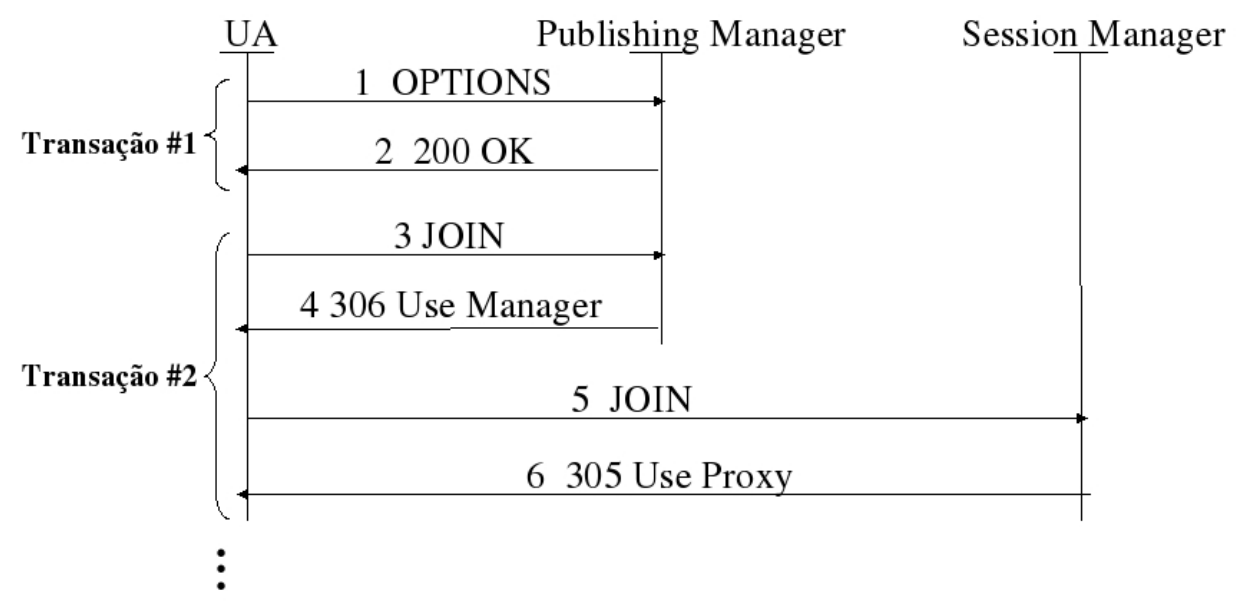

Figura 4.8: Sequência de troca de mensagens SMCP para participação em sessão de um novo cliente: interação UA/Publishing Manager e UA/Session Manager.

SMCP REGISTER. Assim que começar a receber dados de aplicação, o UA deve também se registrar como participante dessa sessão enviando uma mensagem SMCP REGISTER para o Session Manager. Este processo final no estabelecimento da sessão é ilustrado pela Figura $4.7^{9}$.

Todas estas trocas de mensagens estão resumidas nos diagramas de sequência das Figuras 4.8 e 4.9 .

\footnotetext{
${ }^{9}$ Observe que novamente omitimos as mensagens de resposta para não sobrecarregar a figura.
} 


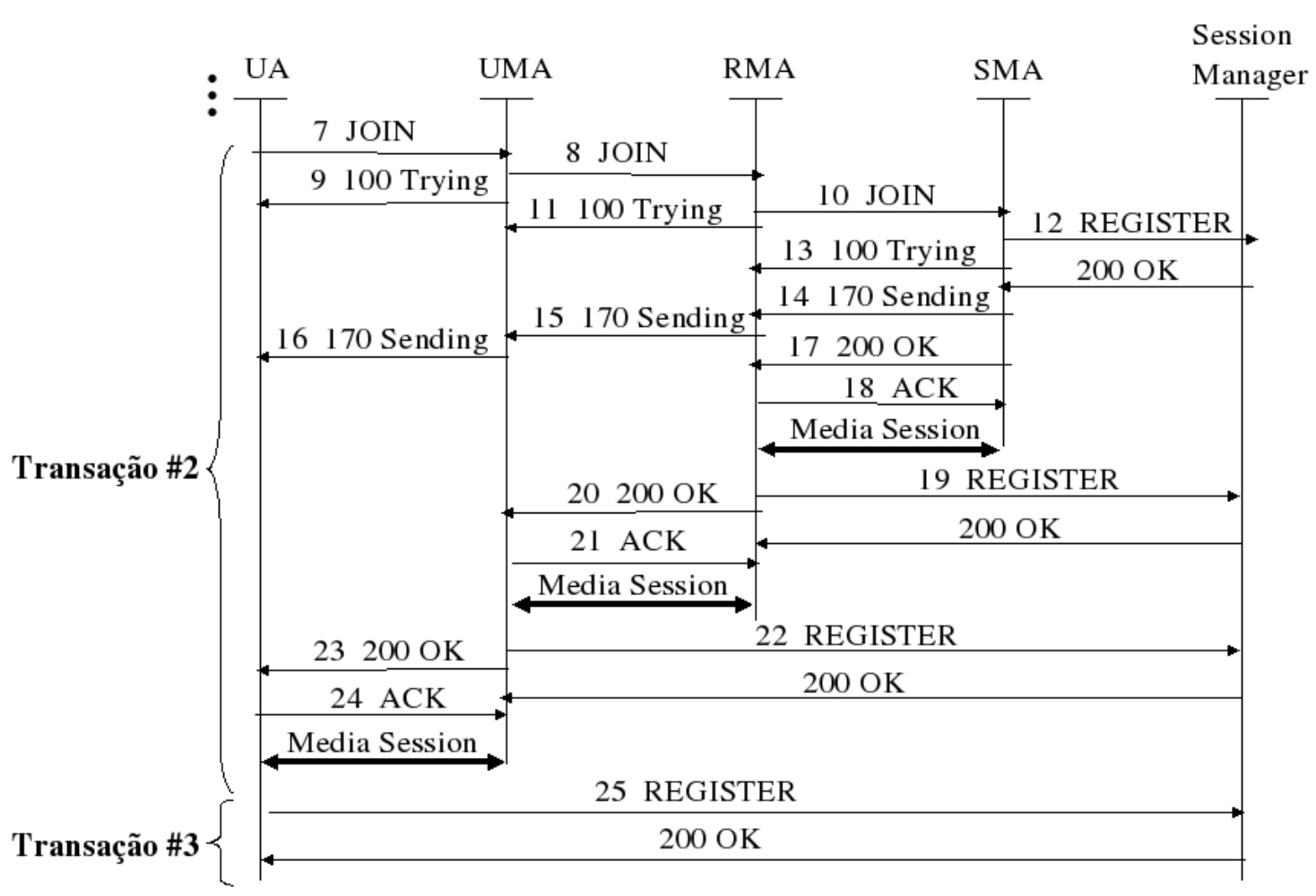

Figura 4.9: Sequência de troca de mensagens SMCP para participação em sessão de um novo cliente: interação UA/MAs e MAs/Session Manager.

\subsubsection{Monitoração da Topologia de Controle}

Este cenário de operação descreve os procedimentos necessários para a manutenção da estrutura de controle da rede sobreposta. Para isso, os MAs precisam atualizar seu registro junto ao Session Manager através da mensagem SMCP REGISTER, com a periodicidade previamente combinada na etapa de inicialização.

Esta nova mensagem SMCP REGISTER deve informar os identificadores das sessões atualmente ativas no momento de seu envio. O Session Manager pode ou não confirmar o recebimento da atualização de registros, mesmo se a atualização ocorrer com sucesso. Dessa forma, o MA não deve esperar uma confirmação desta atualização, mas precisará interpretá-la caso ela seja enviada. Caso não esteja participando de nenhuma sessão no momento, o MA mesmo assim precisa enviar a mensagem SMCP REGISTER obedecendo a periodicidade previamente combinada, porém sem enviar identificadores de sessão. Este cenário está ilustrado na Figura 4.1010. O diagrama de sequência dessa mensagem é apresentado na Figura 4.11.

\footnotetext{
${ }^{10}$ Observe que, diferentemente das figuras do cenário anterior, a seta neste cenário tem apenas um sentido, indicando que não há respostas para a mensagem enviada.
} 


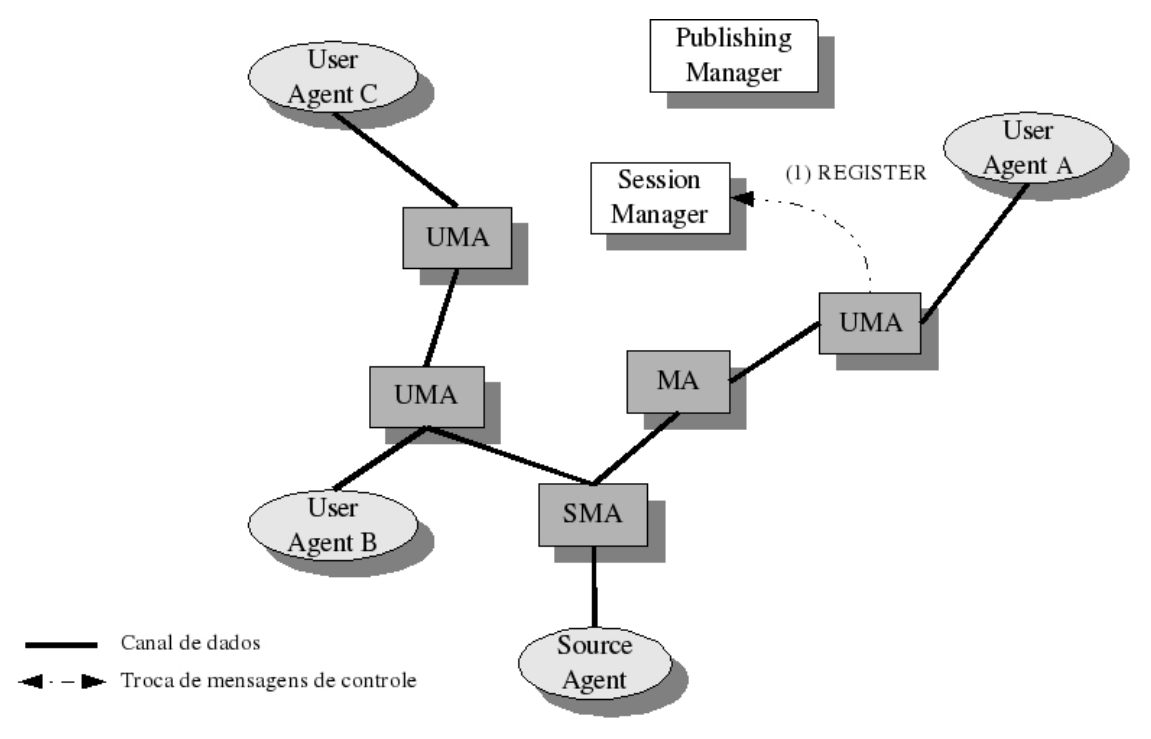

Figura 4.10: MAs mantém status das sessões de multidifusão das quais participam e enviam curtos informes de status periodicamente.

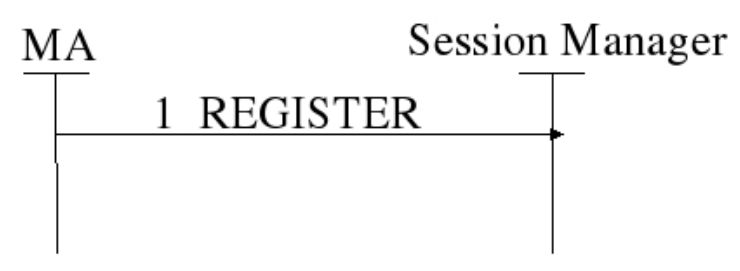

Figura 4.11: Mensagem SMCP REGISTER periodicamente enviada por todos os MAs ao Session Manager.

Perceba que o envio descontrolado de mensagens de status por todos os MAs ao Session Manager pode inundar a rede, ocupando a largura de banda da rede com informações de controle em detrimento dos dados em si, prejudicando a transmissão nas sessões. No entanto, este é um problema já resolvido em (PERKINS, 2003), cuja análise e heurística dita que este fluxo de controle nunca poderá ultrapassar mais de $5 \%$ da taxa de transmissão envolvida nos canais de dados.

A partir dessa atualização de registro provida pelo SMCP, torna-se possível gerenciar os elementos de controle da rede de distribuição, podendo-se levantar seu status operacional (up ou down), suas sessões ativas, e até mesmo reconstruir a árvore de dados de cada sessão, comparando a árvore construída pelo Session Manager com a árvore de fato criada pelos elementos de rede. Tal levantamento pode ser utilizado para identificar possíveis gargalos na rede física, e evitá-los ou minimizá-los na rede sobreposta. 


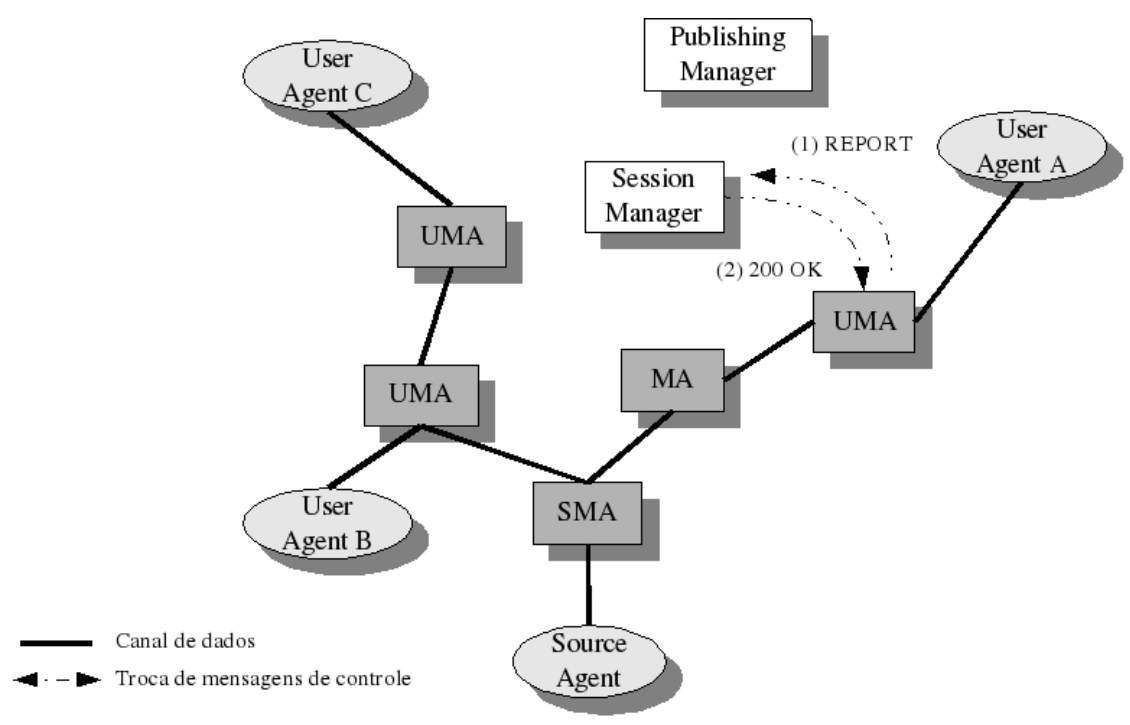

Figura 4.12: Quando houver interesse, o Session Manager solicita um relatório de monitoração detalhado a um dado MA, o qual precisa responder com todas as informações solicitadas.

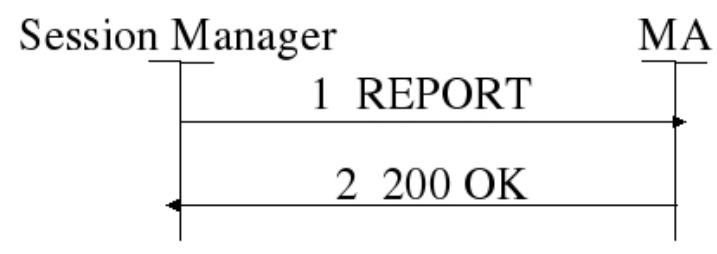

Figura 4.13: Troca de mensagens envolvidas quando da solicitação de relatório de monitoração enviada pelo Session Manager a um dado MA, e sua respectiva resposta.

\subsubsection{Monitoração da Topologia de Dados}

Além de prover as informações necessárias para a monitoração da estrutura de controle, o SMCP também define primitivas para possibilitar a monitoração da estrutura de entrega de dados. Neste cenário, o Session Manager solicita de forma explícita um relatório de status de serviço para um MA através do envio da mensagem SMCP REPORT. Ao receber tal mensagem, o MA deve obter dos serviços de distribuição de mídia as informações solicitadas e retorná-las ao Session Manager.

Observe que não é objetivo do SMCP definir a forma e a periodicidade com que estas informações são coletas, quais informações devem ser consideradas, e como representá-las. Como o projeto visa flexibilidade, o SMCP provê apenas uma forma de transportar tais mensagens, onde protocolos específicos para monitoração de sessões multimídia devem ser utilizados. 
Dessa forma, no corpo da mensagem SMCP REPORT podem ser solicitados tabelas de sessões ou tabelas de serviços, as quais possuem informações completas sobre as transmissões, tais como duração da sessão, número de usuários atendidos, tempo médio em sessão, taxa do fluxo agregado de entrada, taxa do fluxo agregado de saída, perda de pacotes, variação de atraso, etc.

O MA precisa responder a esta solicitação, incluindo no corpo da mensagem o resultado da consulta de status dos serviços. Este cenário está ilustrado na Figura 4.12, cuja sequência de mensagens é apresentada na Figura 4.13.

\subsubsection{Multidifusão Interdomínio}

Esta seção trata de um cenário ainda não solucionado na multidifusão nativa em rede, porém resolvido pelo SMCP: o suporte à multidifusão interdomínio. Para ilustrar tal funcionalidade, este cenário considera três sistemas autônomos sobrepostos (OAS) interconectados de forma a permitir que fluxos multimídia trafeguem de um a outro OAS, em uma transmissão por multidifusão, conforme ilustrado na Figura 4.14.

Como vimos no cenário de inicialização da rede sobreposta (ver Seção 4.4.1), ao ser inicializado um agente precisa se inscrever para Sesssion Manager, enviando uma mensagem SMCP REGISTER, informando seu identificador global e seu identificador de dispositivo. Este Sesssion Manager irá gerenciar as entidades em sua região de cobertura, normalmente entidades pertencentes a seu OAS.

O problema deste cenário pode ser resumido na seguinte pergunta: como garantir que um cliente pertencente a um OAS tenha acesso a conteúdos multimídia mantidos em outro OAS de forma eficiente? Por eficiência, entendemos uma transmissão umpara-muitos que não inunde as redes ou necessite que cada rede envolvida tenha conhecimento sobre todas as outras redes.

Para visualizarmos melhor o problema, suponha que um Cliente $A$, pertencente ao OAS X, acesse um Portal de Mídias hospedado no OAS Z, sendo que os OASs $\mathrm{X}$ e $Z$ são interconectados pelo OAS Y, conforme ilustrado na Figura 4.14. Na prática, o problema de roteamento é: como o Session Manager de $Z$ descobre a qual OAS o Cliente A pertence? Como montar uma rota de forma que o fluxo atravesse a rede apenas uma vez? 


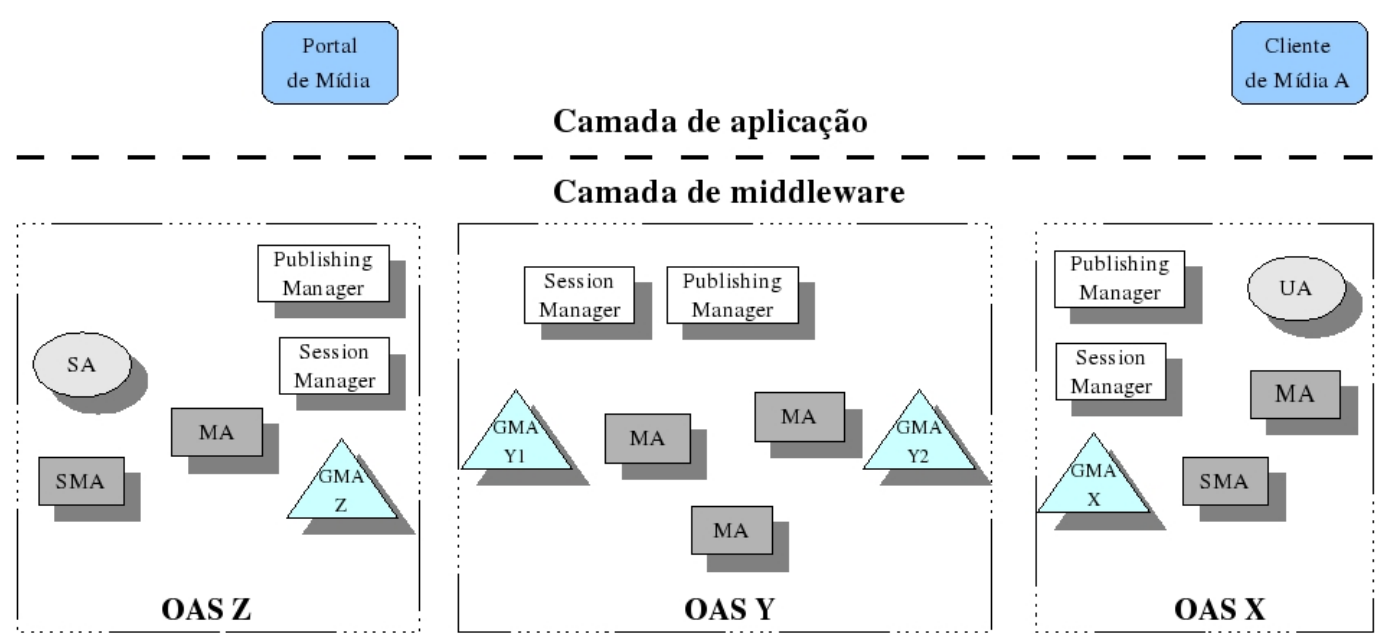

Figura 4.14: Cenário de multidifusão interdomínio através de três sistemas autônomos sobrepostos: OAS X, OAS Y, e OAS Z.

Para solucionar este problema, algumas considerações são necessárias. Primeiro, consideramos que cada OAS pode apenas publicar diretamente conteúdos hospedados em seu próprio domínio. Além disso, cada OAS precisa manter seus próprios elementos sobrepostos, tais como SAs, UAs, MAs, Session Manager e Publishing Manager.

Neste caso, teremos elementos MAs interconectando diferentes sistemas autônomos, atuando como Gateway Multicast Agents (GMA). Os GMAs são elementos sobrepostos responsáveis por prover e gerenciar um roteamento por multidifusão sobreposta interdomínio através de diferentes OASs. Estes agentes propagam informações de roteamento sumarizadas apenas entre os gateways, e estabelecem os caminhos de roteamento entre os OASs. A forma como um MA atua como gateway segue a idéia do protocolo MBGP (Multiprotocol Border Gateway Protocol) (BATES et al., 2007). Dessa forma, os GMAs são sempre configurados como pares (peers), cada um em seu próprio domínio.

Por ser um cenário bem mais complexo, ilustraremos passo-a-passo o estabelecimento dos canais de dados por multidifusão através dos três OASs. Para um melhor entendimento, como opção de implementação, mostraremos também a utilização de outros protocolos em conjunto com o SMCP.

Tudo se incia com o Cliente de Mídia A no OAS X, acessando o Portal de Mídias no OAS $Z$ através de seu navegador, via protocolo HTTP, como mostrado na Figura 4.15. Ao desejar um certo conteúdo, o usuário clicará no ícone que representa aquela mídia. Neste momento, seu navegador lança uma mensagem HTTP GET solicitando o 


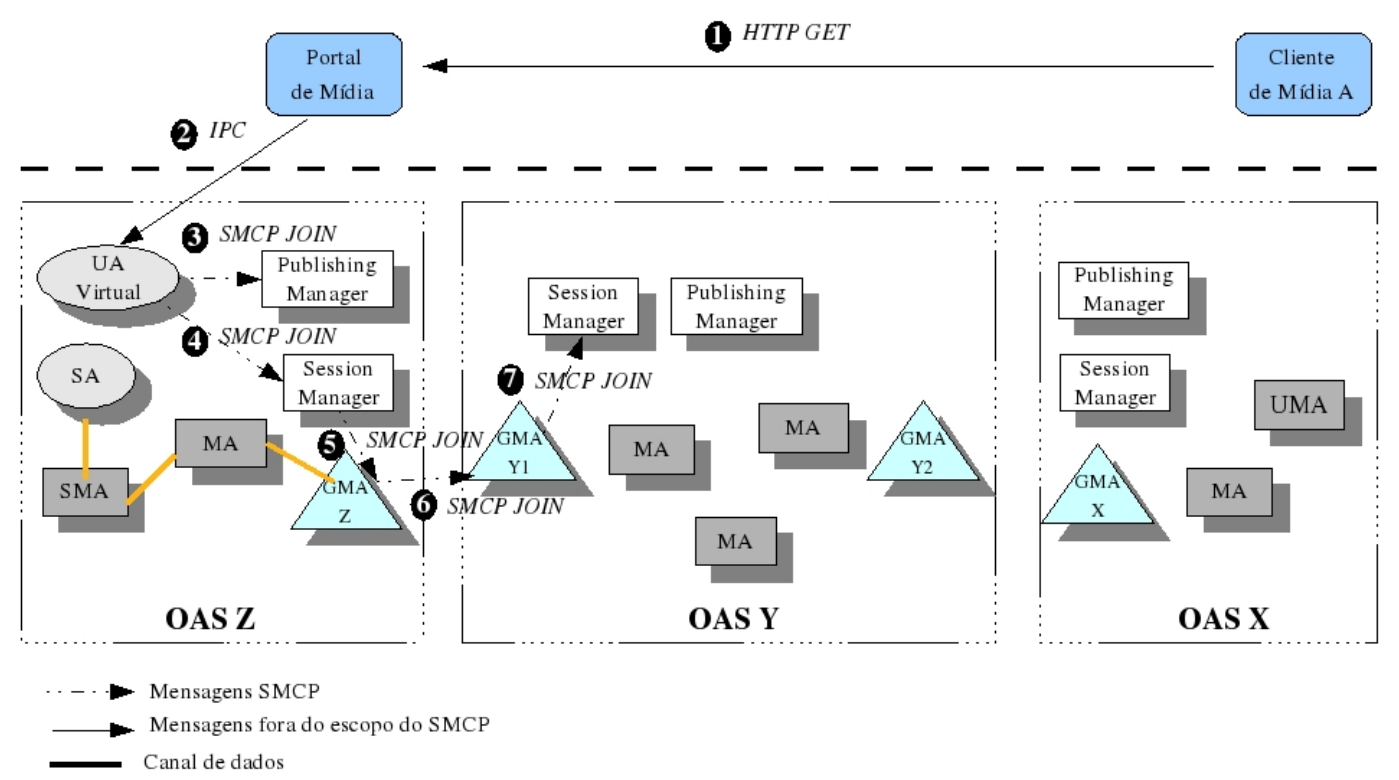

Figura 4.15: Troca de mensagens fora do escopo SMCP, mensagens SMCP intradomínio para estabelecimento de parte do canal de dados, e atuação dos GMAs para se alcançar o Session Manager do OAS Y.

conteúdo de mídia. Uma opção de implementação desse sistema multimídia que evita a instalação de software cliente na máquina do usuário é representá-lo por um UA Virtual na máquina servidora. Dessa forma, para cada usuário acessando o sistema, instancia-se no servidor do Portal de Mídias um terminal virtual que represente o User Agent do usuário.

Dentro do OAS Z, o Portal de Mídias se comunica então com o UA Virtual construído para este usuário, repassando as informações obtidas do cliente, no OAS X, e da mídia solicitada. A comunicação entre o Portal de Mídias e o UA Virtual também não é definida pelo protocolo SMCP, podendo ser até comunicação entre processos (InterProcess Communication - IPC), conforme mostrado no passo 2 da Figura 4.15.

A partir desse ponto, a comunicação SMCP entra em cena, e os passos para participação em sessão por um novo cliente ocorrem conforme cenário intradomínio explicado na Seção 4.4.2, porém a partir da Transação \#2. Além de não apresentar a Transação \#1, onde o envio da mensagem SMCP OPTIONS foi substituído pelas mensagens HTTP GET e IPC, a grande diferença é que o UA Virtual encaminha no SMCP JOIN lançado para o Session Manager informações URI AOR e URI de contato de um cliente fora deste sistema autônomo, ou seja, no OAS X. Isso é ilustrado no passo 4 da Figura 4.15.

Neste momento, o Session Manager percebe que não há como alcançar o dispositivo 


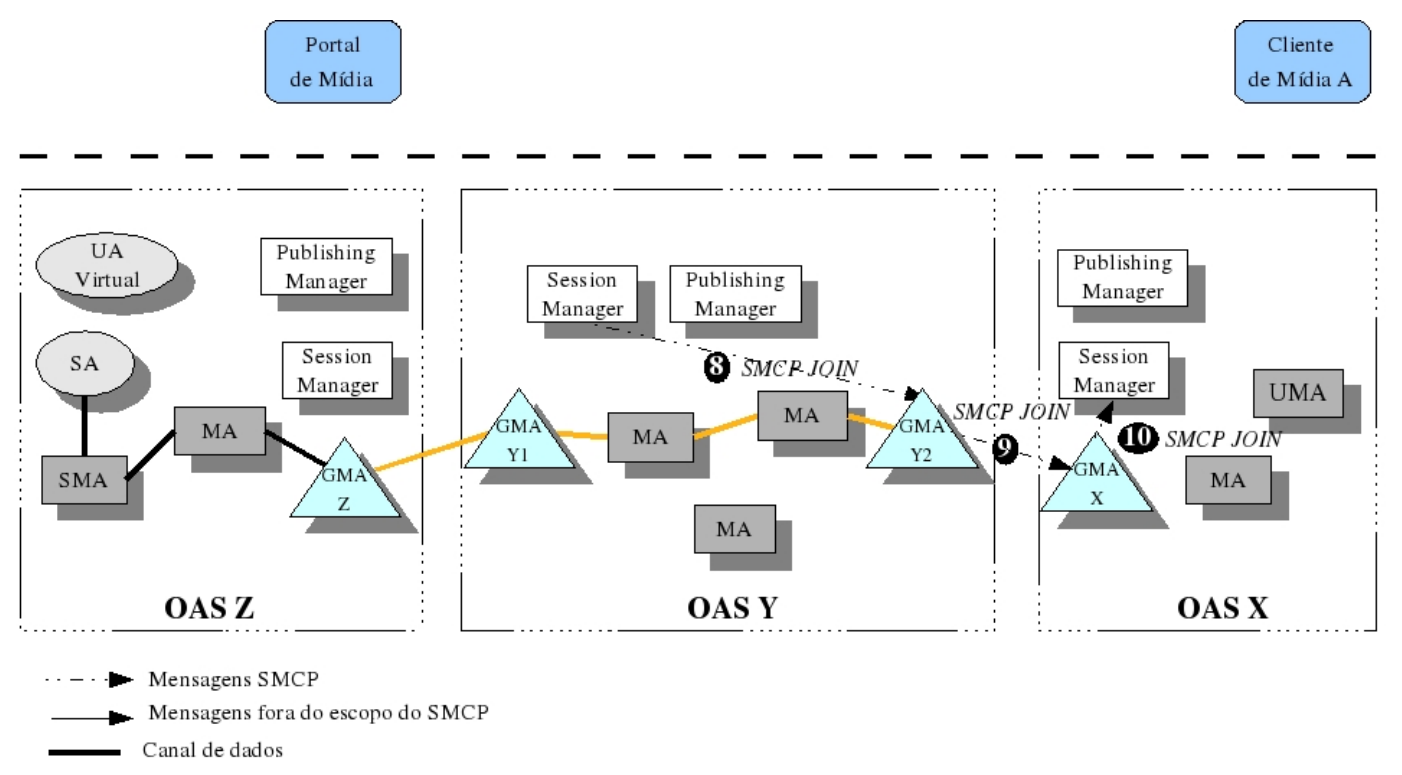

Figura 4.16: Continuação da troca de mensagens SMCP da Figura 4.15. O fluxo de dados é roteado para o OAS Y, através do qual é possível alcançar-se a máquina do Cliente A no OAS Z.

do cliente, já que este não pertence a seu OAS. No entanto, ele sabe que é possível alcançar o OAS X via OAS Y, através das informações de roteamento sumarizadas obtidas pelos gateways. Dessa forma, o Session Manager elege um GMA que fará a interconexão com o próximo OAS no fluxo de descida. Isso é feito em duas etapas. Primeiro, o GMA Z repassa no fluxo de subida a mensagem SMCP JOIN, para que ele participe da sessão. Ele então atua como se fosse o UMA do cliente, de acordo com o cenário intradomínio apresentado da Seção 4.4.2. Assim, ele monta o caminho de redirecionamento partindo da fonte do SA até ele próprio, como ilustrado na Figura 4.15 .

A interconexão entre o OAS Z e o OAS Y no fluxo de descida continua com o GMA Z contactando seu par, no AOS Y. Ele redireciona o pedido SMCP JOIN que recebeu do Session Manager para o GMA Y1, informando que uma parte da rota já foi montada, mas ainda é necessário atingir-se o dispositivo do cliente. O GMA Y1 recebe este pedido, e redireciona-o a seu Session Manager. Esta é a última parte da comunicação mostrada na Figura 4.15.

Ao receber este pedido, o Session Manager do OAS Y percebe que se trata de um cliente localizado fora de seu OAS, e que é possível alcançar o OAS $X$ através de outro GMA, o GMA Y2. Ele então redireciona o pedido SMCP JOIN para o GMA Y2, que por sua vez, solicita participação em sessão para os MAs no fluxo de subida, na direção do GMA Y1. Dentro do OAS Y, a troca de mensagens é semelhante àquela apresentada 


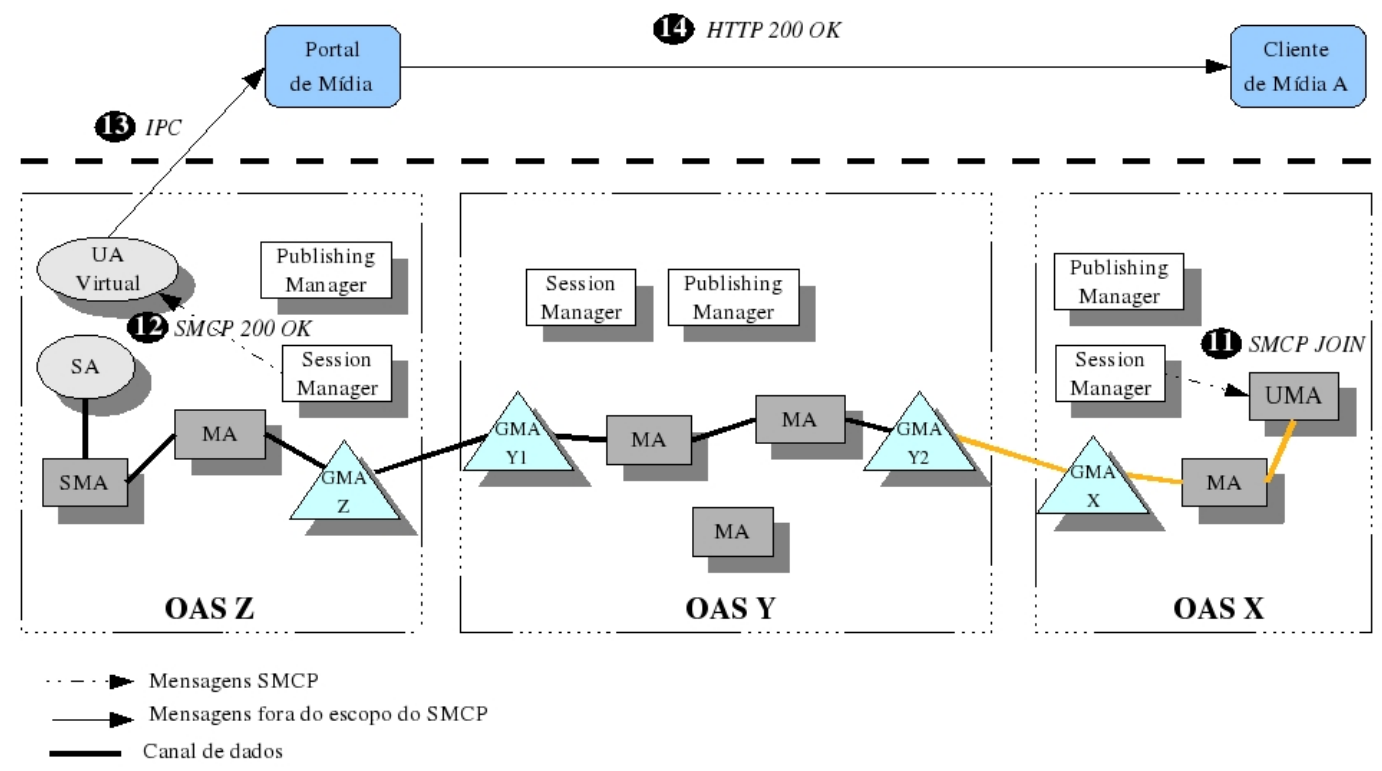

Figura 4.17: Session Manager do OAS X percebe que este cliente pertence à sua rede, e aciona um UMA representante, o qual solicita aos outros MAs participação no fluxo de subida, fechando o caminho de redirecionamento da fonte primária até o representante do cliente, interconectando os três OASs.

no cenário intradomínio da Seção 4.4.2, porém é como se o GMA Y2 fosse o UMA, e o GMA Y1 a fonte para esse pedido. Ao chegar no GMA Y1, o pedido SMCP JOIN é repassado para seu GMA par, o GMA Z. Como este já possui o fluxo, ele alimenta os outros componentes agora no sentido do fluxo de descida, até que o fluxo alcance o GMA Y2. Isto é ilustrado na Figura 4.16. Enquanto aguarda o recebimento do fluxo, o GMA Y2 lança um pedido SMCP JOIN para seu par no OAS X, o GMA X. Este, por sua vez, repassa o pedido para seu Session Manager.

Dessa vez, o Session Manager do OAS X percebe se tratar de um cliente em seu domínio, e determina um representante UMA em melhores condições para atendê-lo. O Session Manager redireciona o pedido SMCP JOIN para o UMA escolhido, incluindo na mensagem a lista de MAs que devem ser acionados até atingir-se o GMA X. Ao receber tal solicitação de um MA, o GMA X contacta seu par, dentro do OAS Y, e passa a receber o fluxo de dados e repassá-lo aos MAs ao longo do fluxo de descida dentro do OAS X, até alcançar o UMA do cliente. Este procedimento é ilustrado na Figura 4.17 .

Ao receber o fluxo, cada elemento confirma o recebimento enviando uma mensagem SMCP REGISTER para o Session Manager de seu domínio. Um resumo dessas confirmações é repassado entre os Session Managers no fluxo de subida, através dos GMAs para outros domínios, até que o Session Manager do OAS Z receba a 
confirmação de que o cliente foi encontrado, e que todo o fluxo para atendê-lo já está estabelecido. Neste momento, o Session Manager do OAS Z finalmente responde o pedido do UA Virtual com uma confirmação SMCP 200 OK. Nesta confirmação, ele repassa a lista de elementos escolhidos no caminho de redirecionamento, partindo da fonte primária da mídia até o representante UMA do cliente. O UA Virtual, através de chamadas IPC, repassa essa confirmação para o Portal de Mídias, que monta uma página Web de resposta embutindo informações para o tocador de mídia na máquina cliente. Estes são os passos 12, 13 e 14 da Figura 4.17.

O navegador do cliente recebe então essa página, repassa as informações para o tocador de mídia, o qual solicita o fluxo para o UMA determinado. Enfim, o caminho inteiro é estabelecido, e uma transmissão por multidifusão acontece utilizando-se apenas enlaces sobrepostos de unidifusão. 


\section{Validação da Proposta}

Validamos nossa proposta de middleware através de dois tipos de análise: uma análise de desempenho e uma análise funcional. Na análise de desempenho, construímos um modelo analítico capaz de comparar a multidifusão sobreposta utilizando o protocolo SMCP com a unidifusão utilizando HTTP e multidifusão nativa através do protocolo PIM-SM, e confrontamos os resultados com medidas experimentais. Já na análise funcional, construímos uma prova de conceito onde uma versão do sistema de middleware foi implantada utilizando quatro sistemas autônomos diferentes. Dados experimentais comprovam a eficácia do middleware proposto na distribuição dos fluxos. Se por um lado a análise de desempenho demonstra que a multidifusão sobreposta pode apresentar desempenho próximo da multidifusão nativa, a análise funcional prova que através da multidifusão sobreposta conseguimos implementar um cenário impraticável com a multidifusão nativa na Internet atual: a multidifusão interdomínio.

\subsection{Análise de Desempenho}

Esta análise visa a aplicação da abordagem sistemática de avaliação de desempenho de sistemas de computação e comunicação definida em (JAIN, 1991), para compararmos o desempenho do protocolo SMCP com outras estratégias. A metodologia utilizada é descrita a seguir.

\subsubsection{Objetivos e Definição do Cenário}

Nosso objetivo é analisar a capacidade de distribuição de fluxos multimídia em rede através de três estratégias de transmissão: 


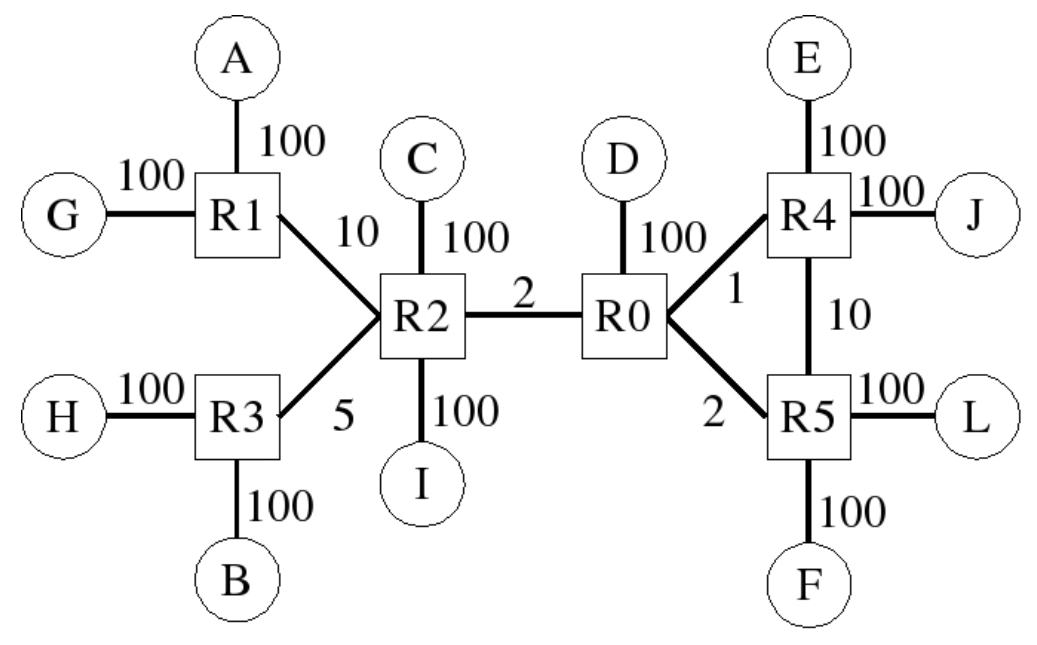

Figura 5.1: Topologia física considerada como sistema para a análise de desempenho das técnicas de distribuição de fluxos multimídia.

- Unifusão;

- Multidifusão nativa em rede;

- Multidifusão sobreposta.

Queremos analisar a qualidade da árvore de entrega construída por cada uma destas estratégicas. Para isso, consideramos como cenário de análise uma rede de computadores de longa distância (WAN - Wide Area Network), conforme ilustrado na Figura 5.1 .

Podemos identificar pela figura elementos que podem ser classificados como:

- Sistemas finais: os sistemas finais fazem parte da borda da rede, consistindo em máquinas de usuários ou provedores de serviços, como servidores, desktops, notebooks, PDAs, e etc;

- Elementos de rede: os elementos de rede formam o núcleo da rede, consistindo em roteadores, switches, firewalls, etc. Enquanto que os elementos de rede se preocupam em direcionar os pacotes através dos enlaces, a partir da fonte até seu destino, os sistemas finais dão utilidade real a estas informações trafegadas; 
- Enlaces de comunicação: os enlaces de comunicação interligam os sistemas finais com os elementos de rede, e trafegam as informações enviadas de uma ponta à outra.

A Figura 5.1 ilustra 6 roteadores geograficamente dispersos, enumerados de $R 0$ a $R 5$, como elementos de rede da nossa rede WAN. A figura mostra também 11 sistemas finais, identificados por letras de $A$ a $L$. Além disso, temos os enlaces físicos conectando estes elementos, e cuja largura de banda (BW) disponível está assinalada em Mbps.

\subsubsection{Métricas}

Na tentativa de avaliar a utilização dos recursos de forma justa em cada uma das estratégias, adotamos três métricas de desempenho propostas em (CHU et al., 2000). Além disso, este trabalho propõe uma forma de cálculo de uma métrica adicional proposta em (ROCA; EL-SAYED, 2001). Portanto, as métricas de desempenho utilizadas nesta análise são:

- Stress: número de cópias idênticas de um pacote trafegando em um enlace físico;

- Utilização de recursos: recursos de rede consumidos no processo de distribuição de conteúdo para todos os receptores;

- Penalidade de Atraso Relativo (RDP): razão do atraso entre dois membros na infraestrutura sobreposta pelo atraso utilizando uma transmissão por unidifusão tradicional;

- Tempo para o Primeiro Pacote (TFP): latência para o recebimento do primeiro pacote de dados.

A seguir discutiremos brevemente cada uma das métricas. 


\section{Stress}

A primeira métrica escolhida é o stress de um enlace, definido como o número de cópias idênticas de um pacote trafegando em um enlace físico ( $\mathrm{CHU}$ et al., 2000). Perceba que, no geral, a estratégia de unidifusão leva a um maior stress nos enlaces mais próximos da fonte quando transmite para vários usuários.

Um esquema de multidifusão sobreposta certamente consegue construir árvores de escoamento de forma mais inteligente que a árvore de unidifusão, distribuindo e equilibrando melhor o stress dos enlaces. Dessa forma, podemos não somente limitar o valor máximo de stress atingido, como também reduzí-lo nos enlaces de maior custo.

\section{Utilização dos Recursos}

Para capturar esta relação entre o stress e o custo do enlace, utilizaremos uma métrica denominada utilização dos recursos (definida como resource usage em (CHU et al., 2000)). A utilização dos recursos pode ser entendida como os recursos de rede consumidos no processo de distribuição de conteúdo para todos os receptores envolvidos. Esta métrica pode ser calculada através da seguinte fórmula:

$$
\text { Utilização dos recursos }=\sum_{i=1}^{L} d_{i} s_{i}
$$

onde $L$ é o número de enlaces ativos na transmissão dos dados, $d_{i}$ é o atraso do enlace $i$, e $s_{i}$ é o stress no enlace $i$. Note que implicitamente assumimos que enlaces com maior atraso tendem a ter um maior custo associado.

\section{Penalidade de Atraso Relativo}

O uso de sistemas finais no repasse dos dados pode melhorar a estrutura de entrega, conforme discutido anteriormente. No entanto, a inclusão de nós intermediários aumenta o atraso entre a fonte e o receptor, no esquema de multidifusão sobreposta. $O$ aumento do atraso na multidifusão sobreposta relativo à unidifusão pode ser capturado 
pela métrica Penalidade de Atraso Relativo (RDP - Relative Delay Penalty) (CHU et al., 2000). Esta métrica é calculada pela razão entre o atraso total no caminho de redirecionamento da estrutura sobreposta, e o atraso envolvido na unidifusão através de uma comunicação direta entre a fonte e receptor.

\section{Tempo para o Primeiro Pacote}

A penalidade RDP captura o aumento no atraso entre o receptor e a fonte causado pela adição de nós sobrepostos na estrutura de entrega, com relação à comunicação direta que existiria caso o esquema adotado fosse a unidifusão. Entretanto, se por um lado o esquema de multidifusão sobreposta pode aumentar o atraso fim-a-fim, ele também pode diminuir a latência do serviço caso um nó intermediário já esteja servindo um outro receptor na mesma sessão de transmissão, ou mesmo através do uso de estratégias de caching.

Dessa forma, além de capturar o atraso envolvido pela RDP, neste trabalho adotamos uma outra métrica de atraso para avaliação de soluções de multidifusão sobreposta denominada tempo para o primeiro pacote (em inglês seria TFP - Time to First Packet), proposta em (ROCA; EL-SAYED, 2001). A TFP é a latência para o recebimento do primeiro pacote de dados do conteúdo solicitado no receptor.

\subsubsection{Listagem dos Parâmetros}

Depois de definidas as métricas, vamos listar os parâmetros que afetam o desempenho do sistema. O primeiro parâmetro que tem influência direta é o custo dos enlaces.

\section{Custos}

Na Figura 5.1 apresentamos o sistema considerado, onde associado aos enlaces temos sua capacidade de transmissão nominal, em Mbps. Em vez de pensarmos nos enlaces em termos de largura de banda, podemos associar pesos que definam seus custos. Os algoritmos de roteamento escolherão caminhos nessa estrutura em razão 


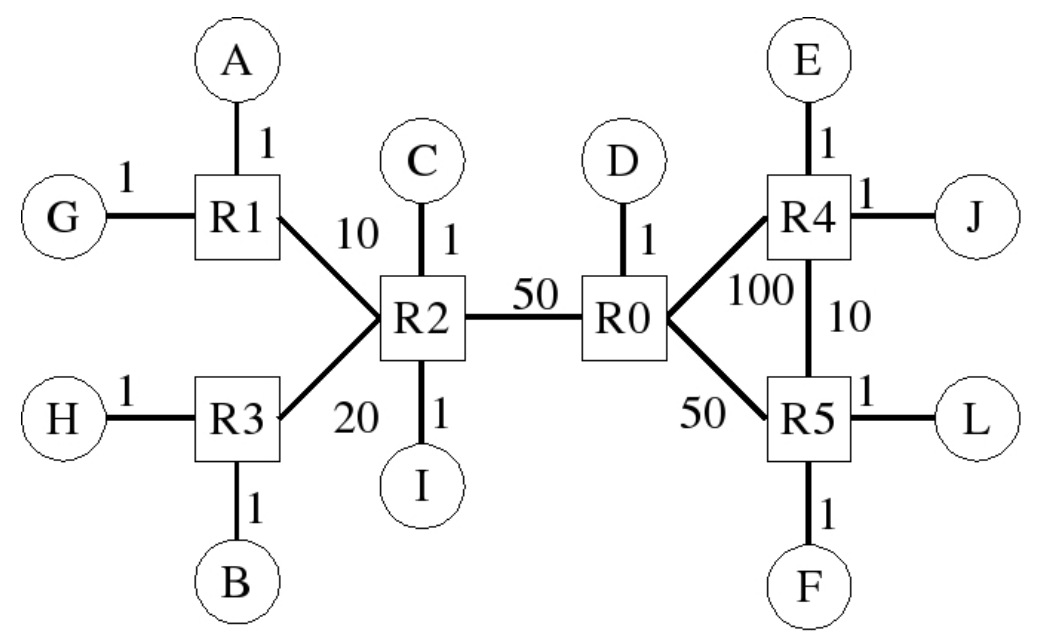

Figura 5.2: Topologia física considerada apresentando o custo como peso dos enlaces.

dos custos do enlace, buscando sempre os caminhos mais curtos, independente da estratégia de comunicação adotada.

Vamos então definir os custos com base na largura de banda disponível, através da seguinte regra ${ }^{1}$ :

$$
\text { Custo }=\frac{1}{B W} 100 \mathrm{Mbps}
$$

onde $B W$ representa a largura de banda nominal de cada enlace.

Através dessa transformação, obtemos uma outra visão da topologia da rede considerada, como mostra a Figura 5.2. Observe que, pelos pesos, este cenário considera que os enlaces $<R 1, R 2>\mathrm{e}<R 2, R 3>$ são enlaces de média distância, interligando países, por exemplo, enquanto que os pesos dos enlaces $\langle R 0, R 2\rangle,\langle R 0, R 4\rangle \mathrm{e}$ $<R 0, R 5>$ representam enlaces transcontinentais. Todos os outros enlaces são enlaces locais de baixo custo.

\footnotetext{
${ }^{1}$ Fórmula normalmente usada para se calcular o custo no protocolo OSPF (MOY, 1998), como pode ser visto em http://www.cisco.com/en/US/tech/tk365/technologies_white_paper09186a0080094e9e.shtml
} 


\section{Protocolos}

Outro parâmetro que tem grande influência na análise do desempenho é o protocolo utilizado. Vamos adotar os seguintes protocolos: HTTP (Hypertext Transfer Protocol) (FIELDING et al., 1999) no caso da unidifusão, SMCP (proposto no Capítulo 4) para multidifusão sobreposta, e o PIM-SM (Protocol Independent Multicast - Sparse Mode) (FENNER et al., 2006) para a multidifusão nativa em rede.

Perceba que tratamos de protocolos em diferentes camadas, e assim as estratégias serão analisadas em nível de pacote. Note que no caso da unidifusão, as mensagens HTTP serão transportadas pelo protocolo TCP (Transmission Control Protocol) (University of Southern California, 1981), o qual inerentemente já apresenta baixo desempenho quando comparado ao UDP (User Datagram Protocol) (HASSAN; JAIN, 2004). Apesar das mensagens SMCP poderem ser transportadas pelo protocolo UDP, vamos considerar nessa análise o pior caso, ou seja, o transporte das mensagens SMCP através do protocolo TCP.

A escolha do PIM-SM, ao invés do uso do PIM-DM (Protocol Independent Multicast - Dense Mode) (ADAMS et al., 2005), deve-se ao cenário considerado. Queremos atender os clientes à medida que estes solicitem expressamente a recepção dos conteúdos. Não queremos já inundar a rede antes de haver demanda por determinado conteúdo, como faz o PIM-DM, visto que estamos considerando uma rede de longa distância (WAN).

Além dos protocolos citados, todas as estratégias utilizarão implicitamente um roteamento por unidifusão baseado no protocolo OSPF (Open Shortest Path First) (MOY, 1998), onde os custos dos enlaces são considerados conforme a Figura 5.2.

\section{Fonte e Número de Receptores}

Um parâmetro que certamente influencia no cálculo das métricas é a localização da fonte de transmissão, e o número de receptores envolvidos. Nesse caso, consideramos que o sistema final $G$ atua como fonte de mídia, transmitindo os fluxos para todos os outros sistemas finais (com exceção do sistema final $I$ ), os quais atuam como receptores de mídia. Dessa forma, teremos uma fonte e nove receptores em uma mesma transmissão. 


\section{Posicionamento do RP}

O posicionamento do Rendevouz Point (RP), nas estratégias de multidifusão, também apresenta influência direta nos resultados. No caso da multidifusão nativa, o RP é um roteador, e nesse caso estamos considerando o roteador $R 2$, devido a sua localização central, otimizando a eficiência na entrega dos fluxos. No caso da multidifusão sobreposta, o RP é um sistema final especialmente dedicado, e neste caso escolhemos o sistema final I para hospedá-lo.

\section{Provisão dos MAs}

No caso da multidifusão sobreposta, um parâmetro de interesse é a definição dos agentes de multidifusão (MAs). Para melhor refletir a topologia física, vamos considerar seis nós de serviço hospedando os MAs na topologia sobreposta: os nós $A, B, C$, $D, E$, e $F$.

\subsubsection{Técnica de Avalilação e Carga de Trabalho}

\section{Técnica de Avaliação}

A respeito da técnica de avalição, existem três possibilidades:

- Modelagem analítica: criação de um modelo matemático com aproximações simplificadoras do sistema real.

- Simulação: criação de um modelo computacional capaz de representar o comportamento de interesse do sistema real.

- Medição em um sistema real: projeto de medições em uma implementação real do sistema.

Nesta análise, adotamos a técnica de modelagem analítica, devido a facilidade de comparação entre as alternativas envolvidas, e avaliamos os resultados obtidos através de medições em sistema real. 


\section{Seleção da Carga de Trabalho}

Inicialmente, consideramos o sistema sem carga, ou seja, sem nenhuma transmissão em curso. Depois, para cada alternativa de comunicação analisada (unidifusão, multidifusão nativa em rede e multidifusão sobreposta), os sistemas finais lançam, um a um, suas solicitações pelo conteúdo seguindo uma distribuição de probabilidade uniformemente distribuída entre os números inteiros de 1 a 9 . Cada número sorteado é mapeado em uma das letras que representam os sistemas finais da Figura 5.2.

\subsubsection{Projeto do Experimento}

O experimento consiste em construir a árvore de caminho mais curto (SPT) da fonte para todos os receptores, de acordo com o algoritmo de roteamento OSPF, utilizando como regra de definição dos custos dos enlaces a Equação 5.2 (ver Figura 5.2). Após a definição das rotas de unidifusão, escolhe-se aleatoriamente a ordem de sequência do lançamento das solicitações pela mídia por cada um dos receptores. A forma de solicitação da mídia, e os procedimentos para sua recepção, serão diferentes para cada uma das estratégias adotadas.

As métricas stress, utilização dos recursos e penalidade de atraso relativo são avaliadas após todos os receptores começarem a receber os fluxos de mídia, e assim não são influenciadas pela ordem na qual os clientes lançam seu pedidos, o que reflete a ordem com a qual os clientes são atendidos. Já o tempo para o primeiro pacote (TFP), tanto na multidifusão nativa em rede como na multidifusão sobreposta, é influenciado pelo sorteio da ordem de laçamento dos pedidos. Pela própria construção da estrutura de entrega de dados, fica claro que quanto mais longe da fonte maior será o TFP dos receptores.

A seguir, descrevemos os procedimentos realizadas em cada uma das estratégias consideradas. 


\section{Entrega de Dados por Unidifusão}

No caso da unidifusão dos fluxos, antes de se lançar o pedido uma conexão TCP entre o receptor e a fonte precisa ser estabelecida. O caminho utilizado para o estabelecimento da conexão segue o caminho mais curto definido pelo OSPF. Após a configuração da conexão, o receptor envia uma mensagem GET HTTP para a fonte, a qual responde já com a primeira parcela da mídia.

O tempo para o primeiro pacote (TFP) é calculado considerando-se o tempo decorrido desde o laçamento da mensagem GET HTTP até o recebimento do primeiro pacote de dados. Cada receptor, respeitando a ordem de sequência definida, solicitará uma cópia da mesma mídia. Após todos estarem recebendo suas cópias dos fluxos, as outras métricas serão avaliadas.

\section{Entrega de Dados por Multidifusão Nativa em Rede}

Na multidifusão nativa em rede, o processo de construção da estrutura de entrega, através do protocolo PIM-SM, pode ser dividido em três fases (EDWARDS et al., 2002), as quais são discutidas a seguir.

\section{Fase 1: Construção da Estrutura de Entrega do RP até os Receptores Antes} de começar a receber o fluxo por multidifusão, o receptor precisa solicitar participação no grupo através do envio de uma mensagem IGMP ${ }^{2}$ Report para seu roteador diretamente conectado. Tal envio dispara na rede um evento para a construção da árvore de caminho reverso (RPT - Reverse Path Tree). A RPT é uma estrutura de entrega dos pacotes semelhante à árvore SPT (ver Seção 2.3), porém enraizada no RP, e não na fonte. Dessa forma, a árvore RPT define apenas uma parte do caminho entre a fonte e o receptor. O processo de construção da árvore RPT é similar ao da árvore SPT, já descrito anteriormente.

\footnotetext{
${ }^{2}$ O Internet Group Management Protocol (IGMP) (FENNER, 1997) é o protocolo utilizado por um sistema final para indicar ao seu roteador de multidifusão adjacente o desejo de participar ou sair de um grupo de multidifusão.
} 
Fase 2: Construção da Estrutura de Entrega da Fonte até o RP Uma vez construída a RPT, precisamos ainda de uma árvore SPT que conecte a fonte ao RP. A construção dessa árvore começa quando a fonte primária de mídia inicia a transmissão dos pacotes de dados para o endereço de grupo que identifica a sessão (um endereço IP classe D). O roteador diretamente conectado na rede local dessa fonte reconhece estes pacotes como sendo os primeiros dados recebidos a partir dessa fonte para esse grupo, já que até este momento ele não mantinha nenhum estado que relacionava estas informações.

O roteador então cria este estado e adiciona esta interface de chegada como a interface para o par fonte-grupo. Então ele lança uma mensagem PIM Register por unidifusão até o RP, a qual já contém os pacotes de dados encapsulados. O roteador continua enviando para o RP uma mensagem PIM Register separada para cada pacote de dados que ele recebe da fonte de mídia, até que ele receba do RP uma mensagem PIM Register-Stop.

O RP recebe cada mensagem PIM Register, desencapsula os pacotes de dados, e os repassa no fluxo de descida utilizando a RPT construída na fase 1. Para receber estes dados de forma nativa no fluxo de descida da SPT, o RP precisa enviar uma mensagem PIM Join no fluxo de subida através de seu vizinho RPF para a fonte de mídia. Os próximos roteadores no fluxo de subida vão repassando a mensagem PIM Join e adicionando as interfaces na lista OIL. Quando esta mensagem atinge o roteador diretamente conectado na rede da fonte, este por sua vez adiciona a interface no sentido do RP em sua lista OIL para o par fonte-grupo.

Neste momento, cada pacote enviado a partir da fonte de mídia para o endereço do grupo considerado é duas vezes enviado para o RP. Uma cópia vai encapsulada na mensagem PIM Register e outra é diretamente enviada para a interface na lista OIL. Quando o RP começar a receber os dados de forma nativa, ele então envia para o roteador ligado à rede da fonte uma mensagem PIM Register-Stop. Ao receber esta mensagem, o roteador ligado à fonte remove a interface virtual formada pelo encapsulamento dos dados nas mensagens PIM Register de sua lista OIL, e continua repassando os pacotes somente através da SPT, cessando a comunicação direta por unidifusão com o RP.

Fase 3: Construção da Estrutura de Entrega Diretamente da Fonte até os Receptores $O$ caminho estabelecido entre a fonte e os receptores nas fases 1 e 2 ainda 
não é ótimo, visto que necessariamente precisamos passar pelo RP. Portanto, a fase 3 na construção da estrutura de entrega do PIM-SM cria uma árvore SPT ótima a partir das duas árvores anteriores.

A partir da recepção do primeiro pacote de dados via RPT, o roteador diretamente conectado à rede do cliente passa a ter o conhecimento sobre a fonte de transmissão, e pode agora iniciar uma busca RPF pela fonte. Uma vez identificada a interface RPF, este roteador lança no fluxo de subida uma mensagem PIM Join. O roteador anexado à rede da fonte adiciona a interface por onde recebeu esta mensagem PIM Join na sua lista OIL para o par fonte-grupo. Assim, o receptor começará a receber os pacotes em duplicatas: uma cópia diretamente via a SPT recém construída, e outra via a RPT da fase 1.

Quando o roteador designado do cliente receber o primeiro pacote através da SPT, ele envia uma mensagem PIM Prune através de seu vizinho RPF para o RP, para cancelar a transmissão via RPT, passando a receber novamente apenas um fluxo de dados via SPT. Á medida que não atendam mais clientes, os roteadores no fluxo de subida da RPT vão se desligando dessa transmissão, até que o RP também deixe de participar do grupo.

Para cada receptor, o tempo para o primeiro pacote (TFP) é calculado considerando-se o tempo decorrido desde o laçamento da mensagem IGMP Register até o recebimento do primeiro pacote de dados. Todo o processo aqui descrito se repetirá para cada receptor, seguindo a sequência definida, até que todos participem da mesma sessão. A partir desse momomento, as outras métricas são avaliadas.

\section{Entrega de Dados por Multidifusão Sobreposta}

Na multidifusão sobreposta utilizaremos o protocolo SMCP, descrito no Capítulo 4. O provisionamento da rede sobreposta se dá conforme apresentado na Figura 5.5, onde o sistema final $I$ hospeda o RP, e os sistemas finais $A, B, C, D, E$, e $F$ hospedam os agentes de multidifusão (MAs). Supomos que nosso RP ganha conhecimento sobre a topologia da rede através de uma ferramenta gráfica, configurada pelo administrador do sistema.

Os receptores, um de cada vez, e respeitando sua ordem de sorteio, lançam pedi- 
dos de participação em sessão de transmissão para o RP, o qual é composto tanto pelo Session Manager quanto pelo Publishing Manager, entidades do SMCP. Através desses pedidos, e seguindo a sequência de mensagens descrita na Seção 4.4.2, o Session Manager constrói uma árvore de escoamento sobreposta como estrutura de controle.

Os receptores são então instruídos a redirecionar o pedido de participação em sessão para o MA mais próximo, o qual repassa o pedido no fluxo de subida seguindo a estrutura de controle criada pelo Session Manager, até atingir um MA que já possua os fluxos solicitados ou até se alcançar a fonte de mídia. A estrutura de entrega de dados é então construída no sentido contrário, no fluxo de descida, até que os receptores ganhem acesso aos fluxos.

O TFP é calculado a partir do laçamento da mensagem SMCP JOIN do User Agent hospedado no receptor para o Publishing Manager no RP, até o recebimento da primeira parcela da mídia recebida através do MA mais próximo. As outras métricas são consideradas depois que todos os participantes forem adicionados à sessão, e já estiverem recebendo os fluxos.

\subsubsection{Análise e Interpretação dos Dados}

Nesta seção, aplicando os procedimentos descritos nas etapas anteriores da metodologia adotada, vamos analisar e interpretar os dados obtidos. A análise será realizada sobre o sistema apresentado na Figura 5.2, considerando cada uma das métricas citadas na Seção 5.1.2. Para cada métrica, analisamos a estratégia de comunicação de dados: (i) por unidifusão; (ii) por multidifusão nativa em rede; (iii) e por multidifusão sobreposta.

\section{Stress}

No caso da entrega por unidifusão, seguindo os procedimentos descritos na Seção 5.1.5, após todos os receptores estarem recebendo cópias dos mesmos fluxos, a situação de stress nos enlaces é aquela apresentada na Figura 5.3. Cada seta representa uma cópia da mídia sendo transmitida pelo enlace. Os números sobre as setas indicam o valor do stress em cada enlace. 
O resultado apresentado foi obtido calculando-se os saltos dados na camada de rede pelos pacotes que transportam os segmentos das conexões TCP estabelecidas entre cada receptor e a fonte. Através da aplicação do algoritmo OSPF na topologia de rede apresentada na Figura 5.2, é possível montar uma tabela de roteamento para cada um dos roteadores apresentados, e assim reconstruir as rotas seguidas pelos pacotes. Sobrepondo-se as rotas dos pacotes para todos os receptores, e contandose o número de cópias, consegue-se montar a Figura 5.3.

Observe que os fluxos vindo do roteador $R 0$, em direção aos nós $E, F, J$ e $L$, não são balanceados entre os roteadores $R 4$ e $R 5$, sendo todos direcionados apenas ao roteador $R 5$. Posteriormente, o roteador $R 5$ repassa para o roteador $R 4$ os pacotes direcionados aos sistemas finais $E$ e $J$. Neste caso, um salto a mais foi realizado por cada pacote endereçado aos nós $E$ e $J$. Esta decisão do OSPF deve-se à diferença entre os custos dos enlaces $\langle R 0, R 4\rangle \mathrm{e}\langle R 0, R 5\rangle$, tendo este último metade do custo do primeiro. Como as outras estratégias de comunicação assumem o mesmo roteamento OSPF por unidifusão, este mesmo comportamento se repetirá em cada estratégia.

Vamos agora analisar a situação de stress nos enlaces para o caso de uma transmissão por multidifusão nativa em rede. Seguindo os procedimentos descritos na Seção 5.1.5, e atuando de forma semelhante ao caso apresentado anteriormente, o stress nos enlaces pode ser visualizado conforme Figura 5.4.

Perceba que todos os enlaces apresentam o menor valor de stress possível, ou seja, 1 (um). Nesse caso, temos a máxima eficiência, o que intuitivamente já estava previsto pela própria definição da métrica.

Procedendo de forma similar, porém aplicando a técnica de multidifusão sobreposta descrita na Seção 5.1.5, chegamos a uma situação intermediária, conforme apresentado na Figura 5.5. Veja que não conseguimos uma eficiência tão boa quanto na multidifusão nativa em rede, no entanto, conseguimos distribuir de uma forma bem mais inteligente o stress dos enlaces quando comparado ao caso da unidifusão.

Resultados No caso da unidifusão, os enlaces próximos à fonte ficam completamente sobrecarregados (como mostra a Figura 5.3), e pior, um alto valor de stress é repassado aos enlaces $\langle R 0, R 2>\mathrm{e}<R 0, R 5>$, que são os de mais alto custo no sistema (apenas abaixo do enlace $<R 0, R 4>$, o qual não foi utilizado por nenhuma 


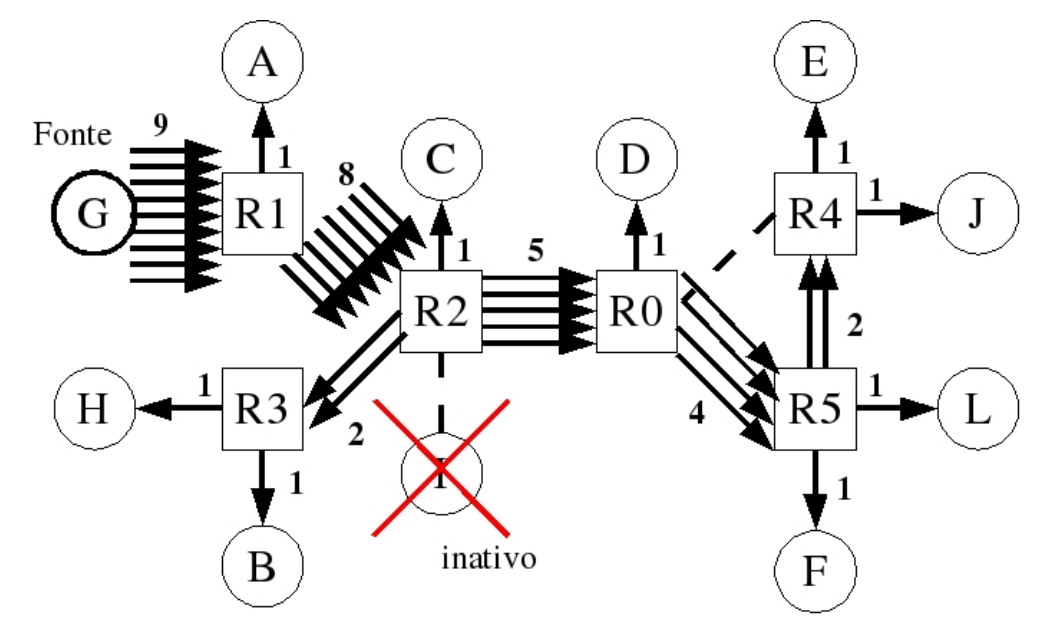

Figura 5.3: Stress nos enlaces utilizando um entrega de dados por unidifusão.

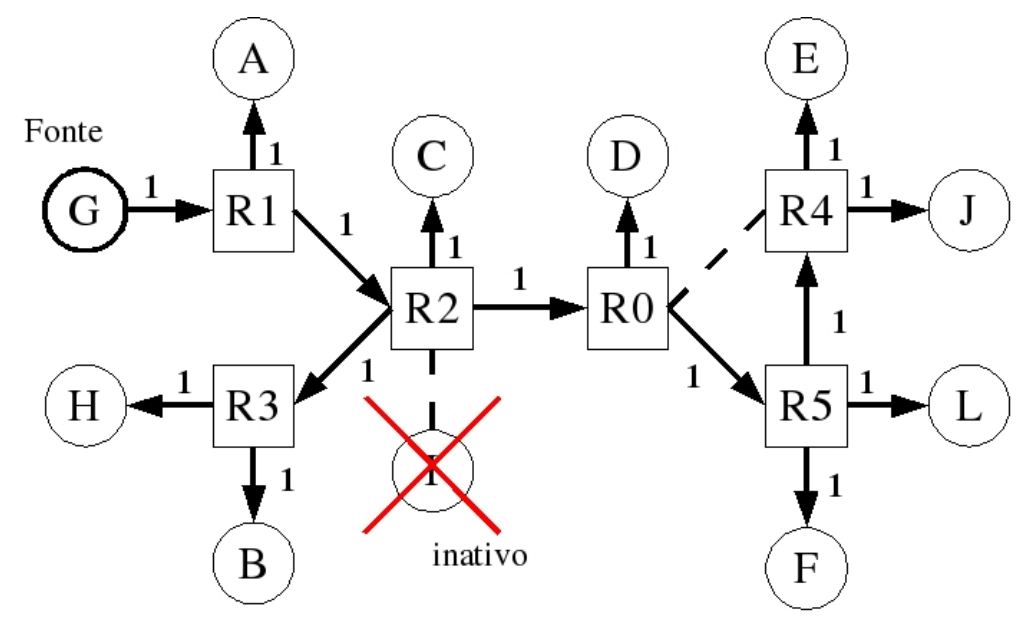

Figura 5.4: Stress nos enlaces utilizando um entrega de dados por multidifusão nativa em rede.

das estratégias).

Contrariamente, o resultado para a multidifusão sobreposta (ver Figura 5.5) mostra um valor de stress ideal (ou seja, apenas um fluxo) para todos os enlaces de alto custo, apresentando uma eficiência comparável àquela apresentada pela multidifusão nativa em rede considerando apenas estes enlaces.

Quando ampliamos a análise também para os enlaces locais de baixo custo (todos os de custo 1 na Figura 5.2), o stress apresentado pela multidifusão sobreposta fica pouco acima do ideal, que seria o caso da multidifusão nativa em rede apresentado na Figura $5.4^{3}$. Porém, veja que o stress máximo é controlado, não ultrapassando o valor 3 (alcançado nos enlaces $\langle R 2, C>\mathrm{e}<R 5, F>$ na Figura 5.5).

\footnotetext{
${ }^{3}$ Observe que após a fase 3 da construção PIM-SM descrita anteriormente, os enlaces $\langle G, R 1\rangle$, $<R 1, A>\mathrm{e}<R 1, R 2>$ não carregam pacotes duplicados.
} 


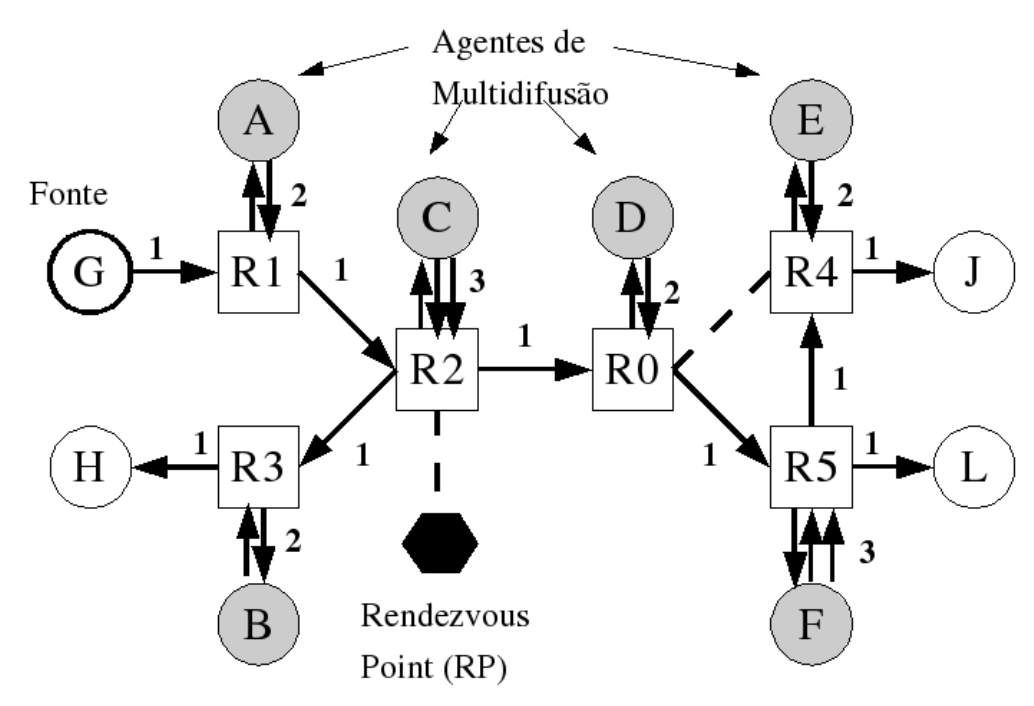

Figura 5.5: Stress nos enlaces utilizando um entrega de dados por multidifusão sobreposta.

Validação A topologia da Figura 5.2 foi montada no laboratório didático de redes de computadores do Departamento de Engenharia da Computação e Sistemas Digitais (PCS) da Escola Politécnica da USP (EPUSP) (ver detalhes de configuração na Figura 5.6). Os custos dos enlaces foram obtidos por configuração nos roteadores através de limitações de banda nas interfaces.

Os procedimentos descritos na Seção 5.1.5 foram realizados considerando uma transmissão de vídeo ao vivo. Para o caso da unidifusão, o software VideoLAN ${ }^{4}$ foi utilizado tanto como fonte de mídia quanto como receptor, e configurado para transmissão via HTTP. Para o caso da multidifusão nativa em rede, configuramos os roteadores com o protocolo PIM-SM habilitado, e o VideoLAN para transmissão por multidifusão. No caso da multidifusão sobreposta, o sistema de middleware desenvolvido (ver detaIhes em (UCHôA et al., 2007) e (UCHôA; SILVEIRA, 2007)) foi implantado na rede do laboratório, conforme o cenário considerado.

Após a solicitação de todos os clientes, em cada caso da análise, as situações de stress das Figuras 5.3, 5.4 e 5.5 foram confirmadas.

\footnotetext{
${ }^{4}$ http://www.videolan.org/.
} 


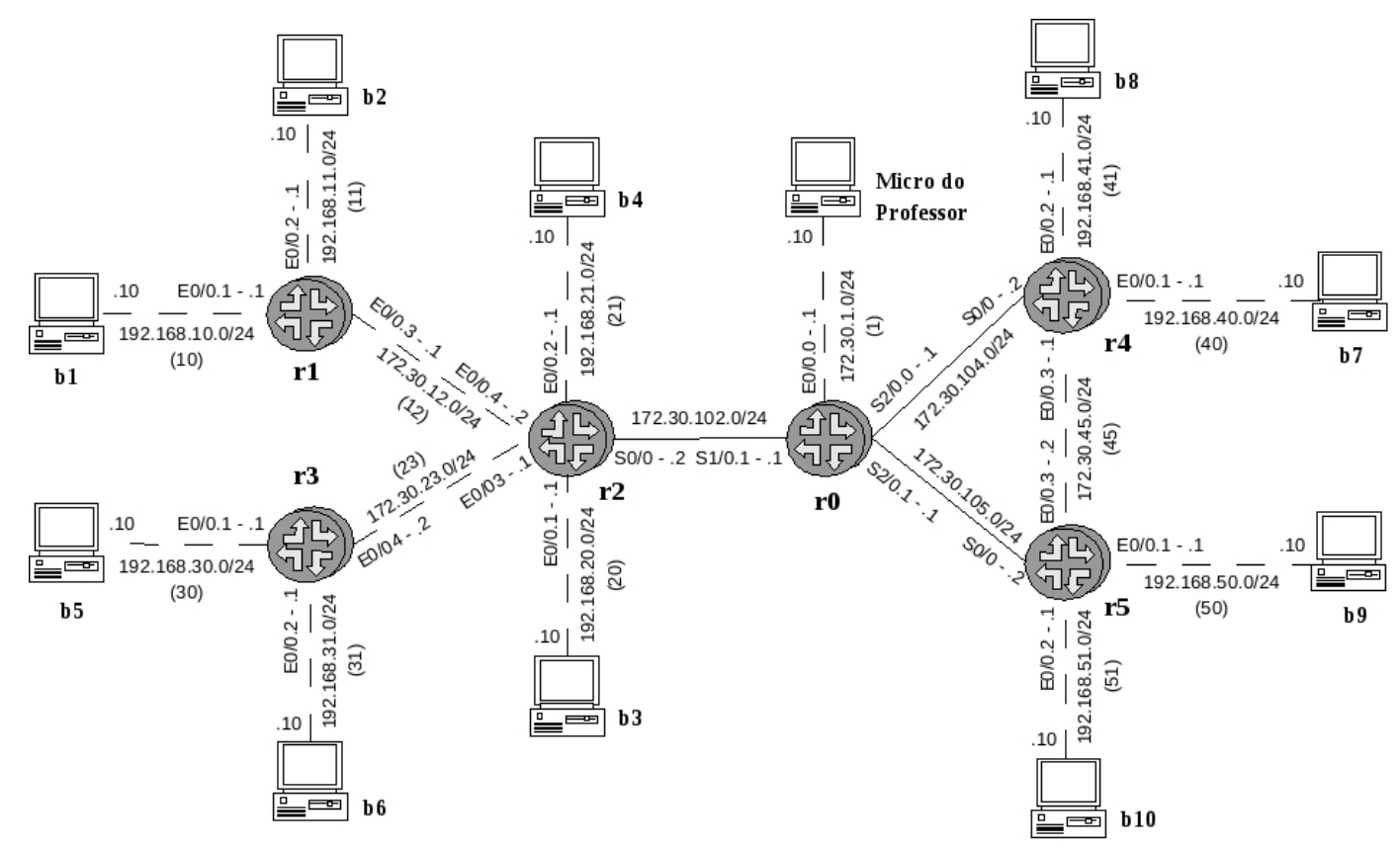

Figura 5.6: Topologia física detalhada configurada em laboratório didático para realização de medições experimentais.

\section{Utilização dos Recursos}

A métrica utilização de recursos, através da Equação 5.1, é capaz de quantizar o resultado da atribuição de valores de stress quando se considera o custo dos enlaces. Dessa forma, podemos calcular a utilização total de recursos da rede para cada uma das estratégias de comunicação de dados analisada. Como forma de facilitar os cálculos, agrupamos os valores obtidos na Tabela 5.1.

A tabela lista todos os enlaces físicos, e apresenta a largura de banda e custo de cada enlace. Além disso, a quarta coluna apresenta o valor de stress encontrado em cada um dos enlaces para o caso da unidifusão, e a quinta coluna faz o mesmo para o caso da multidifusão sobreposta. Os valores de stress para o caso da multidifusão nativa em rede foram omitidos, já que todos os enlaces apresentam o mesmo valor 1.

A última linha na Tabela 5.1 apresenta o resultado do cálculo da utilização de recursos para cada um dos casos. A princípio, o último valor da coluna 3 seria apenas a soma de todos os custos, no entanto, como os valores de stress para a multidifusão nativa em rede são todos iguais a 1 , este cálculo na verdade representa sua utilização de recursos. O último valor da coluna 4 foi obtido somando-se todos os resultados da multiplicação entre o valor de stress de cada enlace (coluna 4) com seu respectivo custo (coluna 3), para o caso da unidifusão. Ou seja, é a aplicação direta da fórmula 


\begin{tabular}{|c|c|c|c|c|}
\hline Enlace Físico & Banda & Custo & Stress $_{u}$ & Stress $_{o}$ \\
\hline \hline$<\mathrm{G}, \mathrm{R} 1>$ & 100 & 1 & 9 & 1 \\
\hline$<\mathrm{R} 1, \mathrm{R} 2>$ & 10 & 10 & 8 & 1 \\
\hline$<\mathrm{R} 2, \mathrm{R} 0>$ & 2 & 50 & 5 & 1 \\
\hline$<\mathrm{R} 2, \mathrm{R} 3>$ & 5 & 20 & 2 & 1 \\
\hline$<\mathrm{R} 0, \mathrm{R} 5>$ & 2 & 50 & 4 & 1 \\
\hline$<\mathrm{R} 0, \mathrm{R} 4>$ & 1 & 100 & 0 & 0 \\
\hline$<\mathrm{R} 4, \mathrm{R} 5>$ & 10 & 10 & 2 & 1 \\
\hline$<\mathrm{R} 1, \mathrm{~A}>$ & 100 & 1 & 1 & 2 \\
\hline$<\mathrm{R} 2, \mathrm{l}>$ & 100 & 1 & 0 & 0 \\
\hline$<\mathrm{R} 2, \mathrm{C}>$ & 100 & 1 & 1 & 3 \\
\hline$<\mathrm{R} 0, \mathrm{D}>$ & 100 & 1 & 1 & 2 \\
\hline$<\mathrm{R} 3, \mathrm{H}>$ & 100 & 1 & 1 & 1 \\
\hline$<\mathrm{R} 3, \mathrm{~B}>$ & 100 & 1 & 1 & 2 \\
\hline$<\mathrm{R} 5, \mathrm{~L}>$ & 100 & 1 & 1 & 1 \\
\hline$<\mathrm{R} 5, \mathrm{~F}>$ & 100 & 1 & 1 & 3 \\
\hline$<\mathrm{R} 4, \mathrm{~J}>$ & 100 & 1 & 1 & 1 \\
\hline$<\mathrm{R} 4, \mathrm{E}>$ & 100 & 1 & 1 & 2 \\
\hline \hline Utilização de Recursos & 150 & 608 & 158 \\
\hline
\end{tabular}

Tabela 5.1: A Tabela reúne valores de stress com o custo de cada enlace do sistema, tanto para a unidifusão (subíndice $u$ ) quanto para a multidifusão sobreposta (subíndice o), e por fim apresenta o resultado do cálculo da utilização de recursos. Observe que a soma dos custos representa a utilização de recursos da multidifusão nativa em rede, já que todos os seus enlaces apresentam um valor de stress igual a 1.

da Equação 5.1, e representa a utilização dos recursos empregados na unidifusão. De forma similar, o último valor da coluna 5 representa a utilização dos recursos empregados na multidifusão sobreposta.

Resultados Observe através da Tabela 5.1 que, enquanto a unidifusão apresenta uma utilização de recursos mais que 4 vezes maior que o caso ideal, ou seja, do que a multidifusão nativa em rede, a diferença entre a utilização de recursos da multidifusão sobreposta para o caso ideal é praticamente desprezível, representando apenas um acréscimo da ordem de $5 \%$.

\section{Penalidade de Atraso Relativo (RDP)}

Observamos até aqui que a inclusão estratégica de nós intermediários pela multidifusão sobreposta melhora bastante o desempenho das métricas de stress e utilização dos recursos, em comparação com os mesmos valores obtidos pela estratégia de unidifusão.

Entretanto, essa melhor distribuição é alcançada através da construção de uma estrutura de entrega em nível de aplicação, a qual provoca uma alteração no caminho 


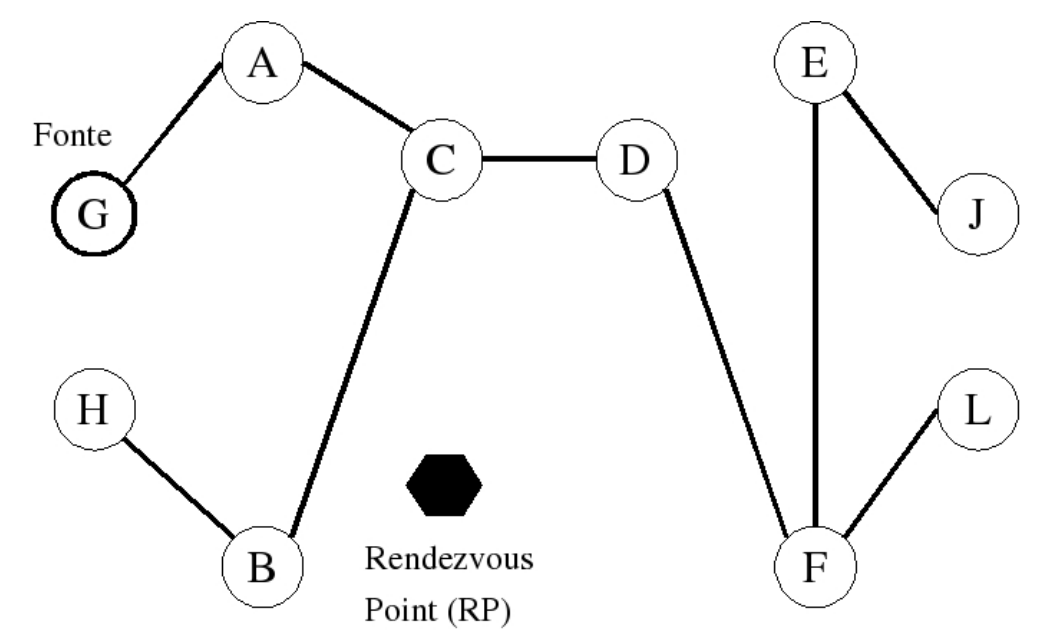

Figura 5.7: Árvore de escoamento sobreposta construída pelo SMCP.

natural que seria assumido apenas com a estratégia de unidifusão, da fonte ao receptor. Essa mudança no caminho de redirecionamento, passando agora por pontos mediadores, pode aumentar o custo total do caminho seguido, em comparação com o custo no caminho direto experimentado pela unidifusão.

Conseguimos capturar e avaliar este efeito em nosso sistema através da métrica $\mathrm{Pe}$ nalidade de Atraso Relativo (RDP). Para calculá-la, precisamos analisar os enlaces sobrepostos construídos pelo protocolo SMCP na estratégia de multidifusão sobreposta, e calcular os seus custos reconstruindo o caminho seguido em nível de rede, na topologia física. Dessa forma, definimos o custo do enlace sobreposto como a soma dos custos individuais dos enlaces físicos que o compõe.

A árvore de escoamento sobreposta construída pelo SMCP para este sistema é apresentada na Figura 5.7. Perceba que estes enlaces sobrepostos podem ser decompostos em seus enlaces físicos constituintes. Uma forma de se visualizar isso seria sobrepor a árvore de escoamento da Figura 5.7 sobre o cenário da transmissão por multidifusão sobreposta da Figura 5.5. Seguindo esta idéia, construímos a Figura 5.8, onde ilustramos os enlaces sobrepostos e seus enlaces físicos constituintes.

Dessa forma, conseguimos visualizar que o enlace sobreposto $\langle G, A>$ é na verdade constituído pelos enlaces físicos $\langle G, R 1>\mathrm{e}\langle R 1, A\rangle$, por exemplo. Neste caso, o custo do enlace sobreposto é calculado somando-se os custos dos enlaces físicos constituintes, o que resultaria em $2^{5}$. Um outro exemplo é o enlace sobreposto <

\footnotetext{
${ }^{5}$ Não confundir os números que aparecem sobre as setas da Figura 5.8 com o custo dos enlaces físicos. Lembre que este número na verdade representa o stress em cada enlace. Todos os custos dos enlaces físicos foram listados na Tabela 5.1
} 


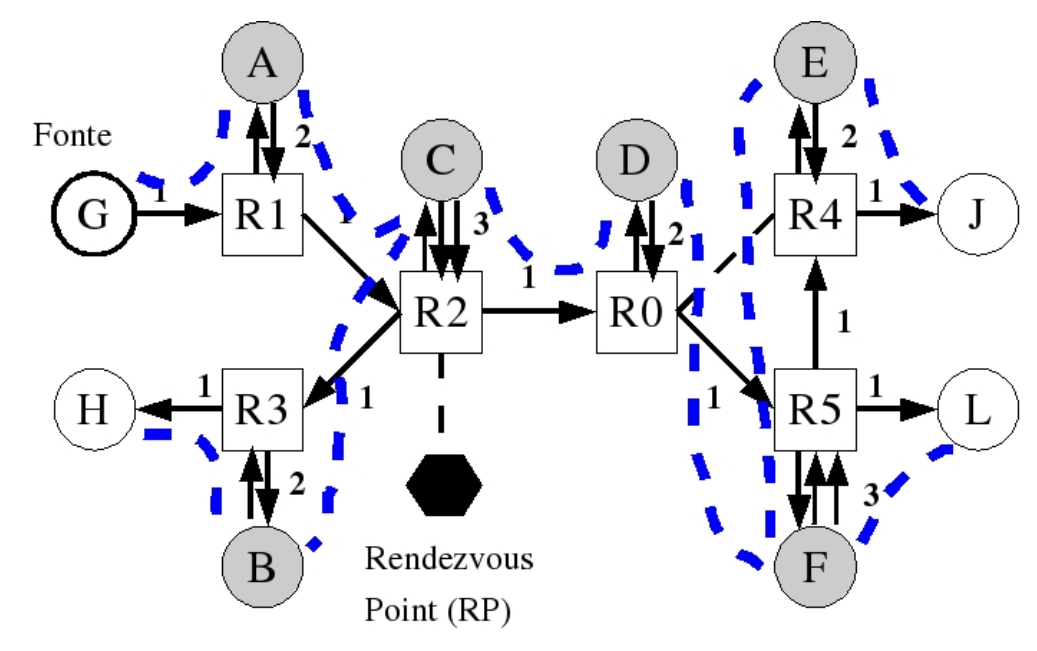

Figura 5.8: Árvore de escoamento evidenciando os enlaces sobrepostos como uma composição de um ou mais enlaces físicos.

$F, E>$, o qual é composto pelos enlaces físicos $\langle F, R 5>,\langle R 5, R 4>\mathrm{e}\langle R 4, E\rangle$, e apresenta um custo de 12. Procedendo de maneira semelhante para todos os enlaces sobrepostos, reunimos seus custos na Tabela 5.2.

\begin{tabular}{|c|c|}
\hline Enlace Sobreposto & Custo \\
\hline \hline$<\mathrm{G}, \mathrm{A}>$ & 2 \\
\hline$<\mathrm{A}, \mathrm{C}>$ & 12 \\
\hline$<\mathrm{C}, \mathrm{B}>$ & 22 \\
\hline$<\mathrm{B}, \mathrm{H}\rangle$ & 2 \\
\hline$<\mathrm{C}, \mathrm{D}>$ & 52 \\
\hline$<\mathrm{D}, \mathrm{F}>$ & 52 \\
\hline$<\mathrm{F}, \mathrm{L}>$ & 2 \\
\hline$<\mathrm{F}, \mathrm{E}>$ & 12 \\
\hline$<\mathrm{E}, \mathrm{J}>$ & 2 \\
\hline
\end{tabular}

Tabela 5.2: Custo de todos os enlaces sobrepostos da Figura 5.8.

Além dos custos dos enlaces sobrepostos, para calcular a RDP precisamos somar o custo total dos caminhos diretos entre a fonte e cada receptor. Tal custo também é calculado pela soma dos componentes individuais de custo dos enlaces físicos. No caso do receptor de mídia $C$, por exemplo, seu caminho direto no fluxo de subida, partindo da fonte, é $\pi_{u}(G, C)$, o qual na verdade é composto pelos enlaces físicos $<G, R 1>,\langle R 1, R 2>, \mathrm{e}\langle R 2, C\rangle$, e apresenta um custo de 12 .

Perceba que, no caso da multidifusão sobreposta, este mesmo receptor $C$ recebe o fluxo do MA no nó $A$, e não diretamente da fonte $G$. Esta quebra no percurso aumenta o custo do caminho de redirecionamento $\pi_{o}(G, C)$, onde neste caso seu custo totaliza 14 , que é a soma do custo dos enlaces sobrepostos $\langle G, A\rangle \mathrm{e}\langle A, C\rangle$. Portanto, a razão $\frac{14}{12}=1,17$ é exatamente a penalidade RDP sofrida pela multidifusão sobreposta por quebrar o caminho direto da unidifusão e forçar um salto intermediário, no caso do caminho $\pi(G, C)$. 
Os valores da RDP para todos os caminhos foram calculados e reunidos na Tabela 5.3.

Resultados Como os saltos adicionais causados pela estratégia de multidifusão sobreposta ocorrem na borda da rede, e assim em torno dos enlaces de baixo custo, a Tabela 5.3 mostra uma ligeira diferença referente ao desvio de caminho em direção aos nós intermediários capturado pela penalidade RDP. Observe que o maior valor obtido foi um aumento de $19 \%$ no custo do caminho $\pi(G, H)$.

\begin{tabular}{|c|c|c|c|}
\hline Caminhos & Custo $_{u}$ & Custo $_{o}$ & RDP \\
\hline \hline$\pi(G, A)$ & 2 & 2 & 1 \\
\hline$\pi(G, C)$ & 12 & 14 & 1,17 \\
\hline$\pi(G, B)$ & 32 & 36 & 1,13 \\
\hline$\pi(G, H)$ & 32 & 36 & 1,19 \\
\hline$\pi(G, D)$ & 62 & 66 & 1,06 \\
\hline$\pi(G, F)$ & 112 & 118 & 1,05 \\
\hline$\pi(G, L)$ & 112 & 120 & 1,07 \\
\hline$\pi(G, E)$ & 122 & 130 & 1,07 \\
\hline$\pi(G, J)$ & 122 & 132 & 1,08 \\
\hline
\end{tabular}

Tabela 5.3: Caminhos de redirecionamento da fonte para cada receptor de mídia, e o valor da respectiva RDP.

\section{Tempo Para o Primeiro Pacote (TFP)}

Vimos na seção anterior que a quebra do caminho direto de unidifusão para a inclusão de nós intermediários na multidifusão sobreposta leva à uma penalidade medida pela RDP. No entanto, analisando os resultados da Tabela 5.3, vemos que o valor da RDP está bastante relacionado com o desvio realizado, mas não propriamente com o número de saltos incorridos. O caminho $\pi(G, J)$, por exemplo, apresenta 6 saltos adicionais, mas como o desvio efetivo não foi grande, sua penalidade fica em torno de apenas $8 \%$.

Portanto, para avaliar o efeito da inclusão de múltiplos saltos em nível de aplicação, utilizamos a métrica tempo para o primeiro pacote (TFP). Estes saltos adicionais só ocorrem com a multidifusão sobreposta, e assim utilizamos essa latência para comparar seu impacto. A métrica TFP, intuitivamente, se baseia na idéia de que quanto maior for o número de saltos incluídos em nível de aplicação, maior será a latência apresentada pela estratégia de multidifusão sobreposta.

O restante dessa seção é dedicado à construção de um modelo matemático que possibilite a avaliação da TFP nas três estratégias: unidifusão, multidifusão nativa em 
rede, e multidifusão sobreposta.

TFP para a Unidifusão Para o caso da unidifusão, o TFP pode ser modelado com base em duas medidas de tempo: o tempo de ida-e-volta (RTT - Round Trip Time) e o tempo de transmissão do pacote de dados (PTT - Packet Transmission Time).

O RTT pode ser definido como o tempo para enviar um pequeno pacote que vai do cliente para o servidor, e retorna para o cliente. Claro que este tempo irá variar, dependendo da localização na rede das partes envolvidas. Dessa forma, representamos por $r t t\left(d_{c}, s\right)$ um valor RTT em função do receptor $d_{c}$ que lança a solicitação, e da fonte $s$ que recebe a solicitação e responde de volta. Nesta notação, representamos os sistemas finais ou hospedeiros (hosts) pela letra $d$, com um subíndice que identifica de forma única o hospedeiro específico.

Para que o receptor $d_{c}$ receba o primeiro pacote de dados, ele precisa antes estabelecer uma conexão TCP com a fonte $s$, para só depois enviar uma solicitação HTTP GET pela mídia desejada. O estabelecimento de uma conexão TCP é feito em três vias: o envio de uma mensagem TCP SYN do receptor para a fonte, uma resposta TCP SYN-ACK da fonte para o receptor, e uma confirmação TCP ACK do receptor para a fonte novamente. Junto com esta confirmação é enviado o pedido HTTP GET, e a fonte envia os primeiros bytes da resposta HTTP 200 OK, caso tudo ocorra com sucesso, seguido dos bytes referentes à primeira parcela da mídia.

O tempo de transmissão dessa primeira parcela da mídia é o tempo de transmissão do pacote (PTT). Como este tempo também depende da localização das partes envolvidas, representamos por $\mathrm{ptt}\left(s, d_{c}\right)$ um valor PTT em função da fonte $s$ transmissora, e do receptor $d_{c}$ que solicitou a mídia.

A modelagem destes tempos está ilustrada na Figura 5.9. Considerando que $\operatorname{rtt}\left(s, d_{c}\right)=$ $r t t\left(d_{c}, s\right)$, podemos então escrever o TFP para a unidifusão como (KUROSE; ROSS, 2003):

$$
t f p_{u}\left(s, d_{c}\right)=2 r t t\left(s, d_{c}\right)+p t t\left(s, d_{c}\right)
$$

onde $t f p_{u}\left(s, d_{c}\right)$ representa um valor TFP para a unidifusão (subíndice $u$ ) em função da 


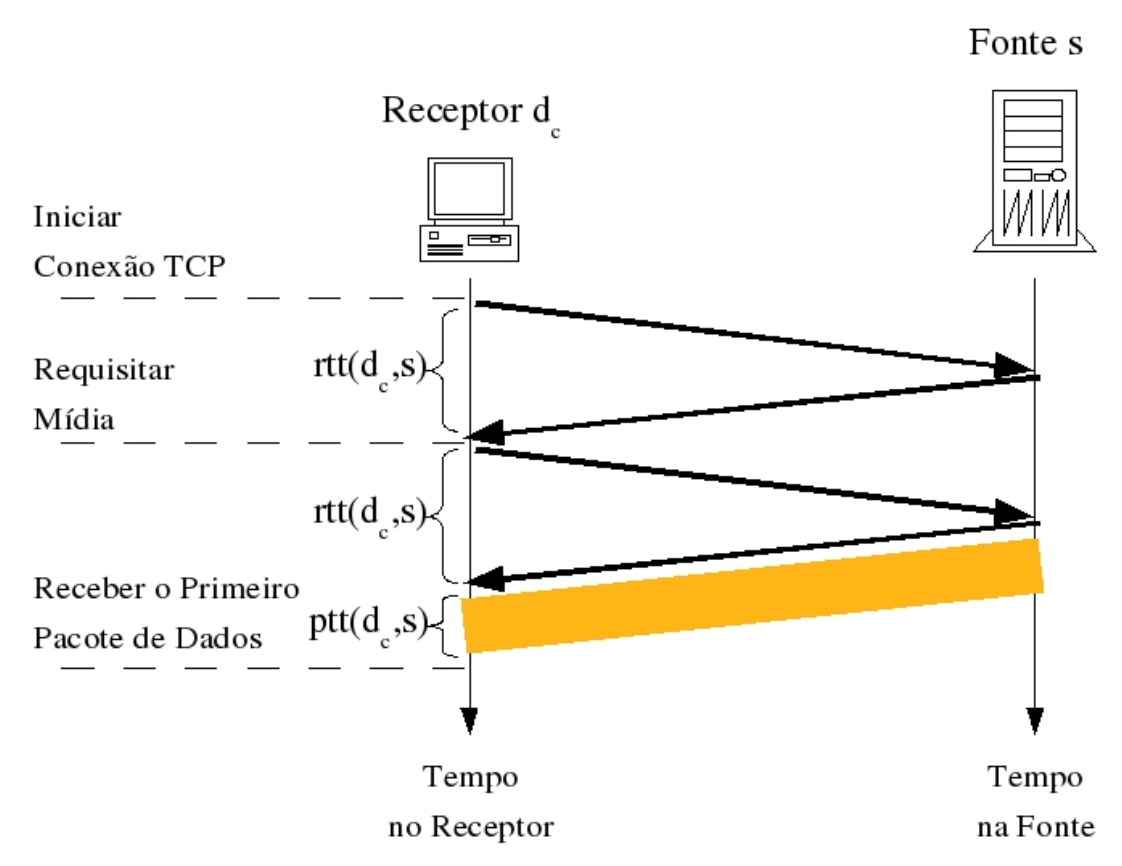

Figura 5.9: Modelagem do TFP para o caso da entrega de dados por unidifusão.

localização da fonte $s$ e do receptor $d_{c}$. Perceba que o RTT captura o atraso envolvido na comunicação de controle da transmissão, enquanto que o PTT já representa a transmissão da primeira parcela de dados propriamente dito. Na nossa modelagem sempre aparecerá uma parcela relacionada ao fluxo de controle e outra relacionada ao fluxo de dados.

TFP para a Multidifusão Nativa em Rede Neste trabalho, vamos modelar o TFP para o PIM-SM decompondo-o em quatro contribuições de atraso (delay): (i) uma porção de atraso relacionada à transmissão da fonte para seu roteador designado; (ii) uma porção de atraso relacionada à transmissão do roteador designado da fonte até o RP; (iii) uma porção de atraso relacionada à transmissão partindo do RP até o roteador designado para o cliente; (iv) e uma última parcela de atraso relacionada à transmissão do roteador designado do cliente para o dispositivo do cliente. Dessa forma, definimos a seguinte relação:

$$
\begin{aligned}
\operatorname{tfp} p_{n}\left(s, d_{c}\right)= & \operatorname{delay}_{n}\left(s, \eta_{0}\right)+ \\
& +\sum_{\substack{i \in\{0, \cdots, l-l\} \\
i: \eta_{i} \in \pi_{n}\left(s, d_{c}\right)}} \operatorname{delay}_{n}\left(\eta_{i}, \eta_{i+1}\right)+
\end{aligned}
$$




$$
\begin{aligned}
& +\sum_{\substack{j \in\{l, \cdots, r-1\}, j: \eta_{j} \in \pi_{n}\left(s, d_{c}\right)}} \operatorname{delay}_{n}\left(\eta_{j}, \eta_{j+1}\right)+ \\
& +\operatorname{delay}_{n}\left(\eta_{r}, d_{c}\right)
\end{aligned}
$$

Note que a partir daqui adotaremos a notação $\eta$ para os roteadores, seguindo a mesma notação de (FAHMY; KWON, 2007). O subíndice de $\eta$ identifica exatamente o roteador envolvido, onde utilizamos $l$ para o roteador $\operatorname{RP}\left(\eta_{l}\right)$, 0 para o roteador designado para a fonte $\left(\eta_{0}\right)$, e $r$ para o roteador designado para hospedeiro $d_{c}\left(\eta_{r}\right)$.

O primeiro termo do lado direito da Equação 5.4 representa o atraso entre a fonte $s$ e o roteador designado para a fonte $\eta_{0}$. O segundo termo, o somatório, contabiliza os atrasos individuais entre os roteadores ao longo do fluxo de descida entre $\eta_{0} \mathrm{e}$ o RP $\eta_{l}$. A condição do somatório indica que serão apenas considerados elementos que pertençam ao caminho de redirecionamento dos dados, representado pela função $\pi$, onde o primeiro parâmetro designa o elemento inicial do caminho, e o segundo parâmetro o último elemento do caminho. Como estes caminhos podem ser diferentes dependendo da técnica de transmissão, teremos $\pi_{u}$ para o caminho assumido na unidifusão, $\pi_{n}$ para o caminho assumido na multidifusão nativa em rede, $\pi_{o}$ para o caminho seguido pela multidifusão sobreposta.

O terceiro termo da Equação 5.4, um outro somatório, captura os atrasos individuais entre os roteadores ao longo do fluxo de descida entre o RP $\eta_{l}$ e o roteador designado para o cliente $\eta_{r}$. O último termo da equação representa o atraso no último salto, entre o roteador $\eta_{r}$ e a máquina do cliente $d_{c}$.

Os atrasos representados pela função delay consideram tanto a comunicação no fluxo de controle quanto o envio dos dados. Podemos separar o atraso de controle do atraso de dados, representado este último pela função ptt. O atraso de controle pode ser modelado em função da $r t t$, considerando todos os passos do protocolo PIMSM, conforme descrito na Seção 5.1.5. Dessa forma, podemos computar o atraso no caminho físico considerando a arquitetura PIM-SM através da seguinte equação:

$$
\begin{aligned}
\operatorname{tfp} p_{n}\left(s, d_{c}\right)= & \operatorname{ptt}\left(s, \eta_{0}\right)+ \\
& +\sum_{\substack{i \in\{0, \cdots, l-1\}, i: \eta_{i} \in \pi_{n}\left(s, d_{c}\right)}}\left[\frac{1}{2} r t t\left(\eta_{i}, \eta_{i+1}\right)+\right.
\end{aligned}
$$




$$
\begin{aligned}
& \left.+\operatorname{ptt}\left(\eta_{i}, \eta_{i+1}\right)\right]+ \\
& +\sum_{\substack{j \in\{l, \cdots, r-1\}, j: \eta_{j} \in \pi_{n}\left(s, d_{c}\right)}}\left[\frac{1}{2} r t t\left(\eta_{i}, \eta_{i+1}\right)+\right. \\
& \left.+\operatorname{ptt}\left(\eta_{j}, \eta_{j+1}\right)\right]+ \\
& +\frac{1}{2} \operatorname{rtt}\left(\eta_{r}, d_{c}\right)+\operatorname{ptt}\left(\eta_{r}, d_{c}\right)
\end{aligned}
$$

Na multidifusão nativa, as mensagens PIM-SM são enviadas diretamente pela camada de rede, como datagramas IP. Dessa forma, surge nas equações o termo $\frac{1}{2} r t t$, representando apenas o tempo de ida de um pacote de controle. Claro que assim estamos considerando que o tempo de ida é igual ao tempo de volta, gastando cada um dos dois metade do tempo de ida-e-volta RTT.

TFP para a Multidifusão Sobreposta Os atrasos envolvidos na multidifusão sobreposta sempre terão algum componente adicional, visto a necessidade de se alcançar a camada de aplicação de nós intermediários para a realização do repasse dos dados. Isto é explicitado através de um subíndice $o$ na função delay, informando que este é um atraso considerado sobre um ou mais enlaces sobrepostos, e não enlaces físicos como anteriormente.

De forma um pouco semelhante ao que fizemos no caso da multidifusão nativa em rede, podemos decompor os componentes de atraso da multidifusão sobreposta considerando a arquitetura do protocolo SMCP. Assim, obtemos:

$$
\begin{aligned}
\operatorname{tfp} p_{o}\left(s, d_{c}\right)= & \operatorname{delay}_{o}\left(s, d_{0}\right)+ \\
& +\sum_{\substack{k \in\{0, \cdots, m-1\} \\
k: d_{k} \in \pi_{o}\left(s, d_{c}\right)}} \operatorname{delay}_{o}\left(d_{k}, d_{k+1}\right)+ \\
& +\operatorname{delay~}_{o}\left(d_{r}, d_{c}\right)
\end{aligned}
$$

A primeira parcela do lado direito da equação representa o primeiro salto no fluxo de descida, da fonte $s$ para o nó de serviço $d_{0}$ que hospeda o Source Multicast Agent (SMA). O próximo termo, o somatório, computa o atraso nos enlaces sobrepostos desde o SMA em $d_{0}$ até o User Multicast Agent (UMA) representante, designado como $d_{r}$. O último termo representa o último salto, do UMA em $d_{r}$ para o User Agent (UA) 
hospedado na máquina do cliente $d_{c}$.

Calculando-se $o$ atraso dos enlaces sobrepostos em função dos atrasos nos enlaces físicos, e considerando que delayo $_{o}\left(d_{i}, \eta_{i}\right)=$ delay $_{o}\left(\eta_{i}, d_{i}\right)$, obtemos:

$$
\begin{aligned}
\operatorname{tfp} p_{o}\left(s, d_{c}\right)= & \operatorname{delay}_{o}\left(s, \eta_{0}\right)+ \\
& +\sum_{\substack{j \in\left\{\{, \ldots, r-1\}, j: \eta_{j} \in \pi_{o}\left(s, d_{c}\right)\right.}} \operatorname{delay}_{o}\left(\eta_{j}, \eta_{j+1}\right)+ \\
& +\operatorname{delay~}_{o}\left(\eta_{r}, d_{c}\right)+ \\
& +2 \sum_{\substack{k \in\left\{0, \ldots, m-1, j, k: d_{k} \in \pi_{o}\left(s, d_{c}\right)\right.}} \operatorname{delay}_{o}\left(d_{k}, \eta_{k}\right)
\end{aligned}
$$

Observe que esta equação é bem semelhante à Equação 5.4, onde os dois somatórios da Equação 5.4 foram agrupados em apenas um, o segundo termo da Equação 5.7.

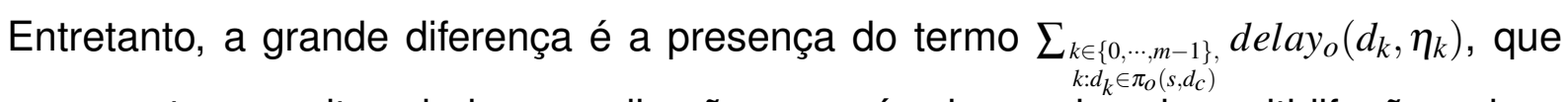
representa os saltos dados em direção aos nós de serviço da multidifusão sobreposta, para que o repasse dos dados aconteça em nível de aplicação. Perceba que na Equação 5.7 este termo está multiplicado por 2, representando a soma dos atrasos de chegada e saída nos nós sobrepostos.

Para modelar o atraso de forma calculável, precisamos computar as contribuições de atraso na topologia de dados e na topologia de controle, de acordo com a arquitetura do protocolo SMCP. Considerando que a topologia de controle seja estabelecida sob demanda através de conexões TCP, e que a transmissão dos dados se dê através de datagramas UDP (assim como na multidifusão nativa), temos ${ }^{6}$ :

$$
\operatorname{delayo}_{o}\left(d_{j}, d_{j+1}\right)=2 \operatorname{rtt}\left(d_{j}, d_{j+1}\right)+\operatorname{ptt}_{o}\left(d_{j}, d_{j+1}\right)
$$

onde $p t t_{o}$ denota o tempo de transmissão de um pacote de dados em função da estratégia sobreposta adotada na topologia de dados.

\footnotetext{
${ }^{6}$ Por analogia ao caso da Equação 5.3.
} 
A primeira parte do lado direito da equação representa o atraso no estabelecimento da conexão TCP. A segunda parte representa o atraso na transmissão do pacote de dados através dos enlaces sobrepostos. Aplicando esta modelagem do atraso na Equação 5.6, obtemos:

$$
\begin{aligned}
t f p_{o}\left(s, d_{c}\right)= & 2 r t t\left(s, d_{0}\right)+p t t_{o}\left(s, d_{0}\right)+ \\
& +\sum_{\substack{k \in\{0, \cdots, m-1\}, k: d_{k} \in \pi_{o}\left(s, d_{c}\right)}}\left[2 r t t\left(d_{k}, d_{k+1}\right)+\right. \\
& \left.+p t t_{o}\left(d_{k}, d_{k+1}\right)\right]+ \\
& +2 r t t\left(d_{r}, d_{c}\right)+p t t_{o}\left(d_{r}, d_{c}\right)
\end{aligned}
$$

Como no caso da multidifusão sobreposta cada nó de serviço intermediário precisa processar o pacote de dados para repassá-lo, podemos mapear a seguinte relação entre o tempo de transmissão do pacote de dados no caminho sobreposto e o tempo de transmissão do pacote de dados no caminho físico:

$$
p t t_{o}\left(d_{j}, d_{j+1}\right)=p t t\left(d_{j}, d_{j+1}\right)+t_{A L M}
$$

onde $t_{A L M}$ denota o tempo gasto pelo processamento na camada de aplicação em um salto.

Reescrevendo a Equação 5.9 em função dos enlaces físicos, de forma semelhante ao que fizemos para obter a Equação 5.7, e substituindo a função $p t t_{o}$ conforme Equação 5.10, finalmente obtemos:

$$
\begin{aligned}
\operatorname{tfp} p_{o}\left(s, d_{c}\right)= & 2 r t t\left(s, \eta_{0}\right)+p t t\left(s, \eta_{0}\right)+ \\
& +\sum_{\substack{j \in\{0, \cdots, r-1\}, j: \eta_{j} \in \pi_{o}\left(s, d_{c}\right)}}\left[2 r t t\left(\eta_{j}, \eta_{j+1}\right)+\right. \\
& \left.+p t t\left(\eta_{j}, \eta_{j+1}\right)\right] \\
& +\left[2 r t t\left(\eta_{r}, d_{c}\right)+p t t\left(\eta_{r}, d_{c}\right)\right]
\end{aligned}
$$




$$
\begin{aligned}
& +2 \sum_{\substack{k \in\{0, \cdots, m-1\}, k: d_{k} \in \pi_{o}\left(s, d_{c}\right)}}\left[2 r t t\left(d_{k}, \eta_{k}\right)+\right. \\
& \left.+p t t\left(d_{k}, \eta_{k}\right)+\frac{1}{2} t_{A L M}\right]
\end{aligned}
$$

Modelo de Comparação do TFP Naturalmente, entende-se que o TFP no caso da multidifusão sobreposta deva ser maior que o TFP no caso da multidifusão nativa em rede. O problema é quantificar a penalidade de atraso incorrida na adoção da abordagem de multidifusão sobreposta em comparação com a transmissão por multidifusão nativa em rede.

Com as equações obtidas anteriormente, podemos então comparar o tempo para chegada do primeiro pacote de dados no caso da multidifusão sobreposta com o mesmo resultado obtido no caso da multidifusão nativa em rede. Isto pode ser feito simplesmente calculando-se a diferença entre as Equações 5.11 e 5.5. Como resultado, temos:

$$
\begin{aligned}
\Delta t f p\left(s, d_{c}\right)= & t f p_{o}\left(s, d_{c}\right)-t f p_{n}\left(s, d_{c}\right) \\
& =2 r t t\left(s, \eta_{0}\right)+\frac{3}{2} \sum_{\substack{j \in\{0, \cdots, r-1\}, j: \eta_{j} \in p_{o}\left(s, d_{c}\right)}} r t t\left(\eta_{j}, \eta_{j+1}\right)+ \\
& +\frac{3}{2} r t t\left(\eta_{r}, d_{c}\right)+2 \sum_{\substack{k \in\{0, \cdots, m-1\}, k: d_{k} \in \pi_{o}\left(s, d_{c}\right)}}\left[2 r t t\left(d_{k}, \eta_{k}\right)+\right. \\
& \left.+\operatorname{ptt}\left(d_{k}, \eta_{k}\right)+\frac{1}{2} t_{A L M}\right]
\end{aligned}
$$

Portanto, medindo-se todos os RTT e PTT entre todos os enlaces do caminho de redirecionamento, e calculando-se um tempo médio razoável para o processamento $t_{A L M}$ realizado em nível de aplicação, podemos estimar o quanto o TFP da multidifusão sobreposta desviou de seu valor ideal, ou seja, do valor encontrado no caso da multidifusão nativa em rede.

No caso de não ser possível realizar tais medições, pode-se ainda supor que todos os enlaces tenham o mesmo custo, fazendo-se portanto $r t t(x, y)=1$, para quaisquer $x$ e $y$ pertencente à rede. Supondo ainda que o pacote de vídeo leva o mesmo tempo para ser transmitido partindo de qualquer nó de serviço para qualquer roteador diretamente 
conectado, independente de sua posição na rede, temos que $\operatorname{ptt}\left(d_{k}, \eta_{k}\right)=C_{1}$, o que resulta em:

$$
\Delta t f p\left(s, d_{c}\right)=\frac{7}{2}+\frac{3}{2} r+\left(4+2 C_{1}+t_{A L M}\right) m
$$

onde $r$ é o número de roteadores na rede, e $m$ o número de nós sobrepostos. Como consideramos um valor constante para $t_{A L M}$, podemos escrever:

$$
C=4+2 C_{1}+t_{A L M}
$$

E assim obtemos:

$$
\Delta t f p\left(s, d_{c}\right)=\frac{7}{2}+\frac{3}{2} r+C m
$$

Considerando uma dada topologia física, o número de roteadores não irá mais mudar, e $r$ então será uma constante. Assim, podemos ainda simplificar fazendo:

$$
K=\frac{7}{2}+\frac{3}{2} r
$$

Finalmente, obtemos:

$$
\Delta t f p\left(s, d_{c}\right)=K+C m
$$

Resultados Com as hipóteses assumidas, $K$ e $C$ são constantes, e a Equação 5.17 mostra que a diferença entre o TFP da multidifusão sobreposta em comparação 
com o TFP da multidifusão nativa em rede cresce linearmente com o número de nós sobrepostos $m$ envolvidos no caminho de redirecionamento.

Validação Uma forma de avaliar a equação encontrada é obter experimentalmente valores médios de $\operatorname{ptt}\left(d_{k}, \eta_{k}\right), t_{A L M}$, e do próprio desvio $\Delta t f p\left(s, d_{c}\right)$ para o cenário considerado na Figura 5.2, e comparar com o resultado do $\Delta t f p\left(s, d_{c}\right)$ calculado pela Equação 5.17.

Conforme descrito no fim da Seção 5.1.6, nosso cenário de análise foi experimentalmente montado, resultando na topologia apresentada na Figura 5.6. Através do auxílio do analisador de protocolos de rede Wireshark ${ }^{7}$, conseguimos medir os valores de tempo de interesse. A Figura 5.10 ilustra uma medida do TFP no receptor $\mathrm{J}$ com a estratégia de multidifusão sobreposta. Configuramos como marca temporal de referência o primeiro pacote TCP enviado pelo receptor, o qual é um segmento TCP SYN solicitando o estabelecimento da conexão TCP. A primeira parcela de dados recebida vem junto com a resposta HTTP 200 OK, que chega após 0,866775 segundos (o $15^{\circ}$ pacote capturado).

\begin{tabular}{|c|c|c|c|c|}
\hline 10.000000 & 3com_8b:d8:4b & Spanning-tree-(for-br & STP & MST. Root $=32768 / 00: 12: a 9: 8 b: 1$ \\
\hline 21.999594 & $3 c o m \_8 b: d 8: 4 b$ & Spanning-tree-(for-br & STP & MST. Root $=32768 / 00: 12: a 9: 8 b: 1$ \\
\hline 33.629791 & $192 . \overline{1} 68.50 .1$ & 224.0 .0 .13 & PIMv2 & Hello \\
\hline 44.000316 & 3com_8b:d8: $4 b$ & Spanning-tree-(for-br & STP & MST. Root $=32768 / 00: 12: a 9: 8 b: 1$ \\
\hline 55.409363 & 3Com_3b:05:5b & Broadcast & ARP & Who has 192.168.50.1? Tell 19: \\
\hline 65.410186 & 3com_33:23:a9 & 3Com_3b:05:5b & ARP & 192.168 .50 .1 is at $00: 16: \mathrm{e} 0: 33$ \\
\hline 7 *REF* & $192 . \overline{168.50 .10}$ & 192.168 .51 .10 & $\mathrm{TCP}$ & pictrography $>$ boks [SYN] Seq= \\
\hline 80.001393 & 192.168 .51 .10 & 192.168 .50 .10 & $\mathrm{TCP}$ & boks > pictrography [SYN, ACK] \\
\hline 90.001418 & 192.168 .50 .10 & 192.168 .51 .10 & $\mathrm{TCP}$ & pictrography > boks [ACK] Seq= \\
\hline 100.015227 & 192.168 .50 .10 & 192.168 .51 .10 & HTTP & GET /teste.ts?data_proto=http\& \\
\hline 110.016136 & 192.168 .51 .10 & 192.168 .50 .10 & $\mathrm{TCP}$ & boks > pictrography [ACK] Seq= \\
\hline 120.016157 & 192.168 .50 .10 & 192.168 .51 .10 & HTTP & Continuation or non-HTTP traff \\
\hline 130.017191 & 192.168 .51 .10 & 192.168 .50 .10 & $\mathrm{TCP}$ & boks > pictrography [ACK] Seq= \\
\hline 140.591118 & $3 c o m \_8 b: d 8: 4 b$ & Spanning-tree- (for-br & STP & MST. Root $=32768 / 00: 12: a 9: 8 b: 1$ \\
\hline 150.866775 & 192.168 .51 .10 & 192.168 .50 .10 & $\mathrm{TCP}$ & [TCP segment of a reassembled \\
\hline 160.877997 & 192.168 .51 .10 & 192.168 .50 .10 & $\mathrm{TCP}$ & [TCP segment of a reassembled I \\
\hline 170.878036 & 192.168 .50 .10 & 192.168 .51 .10 & TCP & pictrography > boks [ACK] Seq= \\
\hline
\end{tabular}

Figura 5.10: Análise dos pacotes enviados e recebidos pelo máquina cliente $\mathrm{J}$, na estratégia de multidifusão sobreposta, através do software Wireshark.

Para encontrarmos um valor médio representativo do $\Delta t f p\left(s, d_{c}\right)$ de forma experimental, definimos a seguinte metodologia: escolhemos os nós $H, J$ e $L$ como nós de interesse, e analisamos os pacotes em cada um destes receptores durante 10 realizações do processo de solicitação de participação em sessão. Os resultados foram então agrupados na Tabela 5.4. Adotaremos como valor $t f p_{o}\left(s, d_{c}\right)_{\exp }$ a média dos valores médios obtidos para os três nós, ou seja, $t f p_{o}\left(s, d_{c}\right)_{\exp }=638,05 \mathrm{~ms}$.

\footnotetext{
${ }^{7}$ http://www.wireshark.org/.
} 


\begin{tabular}{|c|c|c|c|}
\hline Amostra & Nó H & Nó L & Nó J \\
\hline \hline 1 & 0,404085 & 0,592674 & 0,866775 \\
\hline 2 & 0,617345 & 0,754352 & 0,800257 \\
\hline 3 & 0,603667 & 0,695527 & 0,685274 \\
\hline 4 & 0,606918 & 0,603238 & 0,691010 \\
\hline 5 & 0,531601 & 0,682527 & 0,768440 \\
\hline 6 & 0,568660 & 0,546408 & 0,627964 \\
\hline 7 & 0,683862 & 0,682152 & 0,674179 \\
\hline 8 & 0,598217 & 0,598174 & 0,510000 \\
\hline 9 & 0,675929 & 0,607101 & 0,674179 \\
\hline 10 & 0,558616 & 0,589523 & 0,642907 \\
\hline \hline Média & 0,584890 & 0,635168 & 0,694099 \\
\hline
\end{tabular}

Tabela 5.4: Amostras do TFP, em segundos, medidos experimentalmente nos nós de interesse para o caso da multidifusão sobreposta.

Procedendo de maneira similar para o caso da multidifusão nativa, obtivemos os valores da Tabela 5.5. O valor $t f p_{n}\left(s, d_{c}\right)_{\text {exp }}$ experimental é então a média dos valores médios obtidos, o que resulta em 43,79 ms. Portanto, a diferença entre a média do TFP para multidifusão sobreposta e a média do TFP obtida para a multidifusão nativa foi de $\Delta t f p\left(s, d_{c}\right)_{\exp }=638,05-43,79=594,26 \mathrm{~ms}$.

\begin{tabular}{|c|c|c|c|}
\hline Amostra & Nó H & Nó L & Nó J \\
\hline \hline 1 & 0,013529 & 0,053703 & 0,071805 \\
\hline 2 & 0,058266 & 0,038562 & 0,044564 \\
\hline 3 & 0,030451 & 0,030676 & 0,062716 \\
\hline 4 & 0,013829 & 0,059138 & 0,042410 \\
\hline 5 & 0,044271 & 0,041626 & 0,045729 \\
\hline 6 & 0,040853 & 0,057311 & 0,046784 \\
\hline 7 & 0,051499 & 0,044319 & 0,060226 \\
\hline 8 & 0,012914 & 0,022322 & 0,049167 \\
\hline 9 & 0,025146 & 0,031868 & 0,074611 \\
\hline 10 & 0,057346 & 0,044371 & 0,043625 \\
\hline \hline Média & 0,034810 & 0,042390 & 0,054164 \\
\hline
\end{tabular}

Tabela 5.5: Amostras do TFP, em segundos, medidos experimentalmente nos nós de interesse para o caso da multidifusão nativa.

Para validarmos a Equação 5.17, precisamos calcular um valor de TFP próximo deste valor medido experimentalmente. Para isso, precisamos definir valores para $\operatorname{ptt}\left(d_{k}, \eta_{k}\right)$ e para $t_{A L M}$, calcular $K$ e $C$, e substituí-los na Equação 5.17. Lembre-se que para nosso modelo analítico utilizamos como hipótese simplificadora que o tempo de transmissão do pacote de dados é constante, ou seja, o mesmo sobre qualquer caminho entre o sistema final $d_{k}$ e o roteador $\eta_{k}$, o que resultou em $p t t\left(d_{k}, \eta_{k}\right)=C_{1}$. Além disso, consideramos que o tempo de processamento em nível de aplicação $t_{A L M}$ em cada nó é sempre o mesmo, para todos os nós. O primeiro parâmetro depende da topologia da rede física e da quantidade média de bytes nos pacotes de dados, já o segundo depende da implementação da solução de multidifusão sobreposta.

Vamos então definir estes valores experimentalmente, como explicado a seguir. Consideraremos como valor $p t t\left(d_{k}, \eta_{k}\right)$ representativo o tempo de transmissão da primeira parcela do pacote de dados entre o roteador $R 5$ e o receptor $L$ (ver Figura 5.2 ). Na ver- 
dade, como todos os enlaces locais têm o mesmo peso, poderíamos ter tomado medidas em qualquer outro ponto similar da topologia. Novamente, tomamos 10 amostras analisadas através do Wireshark, e reunimos os valores medidos na Tabela 5.6. As medições foram realizadas com o protocolo PIM-SM habilitado, mas descartando-se os pacotes de controle, considerando apenas o tempo de viagem do pacote de dados. Assim, temos o parâmetro $p t t\left(d_{k}, \eta_{k}\right)$ medido experimentalmente como sendo $\operatorname{ptt}\left(d_{k}, \eta_{k}\right)=22,84 \mathrm{~ms}$.

\begin{tabular}{|c|c|}
\hline Amostra & $p t t\left(d_{7}, \eta_{5}\right)$ \\
\hline \hline 1 & 0,028996 \\
\hline 2 & 0,020154 \\
\hline 3 & 0,010811 \\
\hline 4 & 0,017939 \\
\hline 5 & 0,020987 \\
\hline 6 & 0,024996 \\
\hline 7 & 0,020650 \\
\hline 8 & 0,031038 \\
\hline 9 & 0,023100 \\
\hline 10 & 0,029732 \\
\hline \hline Média & 0,022840 \\
\hline
\end{tabular}

Tabela 5.6: Amostras do $\operatorname{ptt}\left(d_{7}, \eta_{5}\right)$, onde $d_{7}$ representa o receptor $L$ e $\eta_{5}$ o roteador 5, em segundos, medidos experimentalmente.

Definimos o parâmetro $t_{A L M}$ através do seguinte critério: com o cliente $F$ já participando da sessão, $t_{A L M}$ foi medido como o tempo gasto no atendimento de um novo cliente no nó $L$, ou seja, apenas o tempo para que o agente de multidifusão abra um novo braço de transmissão. Este procedimento foi realizado 10 vezes, e os resultados estão na Tabela 5.7. Dessa forma, medimos experimentalmente um $t_{A L M}$ de $58 \mathrm{~ms}$.

\begin{tabular}{|c|c|}
\hline Amostra & $t_{A L M}$ \\
\hline \hline 1 & 0,009155 \\
\hline 2 & 0,178615 \\
\hline 3 & 0,036319 \\
\hline 4 & 0,022993 \\
\hline 5 & 0,107446 \\
\hline 6 & 0,022803 \\
\hline 7 & 0,151540 \\
\hline 8 & 0,027984 \\
\hline 9 & 0,011653 \\
\hline 10 & 0,011517 \\
\hline \hline Média & 0,058003 \\
\hline
\end{tabular}

Tabela 5.7: Amostras do tempo de atendimento ao nó $L$ quando o nó $F$ já participa da sessão, medido em segundos.

Com os valores experimentais de $p t t\left(d_{k}, \eta_{k}\right)$ e $t_{A L M}$, através da Equação 5.14 encontramos $C=4+2(22,84)+58=107,68 \mathrm{~ms}$. Podemos calcular $K$ através da Equação 5.16, resultando em $K=12,5 \mathrm{~ms}$. Com isso, usando a Equação 5.17 chegamos a $\Delta t f p\left(s, d_{c}\right)_{c a l c}=12,5+107,68(6)=658,58 \mathrm{~ms}$ (lembrando que no cenário considerado $r=m=6$ ). Podemos calcular o erro relativo da seguinte forma: 


$$
\begin{aligned}
\text { Erro relativo } & =\frac{\left|\Delta t f p\left(s, d_{c}\right)_{\text {calc }}-\Delta t f p\left(s, d_{c}\right)_{\exp }\right|}{\Delta t f p\left(s, d_{c}\right)_{\exp }} 100 \%= \\
& =\frac{658,58-594,26}{594,26} 100 \%=10,82 \%
\end{aligned}
$$

Observe então que, para este cenário, e utilizando-se os valores médios, a Equação 5.17 foi capaz de estimar a latência adicional da multidifusão sobreposta, em comparação com a latência da multidifusão nativa, com um erro relativo de $10,82 \%$, o que sugere que a equação representa uma boa aproximação.

Veja que obtivemos valores de TFP para a multidifusão sobreposta na ordem de 15 vezes maior que o TFP para a multidifusão nativa. Devemos lembrar que valores desta magnitude foram alcançados considerando o pior caso, ou seja, para o primeiro cliente que entra na sessão. Em média, o valor de $\Delta t f p\left(s, d_{c}\right)$ para o segundo cliente (nó $L$, com o nó $F$ já na sessão) foi de $72,54 \mathrm{~ms}$. Esta redução acontece por já existerem MAs engajados na sessão solicitada, onde o cliente é prontamente atendido, visto que a estrutura de entrega já está (completamente ou parcialmente) montada.

\subsubsection{Conclusões da Análise}

Através da avaliação do desempenho realizada aqui, fica claro as vantagens da multidifusão sobreposta e multidifusão nativa em rede sobre a unidifusão. Entretanto, as métricas de stress, utilização dos recursos, e penalidade RDP, apenas mostram uma ligeira desvantagem da multidifusão sobreposta em comparação com a multidifusão nativa em rede.

Este bom desempenho deve-se à distribuição estratégica dos nós sobrepostos ao longo da rede. Nesse caso, recriamos um visão de rede lógica bastante semelhante à rede física, com o mesmo número de nós, e com enlaces sobrepostos traçando caminhos bem similares àqueles apresentados pelos enlaces físicos. Entretanto, apenas as métricas de stress, utilização dos recursos, e penalidade RDP, não são suficientes para capturar o atraso provocado pelos nós intermediários da multidifusão sobreposta. Daí a importância da métrica TFP, a qual é capaz de avaliar a latência do serviço de entrega adotado. 
Através da Equação 5.12, ou de sua versão simplificada apresentada pela Equação 5.17, demonstramos que o TFP apresentado pela multidifusão sobreposta cresce linearmente com o número de nós sobrepostos envolvidos no caminho de redirecionamento, em comparação com o valor de TFP obtido no caso da multidifusão nativa em rede. Além de comprovar matematicamente uma suspeita intuitiva, este resultado permite estimar o valor de TFP adicional ao se escolher o SMCP em detrimento da multidifusão nativa em rede com o PIM-SM.

\section{Utilizando o Modelo Analítico para Provisionamento da Rede Sobreposta}

Observe que o modelo analítico desenvolvido pode ser utilizado para se definir a seguinte heurística para o provisionamento da rede sobreposta, quando a topologia física for conhecida:

1. Estimar valores reais para o $p t t\left(d_{k}, \eta_{k}\right)$ e $t_{A L M}$, e assumir inicialmente tantos nós sobrepostos quanto o número de roteadores, ou seja, $m=r$;

2. Utilizar a Equação 5.17 para estimar a priori o valor da $\Delta t f p\left(s, d_{c}\right)$;

3. Se o $\Delta t f p\left(s, d_{c}\right)$ estimado for menor que $(1-\alpha)$ do limite de tempo real aceitável pela aplicação multimídia, distribuir os nós ao longo da rede observando as métricas de stress, utilização dos recursos e penalidade RDP, até se atingir uma configuração com desempenho satisfatório;

4. Caso contrário, adotar um novo $m^{\prime}=m-1$ e voltar para o passo 2;

Veja que estamos considerando que $t f p_{n}\left(s, d_{c}\right)=\alpha t f p_{o}\left(s, d_{c}\right)$, sendo $0<\alpha<1$. Durante nossas medições observamos um valor de $\alpha=\frac{43,79}{638,05}=0,07$, para o primeiro cliente que entra na sessão. Entretanto, este valor pode aumentar a medida que conseguimos diminuir o $t_{A L M}$ nos nós sobrepostos, tornando o TFP para a multidifusão sobreposta mais próximo do TFP para a multidifusão nativa. Além disso, considerando que já existam clientes na sessão, este valor pode cair para $\alpha=\frac{43,79}{72,54}=0,6$.

Exemplo Considere o seguinte problema hipotético. Uma rede com $r=6$ roteadores oferece um serviço de multidifusão sobreposta com os seguintes parâmetros de 
implementação: $t_{A L M}=60 \mathrm{~ms}$ e $\alpha=0,07$. Considera-se que enlaces de $100 \mathrm{Mbps}$ ligarão os nós de serviço aos roteadores, e que, em média, um pacote de dados carrega 300 kbytes. Defina o número ótimo de nós sobrepostos para que a latência do serviço de multidifusão não ultrapasse $500 \mathrm{~ms}$.

Começamos a resolver o problema calculando $C_{1}=\frac{300 \mathrm{kbyte}}{100 \mathrm{Mbps}}=\frac{300 \cdot 1024 \cdot \text { byte } \cdot 8 \cdot \frac{\mathrm{bits}}{\mathrm{byte}}}{100 \cdot 1024 \frac{\mathrm{kbis}}{\mathrm{s}}}=$ $24 \mathrm{~ms}$. Agora, podemos calcular $C=4+2(24)+60=112 \mathrm{~ms}$. Como temos $r=6$ roteadores, obtemos um valor de $K=\frac{7}{2}+\frac{3}{2}(6)=12,5 \mathrm{~ms}$.

Dessa forma, a equação que estima o quanto de TFP adicional a multidifusão sobreposta com o SMCP acrescenta em comparação com o esquema de multidifusão nativa com PIM-SM é:

$$
\Delta t f p\left(s, d_{c}\right)=12,5+112 m
$$

com $m$ sendo o número de nós sobrepostos.

Seguindo a heurística definida acima, temos que:

$$
\begin{aligned}
& m=6 \rightarrow t f p_{o}\left(s, d_{c}\right)=\frac{\Delta t f p\left(s, d_{c}\right)}{(1-\alpha)}=\frac{684,5}{0,93}=793,02 \mathrm{~ms} \\
& m=5 \rightarrow t f p_{o}\left(s, d_{c}\right)=\frac{\Delta t f p\left(s, d_{c}\right)}{(1-\alpha)}=\frac{572,5}{0,93}=615,59 \mathrm{~ms} \\
& m=4 \quad \rightarrow t f p_{o}\left(s, d_{c}\right)=\frac{\Delta t f p\left(s, d_{c}\right)}{(1-\alpha)}=\frac{460,5}{0,93}=495,16 \mathrm{~ms}
\end{aligned}
$$

Veja que com o modelo analítico aqui proposto conseguimos saber a priori que com um $m=6$ nós sobrepostos podemos ter uma latência maior que a desejada. O mesmo ocorre $\operatorname{com} m=5$. Somente com $m=4$ é que o sistema consegue satisfazer a restrição de latência controlada em $500 \mathrm{~ms}$, no pior caso. O próximo passo na provisão da rede sobreposta é distribuir estes 4 nós ao longo da rede observando as métricas de stress, utilização de recursos, e RDP. 


\section{Considerações Finais}

Concluimos que utilizando-se o modelo comparativo e a heurística de projeto propostos, o desempenho alcançado com o SMCP será próximo daquele que seria obtido com o PIM-SM, com maior latência, mas pondendo alcançar níveis aceitáveis. Este maior valor de latência pode ser previsto a priori, e é compensado pelas vantagens de facilidade de implantação e manutenção, e principalmente, o requesito de implementação prática da funcionalidade de multidifusão interdomínio. Esta funcionalidade adicional, não implementável de forma prática pelo PIM-SM em ambiente de redes públicas de larga escala, será demonstrada na próxima seção através de uma análise funcional.

\subsection{Análise Funcional}

A análise funcional aqui desenvolvida visa comprovar através de medições no sistema real a funcionalidade de multidifusão interdomínio. O cenário de validação considerado analisa uma transmissão real em escala continental. Fluxos ao vivo gerados no $23^{\circ}$ Simpósio Brasileiro de Redes de Computadores e Sistemas Distribuídos (SBRC) foram transmitidos através do sistema de middleware especialmente implantado para esta ocasião (UCHôA et al., 2009).

Neste cenário, os fluxos de dados atravessam caminhos de rede através de quatro domínios administrativos diferentes: três domínios de rede acadêmica, e um domínio de rede comercial. Listando os domínios seguindo a sequência no fluxo de descida, partindo da fonte de mídia para os receptores, as três redes acadêmicas foram: (i) Rede Clara, a rede avançada da América Latina; (ii) Rede Ipê, a rede brasileira acadêmica da RNP; e a (iii) Rede USPNet, a rede da Universidade de São Paulo.

Este arranjo evidencia a Rede Ipê como o backbone da rede continental considerada; ela é conectada com a Rede Clara por um enlace de $155 \mathrm{Mbps}$, e conectada com a Rede USPNet através de um enlace de $1 G p b s^{8}$. O domínio de rede comercial foi suportado por um Provedor de Serviço de Internet (ISP - Internet Service Provider) contratado pelo SBRC, o qual conectava a rede do evento à Rede Ipê através de um

$\begin{array}{clccrr}{ }^{8} \text { As topologias físicas das três } & \text { redes estão disponíveis } & \text { em } \\ \text { http://www.redclara.net/index.php?option=com_content\&task=view\&id=51\&ltemid=77 } & \text { http://www.rnp.br/en/backbone/index.php } & \text { e } \\ \text { http://www.cirp.usp.br/status/status_backbone_uspnet_new.html, } & \text { respectivamente. }\end{array}$




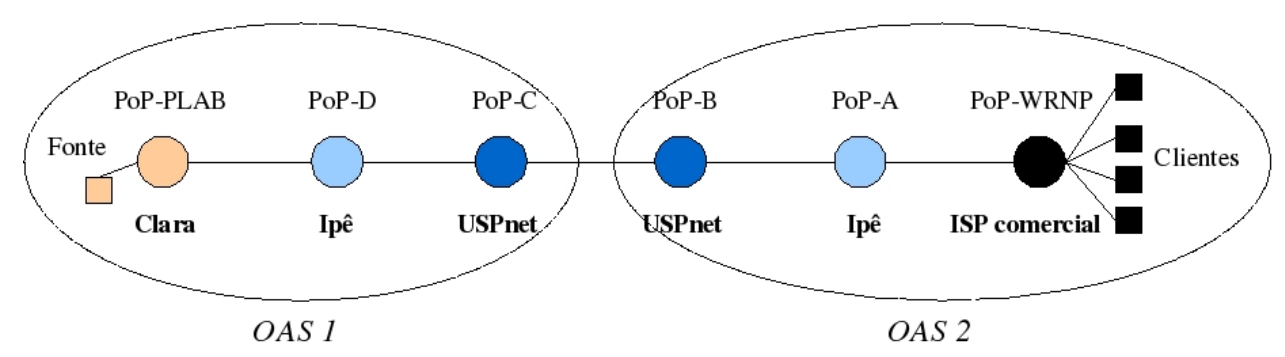

Figura 5.11: Cenário de validação da funcionalidade de multidifusão interdomínio.

enlace de 1 Gbps.

Sobre estas infraestruturas de rede, dois sistemas autônomos sobrepostos (OAS Overlay Autonomous Systems) foram construídos, ambos compostos de quatro nós sobrepostos. A Figura 5.11 apresenta apenas os nós com agentes de transmissão. A Tabela 5.8 resume o provisionamento dos nós sobrepostos.

Tabela 5.8: Provisionamento da rede sobreposta.

\begin{tabular}{|c|c|c|c|c|c|c|}
\hline $\begin{array}{l}\text { Sistema } \\
\text { autônomo } \\
\text { sobreposto }\end{array}$ & $\begin{array}{l}\text { Nome do nó } \\
\text { sobreposto }\end{array}$ & $\begin{array}{l}\text { Nome do nó de } \\
\text { serviço }\end{array}$ & $\begin{array}{ll}\text { Papel } & \text { no } \\
\text { cenário } & \text { de } \\
\text { validação } & \end{array}$ & Rede física & $\begin{array}{l}\text { Nome } \\
\text { do PoP }\end{array}$ & $\begin{array}{l}\text { Localização } \\
\text { geográfica }\end{array}$ \\
\hline \multirow{4}{*}{ OAS 1} & PoP-Manager-1 & Server-Manager-1 & Session Manager & USPNet & $\mathrm{SP}$ & São Paulo \\
\hline & PoP-PLAB & Server-PoP-PLAB & Source Agent & Clara & $\mathrm{SCL}$ & Santiago \\
\hline & PoP-D & Server-PoP-D & Multicast Agent & Ipê & PoP-SP & São Paulo \\
\hline & PoP-C & SNMP-Server-PoP-C & Gateway Agent & USPNet & SP & São Paulo \\
\hline \multirow{4}{*}{ OAS 2} & PoP-B & SNMP-Server-PoP-B & Gateway Agent & USPNet & SP & São Paulo \\
\hline & PoP-A & Server-PoP-A & Multicast Agent & Ipê & PoP-RJ & Rio de Janeiro \\
\hline & PoP-WRNP & Server-PoP-WRNP & Multicast Agent & ISP comercial & - & Rio de Janeiro \\
\hline & PoP-Manager-2 & Server-Manager-2 & Session Manager & ISP comercial & - & Rio de Janeiro \\
\hline
\end{tabular}

\subsubsection{Resultados Experimentais}

A Tabela 5.9 resume os dados coletados através dos agentes de monitoração dos serviços de distribuição de mídia implantados em cada um dos nós de serviço (com exceção dos nós que hospedam o Session Manager). As colunas foram organizadas de acordo com o engajamento dos agentes no repasse dos dados seguindo o fluxo de descida, a partir da fonte (no OAS1) para os clientes na rede do evento (no OAS2).

Tabela 5.9: Resultados experimentais coletados a partir de uma transmissão por multidifusão sobreposta interdomínio de fluxos de vídeo ao vivo.

\begin{tabular}{|c|c|c|c|c|c|c|}
\hline \multirow{2}{*}{$\begin{array}{c}\text { Variáveis de } \\
\text { monitoração }\end{array}$} & \multicolumn{3}{|c|}{ OAS 1 } & \multicolumn{2}{c|}{ OAS 2 } \\
\cline { 2 - 7 } & Server-PoP-PLAB & Server-PoP-D & SNMP-Server-PoP-C & SNMP-Server-PoP-B & Server-PoP-A & Server-PoP-WRNP \\
\hline \hline tempo de execução (minutos) & 22 & 21 & 22 & 25 & 25 \\
\hline taxa de bits de entrada (kbps) & 145 & 146 & 146 & 147 & 146 & 146 \\
\hline taxa total de bits de saída (kbps) & 146 & 146 & 145 & 146 & 146 & 1 \\
\hline número de clientes & 1 & 1 & 1 & 23 & 4 \\
\hline tempo médio em sessão (minutos) & 22 & 21 & 22 & 25 & 25 & 19 \\
\hline
\end{tabular}


Note que, além de informações básicas, tais como nome do servidor, endereço IP, porta de serviço, e status operacional do serviço (up/down), também é possível extrair medidas do fluxo de dados ${ }^{9}$, tais como tempo de execução do serviço, taxa de bits de entrada, taxa total de bits de saída, e tempo médio em sessão por parte dos clientes ${ }^{10}$. Além disso, os agentes de controle SMCP mantém informações sobre a relação de membros, coletando o número de clientes e o hostname em todas as sessões sendo servidas.

\subsubsection{Discussão}

A discussão sobre os resultados experimentais se concentra especialmente em torno de duas variáveis de monitoração, já que elas são essenciais para provar a eficácia da rede de serviço de multidifusão construída de acordo com nossa proposta de middleware.

Observando o número de clientes na Tabela 5.9, vemos que todos os clientes foram redirecionados para o nó de serviço Server-PoP-WRNP, como esperado, desde que todos eles pertecem topologicamente a este nó. Portanto, os 4 clientes do cenário formaram um aglomerado em torno do nó sobreposto PoP-WRNP.

Além disso, analisando as taxas de bit de entrada e saída confirmamos que apenas uma cópia do fluxo atravessa os nós de serviço intermediários ao longo do caminho de redirecionamento. Note que o fluxo de dados é replicado apenas no nó de serviço Server-PoP-WRNP, onde os quatro clientes são anexados. Isso justifica a taxa de bits de saída de Server-PoP-WRNP, a qual é aproximadamente 4 vezes maior que a taxa de bits de entrada.

Além de mostrar a precisão na construção da estrutura de entrega sobreposta, os dados experimentais comprovam a viabilidade do uso da infraestrutura de middleware proposta nesta dissertação para a implantação de redes de serviço de multidifusão sobreposta capazes de prover uma distribuição eficiente de conteúdos de mídia contínua em um cenário interdomínio real.

\footnotetext{
${ }^{9}$ Todas as variáveis de monitoração relacionadas ao fluxo de dados foram obtidas a partir do serviço de distribuição de mídia JDLive (http://www.lavid.ufpb.br/dlive/).

${ }^{10}$ Estas medições foram obtidas a partir dos valores médios periodicamente avaliados sobre um intervalo de tempo de 2 minutos.
} 


\section{Conclusões e Trabalhos Futuros}

Este trabalho propõe uma organização e arquitetura de middleware cujo objetivo é padronizar a construção dos serviços avançados sobre redes sobrepostas. A idéia é facilitar o desenvolvimento através do oferecimento de primitivas de serviços básicos, além de evitar situações de sobrecarga de informação e criação de gargalos quando cada aplicação em rede sobreposta tenta reconstruir sua própria infraestrutura independentemente umas das outras. Sobre esta camada de serviços básicos de sobreposição, serviços específicos podem ser construídos, tais como multidifusão, QoS, segurança, e gerenciamento baseado em políticas. Como prova de conceito, desenvolvemos um protocolo de middleware capaz de suportar um serviço de multidifusão sobreposta. O sistema de middleware implantado foi validado através de dois tipos de análise: uma análise de desempenho e uma análise funcional. Este capítulo resume os resultados e contribuições desta dissertação, bem como enumera os trabalhos futuros.

\subsection{Contribuições}

As principais contribuições deste trabalho são:

- Definição de uma arquitetura de sistema de middleware para redes sobrepostas, onde as funcionalidades foram organizadas de maneira bem definida para prover um suporte escalável e efetivo para redes de serviços sobrepostos;

- Construção de uma infraestrutura de multidifusão sobreposta como uma instância do middleware capaz de estender o serviço de entrega IP de melhor esforço através da implantação de características de multidifusão, sem modificar a infraestrutura de rede. 
A seguir, detalhamos melhor estas duas contribuições principais, além de descrever outras contribuições secundárias incorporadas ao longo do trabalho. Estas contribuições foram organizadas na ordem em que aparecem no texto.

1. Taxonomia para Multidifusão Sobreposta: nosso estudo das redes sobrepostas levou à análise das decisões de projeto necessárias para a definição de um esquema de multidifusão sobreposta. Verificamos a necessidade de se definir a arquitetura de distribuição, a topologia sobreposta, e o modelo de comunicação em grupo. Neste trabalho, abordamos a arquitetura de distribuição diferenciando a multidifusão sobreposta direta, realizada somente através da interação entre os dispositivos dos usuários, da multidifusão sobreposta mediada por servidores dedicados como elementos intermediários no repasse dos dados.

2. Arquitetura de Middleware para Redes Sobrepostas: uma arquitetura de middleware capaz de estender os serviços de entrega das redes de melhor esforço para atender à demanda das aplicações de mídias contínuas sobre redes de larga escala, como a Internet. Como possibilidade de serviços avançados, podemos citar multidifusão, qualidade de serviço e segurança. Esta arquitetura defende um modelo de duas camadas: a camada BOS, a qual reúne os serviços básicos para a criação de redes sobrepostas; e a camada SON, onde funcionalidades de mais alto nível especializam os serviços BOS e criam novos serviços de rede avançada.

3. Serviço de Multidifusão em Redes Sobrepostas: um serviço sobreposto capaz de incorporar características de multidifusão sem modificar a infraestrutura da rede. Para tanto, este serviço utiliza os mecanismos oferecidos pelo protocolo de middleware aqui proposto para implementar funcionalidades de mais alto nível, tal como descoberta da topologia da rede física e conhecimento da topologia lógica, definição de algoritmos para a escolha do melhor caminho, escolha das métricas utilizadas como custo, gerência da publicação das sessões de multidifusão, descoberta e localização de serviços de distribuição de mídia para transporte dos dados das sessões, etc.

4. Protocolo de Controle para Multidifusão Sobreposta: um protocolo de controle em nível de aplicação para a provisão e gerenciamento da multidifusão sobreposta em um modelo de comunicação um-para-muitos, tanto intra como interdomínio. O SMCP tem a proposta de ser um protocolo padrão, e por isso foi desenvolvido em acordo com a recomendação internacional ITU-T X.603 (International Telecommunication Union (ITU) - International Organization for Standardization (ISO/IEC), 2004). Este protocolo de middleware é capaz de estabele- 
cer, manter, modificar, finalizar e monitorar sessões de multidifusão sobreposta, bem como adicionar participantes à sessões já existentes. Mídias também pode ser adicionadas ou removidas a qualquer momento. O SMCP atende tanto os cenários de multidifusão de vídeo ao vivo, vídeo sob demanda e vídeo agendado, quanto um cenário de IPTV.

5. Modelo Analítico para a Análise de Desempenho da Multidifusão: uma modelagem analítica capaz de comparar o desempenho do protocolo SMCP aqui proposto com estratégias já existentes, como a unidifusão IP e a multidifusão IP através do protocolo PIM-SM. O modelo desenvolvido segue a metodologia de análise de desempenho definida em (JAIN, 1991), e pode ser estendido para contemplar outros protocolos. Além de selecionarmos métricas já comuns em análises de multidifusão, adotamos também uma métrica de latência denominada TFP ( Time to First Packet). Através de um modelo matemático conseguimos estimar o TFP para cada estratégia de distribuição, e assim podemos compará-las também quanto à latência.

\section{Heurísticas de Projeto para o Provisionamento da Rede de Multidifusão} Sobreposta: o modelo analítico desenvolvido aponta a seguinte heurística de projeto: escolher inicialmente tantos nós sobrepostos quanto o número de roteadores, e verificar o valor da TFP adicional para esta configuração. Se a latência ultrapassar o valor máximo tolerado pela aplicação usuária, o número de nós sobrepostos deve ser diminuído, e uma nova estimativa de TFP deve ser calculada. Caso contrário, distribuir os nós ao longo da rede observando as métricas de stress, utilização dos recursos e penalidade RDP, até que a rede sobreposta apresente a priori um bom desempenho com latência controlada.

\subsection{Trabalhos Futuros}

Pretendemos continuar nossa investigação sobre os serviços sobrepostos e a infraestrutura de middleware capaz de suportá-los de forma eficiente e eficaz, e em larga escala. O próximo passo é evoluir o middleware para suportar outras redes de serviços sobrepostos específicos além da multidifusão, tais como QoS e segurança. A criação destes novos serviços avançados aumentará nosso conhecimento sobre o sistema, permitindo uma melhor alocação de funcionalidades entre as camadas BOS e SON, ajudando a identificar novos candidatos a serviços básicos de sobreposição. 
Uma atenção especial precisa ser dada ao serviço de topologia do middleware, onde estratégias para descoberta de topologia precisam ser estudadas, de forma a viabilizar o uso do sistema em ambientes de rede caóticos como a rede pública da Internet. O conhecimento desta topologia é crucial para o bom desempenho das redes sobrepostas.

Além disso, mais pesquisas precisam ser realizadas no sentido de automatizar as redes SON. Apesar de arquiteturalmente solucionado nesta proposta, uma continuação deste trabalho precisaria definir um modelo de políticas adequado para a gerência de redes sobrepostas, permitindo a convivência entre serviços sobrepostos de multidifusão, QoS e segurança, decidindo sobre situações conflitantes que venham a surgir.

Continuaremos a especificação do protocolo SMCP, descrevendo com mais detalhes cada mensagem, todos os seus campos, e seu modelo de dados. A arquitetura do protocolo será melhor descrita, apresentando seu suporte a transações e diálogos, e sua máquina de estados. Além disso, pretendemos melhorar nossa modelagem analítica, permitindo a comparação do SMCP com outras propostas de multidifusão sobreposta. Nesse sentido, pretendemos também implementá-lo em simuladores, e analisar através de simulação seu comportamento, comparando-o com outras propostas.

\subsection{Considerações Finais}

Este trabalho demonstrou através de medidas experimentais a eficácia do sistema de middleware proposto na provisão de serviços de rede avançada em nível de aplicação, mais especificamente, de um serviço de multidifusão sobreposta. As características de multidifusão implementadas na infraestrutura do middleware conseguiram garantir que apenas uma cópia do fluxo de dados atravessasse diferentes sistemas autônomos reais e sobrepostos, demonstrando a eficácia do protocolo SMCP também em um cenário de mutidifusão interdomínio. Tal funcionalidade é impraticável em redes públicas como a Internet utilizando-se esquemas de multidifusão nativa em rede.

O modelo análitico desenvolvido complementa os resultados experimentais, mostrando que é possível se alcançar um desempenho próximo da multidifusão nativa em rede através de uma multidifusão sobreposta bem projetada, porém com uma maior latência inicial. Aplicando-se a heurística de projeto aqui descrita, chegamos a diferenças de 
desempenho praticamente desprezíveis com as métricas consideradas, aproveitandose ainda as vantagens de mais baixo custo, facilidade de implantação e manutenção, possibilidade de implantação gradativa, e implementação de um serviço de multidifusão interdomínio, apresentadas pela multidifusão sobreposta. 


\section{Referências Bibliográficas}

ADAMS, A.; NICHOLAS, J.; SIADAK, W. Protocol Independent Multicast - Dense Mode (PIM-DM): Protocol Specification (Revised). [S.I.]: Internet Engineering Task Force - IETF, 2005.

AL-OQILY, I.; KARMOUCH, A. Automating overlay networks management. In: Advanced Networking and Applications (AINA'07). [S.I.: s.n.], 2007. p. 386-393.

ALMEROTH, K. The evolution of multicast: From the MBone to inter-domain multicast to Internet2 deployment. IEEE Network, v. 14, p. 10-20, jan./fev. 2000.

ANDROUTSELLIS-THEOTOKIS, S.; SPINELLIS, D. A survey of peer-to-peer content distribution technologies. ACM Computing Surveys (CSUR), ACM Press New York, NY, USA, v. 36, n. 4, p. 335-371, 2004.

BANERJEE, S.; BHATTACHARJEE, B.; KOMMAREDDY, C. Scalable application layer multicast. In: Proc. ACM Special Interest Group on Data Communications (SIGCOMM'02). [S.I.: s.n.], 2002. p. 205-217.

BANERJEE, S. et al. OMNI: An efficient overlay multicast infrastructure for real-time applications. Computer Networks, Elsevier, v. 50, n. 6, p. 826-841, 2006.

BATES, T. et al. Multiprotocol Extensions for BGP-4. [S.I.]: Internet Engineering Task Force - IETF, 2007.

BERNERS-LEE, T.; FIELDING, R.; MASINTER, L. Uniform Resource Identifiers (URI): Generic Syntax. [S.I.]: Internet Engineering Task Force - IETF, 1998.

BUSH, R.; MEYER, D. Some Internet Architectural Guidelines and Philosophy. [S.I.]: Internet Engineering Task Force - IETF, 2002.

CASE, J. et al. A Simple Network Management Protocol (SNMP). [S.I.]: Internet Engineering Task Force - IETF, 1990.

CASTRO, M. et al. Scribe: a large-scale and decentralized application-level multicast infrastructure. Selected Areas in Communications, IEEE Journal on, v. 20, n. 8, p. 1489-1499, 2002.

CASTRO, M. et al. QRON: QoS-aware routing in overlay networks. Selected Areas in Communications, IEEE Journal on, v. 22, n. 1, 2004.

CHAWATHE, Y. Scattercast: an adaptable broadcast distribution framework. IEEE Multimedia Systems, Springer, v. 9, n. 1, p. 104-118, 2003. 
CHAWATHE, Y.; MCCANNE, S.; BREWER, E. A. RMX: Reliable multicast for heterogeneous networks. In: IEEE. IEEE Conference on Computer Communications (INFOCOM'00). Tel Aviv, Israel, 2000. p. 795-804.

CHU, Y.-H.; RAO, S. G.; ZHANG, H. A case for end system multicast. In: ACM. ACM SIGMETRICS 2000. Santa Clara, CA, 2000. p. 1-12.

CROCKER, D.; OVERELL, P. Augmented BNF for Syntax Specifications: ABNF. [S.I.]: Internet Engineering Task Force - IETF, 1997.

DEERING, S. E. Multicast routing in internetworks and extended lans. In: Proc. ACM Special Interest Group on Data Communications (SIGCOMM'88). Stanford, CA: [s.n.], 1988. p. 55-64.

DIOT, C. et al. Deployment issues for the IP multicast service and architecture. IEEE Network, v. 14, n. 1.

DUAN, Z.; ZHANG, Z.-L.; HOU, Y. T. Service overlay networks: Slas, qos and bandwidth provisioning. In: ICNP. [S.I.: s.n.], 2002. p. 334-343.

EDWARDS, B. M.; GIULIANO, L. A.; WRIGHT, B. R. Interdomain Multicast Routing. [S.I.]: Addison-Wesley, 2002.

EL-SAYED, A. Application-Level Multicast Transmission Techniques Over The Internet. Tese (Doutorado) — INSTITUT NATIONAL POLYTECHNIQUE DE GRENOBLE, 2004.

FAHMY, S.; KWON, M. Characterizing overlay multicast networks and their costs. IEEE/ACM Transactions on Networking, v. 15, n. 2, p. 373-386, abr. 2007.

FENNER, B. et al. Protocol Independent Multicast - Sparse Mode (PIM-SM): Protocol Specification (Revised). [S.I.]: Internet Engineering Task Force - IETF, 2006.

FENNER, W. Internet Group Management Protocol, Version 2. [S.I.]: Internet Engineering Task Force - IETF, 1997.

FIELDING, R. et al. OSPF Version 2. [S.I.]: Internet Engineering Task Force - IETF, 1999.

FRANCIS, P. Yoid: Extending the Multicast Internet Architecture. 2007. Disponível em: $<$ http://www.aciri.org/yoid/>.

FUCHS, H.; FÄRBER, N. Isma interoperability and conformance. IEEE MultiMedia, v. 12, n. 2, p. 96-102, 2005.

GUTTMAN, E. et al. Service Location Protocol, Version 2. [S.I.]: Internet Engineering Task Force - IETF, 1999.

HANDLEY, M.; JACOBSON, V.; PERKINS, C. SDP: Session Description Protocol. [S.I.]: Internet Engineering Task Force - IETF, 2006.

HASSAN, M.; JAIN, R. High performance TCP/IP networking. [S.I.]: Pearson Prentice Hall, 2004. 
HELDER, D.; JAMIN, S. End-host multicast communication using switch-tree protocols. 2002.

HOLBROOK, H. W.; CHERITON, D. R. IP multicast channels: EXPRESS support for large-scale single-source applications. In: Proc. Special Interest Group on Data Communications (SIGCOMM'99). [S.I.: s.n.], 1999. p. 65-78.

HUA, K.; TRAN, D. A.; VILLAFANE, R. Overlay multicast for video on demand on the internet. ACM Symposium on Applied Computing, v. 784.

International Telecommunication Union (ITU) - International Organization for Standardization (ISO/IEC). Information technology - Relayed Multicast Control Protocol: Framework. [S.I.]: ITU-ISO/IEC, 2004.

Internationl Organization for Standardization ISO/IEC. MPEG-7 Overview. [S.I.]: Internationl Organization for Standardization ISO/IEC, 2002.

ISO/IEC. Information Technology - Multimidia Framework (MPEG-21. [S.I.]: Internationl Organization for Standardization ISO/IEC, 2004.

JAIN, R. The Art of Computer System Performance Analysis. [S.I.]: John Wiley and Sons, INC., 1991.

JAIN, S. et al. Scalable Self-Organizing Overlays. University of Washington, Seattle, Tech. Rep. UW-CSE, 2000.

JANNOTTI, J. et al. Overcast: Reliable multicasting with an overlay network. In: Proc. 4th USENIX Symp. Operating Systems Design and Implementation (OSDI). [S.I.: s.n.], 2000. p. 197-212.

JIANG, W.; LUI, J.; CHIU, D. Interaction of Overlay Networks: Properties and Implications. PERFORMANCE EVALUATION REVIEW, ACM ASSOCIATION FOR COMPUTING MACHINERY, v. 33, n. 2, p. 27, 2005.

KEROMYTIS, A.; MISRA, V.; RUBENSTEIN, D. SOS: secure overlay services. Proceedings of the 2002 conference on Applications, technologies, architectures, and protocols for computer communications, ACM Press New York, NY, USA, p. 61-72, 2002.

KUROSE, J.; ROSS, K. Computer Networking - A Top-Down Approach Featuring the Internet. [S.I.]: Addison Wesley, 2003.

$\mathrm{LAO}$, L. et al. A comparative study of multicast protocols: top, bottom, or in the middle?. In: IEEE Conference on Computer Communications (INFOCOM'05). [S.I.: s.n.], 2005. p. 2809-2814.

LAO, L. et al. A scalable overlay multicast architecture for large-scale applications. IEEE Trans. Parallel Distrib. Syst., v. 18, n. 4, 2007.

LAO, L.; GOKHALE, S. S.; CUI, J.-H. Distributed qos routing for backbone overlay networks. In: Networking. [S.I.: s.n.], 2006. p. 1014-1025.

LEE, J. Y. B. A Scalable Continuous Media Streaming Systems - Architecture, Design, Analysis, and Implementation. [S.I.]: John Wiley and Sons, 2005. 
LI, Z. Resiliency and Quality-of-Service (QoS) Support in Multicasting and Overlay Networks. Tese (Doutorado) — University of California, Davis, 2005.

LIEBEHERR, J.; SI, M. Application-layer multicasting with Delaunay triangulation overlays. Selected Areas in Communications, IEEE Journal on, v. 20, n. 8, p. 1472-1488, 2002.

LUA, K. et al. A survey and comparison of peer-to-peer overlay network schemes. Communications Surveys \& Tutorials, IEEE, p. 72-93, 2005.

MAMBRETTI, J.; SCHMIDT, A. Next-generation Internet: Creating Advanced Networks and Services. [S.I.]: Wiley New York, 1999.

MOY, J. OSPF Version 2. [S.I.]: Internet Engineering Task Force - IETF, 1998.

NAKAO, A.; PETERSON, L.; BAVIER, A. A routing underlay for overlay networks. In: Proc. Special Interest Group on Data Communications (SIGCOMM'03). Karlsruhe, Germany: [s.n.], 2003. p. 11-18.

PENDARAKIS, D. et al. ALMI: An application level multicast infrastructure. In: Proceedings of the 3rd USENIX Symposium on Internet Technologies and Systems (USITS). [S.I.: s.n.], 2001. p. 49-60.

PERKINS, C. RTP - Audio and Video for the Internet. [S.I.]: Addison-Wesley, 2003.

PERLMAN, R. et al. Simple multicast: A design for simple, low-overhead multicast. [S.I.], 1999.

PLAXTON, C.; RAJARAMAN, R.; RICHA, A. Accessing Nearby Copies of Replicated Objects in a Distributed System. Proceedings of the Symposium of Parallel Algorithms and Architectures (SPAA'97), p. 311-320, 1997.

RATNASAMY, S. et al. A Scalable Content-Addressable Network (CAN). Proc. of ACM SIGCOMM, 2001.

RATNASAMY, S. et al. Application-level multicast using content-addressable networks. Lecture Notes in Computer Science, v. 2233, p. 14-??, 2001.

ROCA, V.; EL-SAYED, A. A Host-Based Multicast (HBM) Solution for Group Communications. Proceedings of IEEE ICN, Springer, v. 1, 2001.

ROSENBERG, J. et al. SIP: Session Initiation Protocol. [S.I.]: Internet Engineering Task Force - IETF, 2002.

ROWSTRON, A.; DRUSCHEL, P. Pastry: Scalable, distributed object location and routing for large-scale peer-to-peer systems. IFIP/ACM International Conference on Distributed Systems Platforms (Middleware), Heidelberg, v. 11, p. 329-350, 2001.

SALTZER, J. H.; REED, D. P.; CLARK, D. D. End-to-end arguments in system design. ACM Transactions on Computer Systems, v. 2, n. 4, p. 277-288, nov. 1984.

SCHULZRINNE, H. et al. RTP: A Transport Protocol for Real-Time Applications. [S.I.]: Internet Engineering Task Force - IETF, 2003. 
SHI, S.; TURNER, J.; WALDVOGEL, M. Dimensioning server access bandwidth and multicast routing in overlay networks. In: Proceedings of NOSSDAV 2001. [S.I.: s.n.], 2001. p. 83-92.

SOBEIH, A.; YURCIK, W.; HOU, J. Vring: a case for building application-layer multicast rings. In: Proceedings of the IEEE Computer Society's 12th Annual International Symposium on Modeling, Analysis, and Simulation of Computer and Telecommunications Systems (MASCOTS'04). [S.I.: s.n.], 2004.

SOCOLOFSKY, T.; KALE, C. A TCP/IP Tutorial. [S.I.]: Internet Engineering Task Force - IETF, 1991.

SteEN, M.; TANENBAUM, A. Distributed Systems: Principles and Paradigms, 2/E. [S.I.]: Prentice Hall, 2007.

STOICA, I.; NG, T. S. E.; ZHANG, H. REUNITE: A recursive unicast approach to multicast. In: IEEE Conference on Computer Communications (INFOCOM'O0). [S.I.: s.n.], 2000. p. 1644-1653.

SUBRAMANIAN, L. et al. OverQoS: offering internet qos using overlays. ACM SIGCOMM Computer Communication Review, ACM Press New York, NY, USA, v. 33, n. 1, p. 11-16, 2003.

SUBRAMANIAN, L. et al. OverQoS: An overlay based architecture for enhancing internet qos. Proceedings of NSDI, 2004.

UCHôA, D. et al. Towards a middleware reference model for overlay networks. In: XIV Brazilian Symposium on Multimedia and the Web (WebMedia 2008). [S.I.: s.n.], 2008.

UCHôA, D. et al. An overlay application-layer multicast infrastructure. In: The IEEE 23rd International Conference on Advanced Information Networking and Applications (AINA-09). [S.I.: s.n.], 2009.

UCHôA, D.; SILVEIRA, R. M. Oversea: Towards a scalable and effective architecture for overlay networks. In: XIII Brazilian Symposium on Multimedia and the Web (WebMedia). [S.I.]: ACM, 2007.

UCHôA, D. C. et al. A management platform for multimedia distribution in country-wide networks. In: SAUVé, J. P.; MADEIRA, E. (Ed.). LANOMS. [S.I.]: IEEE, 2007. p. 20-27.

University of Southern California. Transmission Control Protocol. [S.I.]: Internet Engineering Task Force - IETF, 1981.

WANG, Z.; CROWCROFT, J. Bandwidth-delay based routing algorithms. Global Telecommunications Conference, 1995. GLOBECOM'95., IEEE, v. 3, 1995.

YEO, C.; LEE, B.; ER, M. A survey of application level multicast techniques. Computer Communications, Elsevier, v. 27, n. 15, p. 1547-1568, 2004.

ZHANG, B.; JAMIN, S.; ZHANG, L. Host multicast: a framework for delivering multicast to end users. INFOCOM 2002. Twenty-First Annual Joint Conference of the IEEE Computer and Communications Societies. Proceedings. IEEE, v. 3, 2002. 
ZHAO, B. et al. Tapestry: A global-scale overlay for rapid service deployment. IEEE Journal on Selected Areas in Communications, 2003.

ZHUANG, S. et al. Bayeux: An architecture for wide-area, fault-tolerant data dissemination. Proc. NOSSDAV'01, 2001. 